\title{
The Use of Zeolites for VOCs Abatement by Combining Non-Thermal Plasma, Adsorption, and/or Catalysis: A Review
}

\author{
Savita K. P. Veerapandian ${ }^{1, * \mathbb{D}}$, Nathalie De Geyter ${ }^{1}$, Jean-Marc Giraudon ${ }^{2} \mathbb{D}$, \\ Jean-François Lamonier ${ }^{2}$ and Rino Morent ${ }^{1}$ \\ 1 Research Unit Plasma Technology, Department of Applied Physics, Faculty of Engineering and Architecture, \\ Ghent University, Sint-Pietersnieuwstraat 41 B4, 9000 Ghent, Belgium; \\ Nathalie.DeGeyter@UGent.be (N.D.G.); Rino.Morent@UGent.be (R.M.) \\ 2 Univ. Lille, CNRS, Centrale Lille, ENSCL, Univ. Artois, UMR 8181-UCCS-Unité de Catalyse et Chimie du \\ Solide, F-59000 Lille, France; jean-marc.giraudon@univ-lille1.fr (J.-M.G.); \\ jean-francois.lamonier@univ-lille.fr (J.-F.L.) \\ * Correspondence: savita.kaliyaperumalveerapandian@ugent.be
}

Received: 12 December 2018; Accepted: 13 January 2019; Published: 17 January 2019

\begin{abstract}
Non-thermal plasma technique can be easily integrated with catalysis and adsorption for environmental applications such as volatile organic compound (VOC) abatement to overcome the shortcomings of individual techniques. This review attempts to give an overview of the literature about the application of zeolite as adsorbent and catalyst in combination with non-thermal plasma for VOC abatement in flue gas. The superior surface properties of zeolites in combination with its excellent catalytic properties obtained by metal loading make it an ideal packing material for adsorption plasma catalytic removal of VOCs. This work highlights the use of zeolites for cyclic adsorption plasma catalysis in order to reduce the energy cost to decompose per VOC molecule and to regenerate zeolites via plasma.
\end{abstract}

Keywords: VOC abatement; air pollution; zeolites; adsorption-plasma catalysis

\section{Introduction}

According to the European Union (EU), volatile organic compounds (VOCs) are defined as organic compounds or substances with a low boiling point $(\leq 523 \mathrm{~K})$ at atmospheric pressure [1]. Volatile organic compounds such as toluene, benzene, and xylene are widely present in the environment due to the fact that they are used in various industries such as in semiconductors, automobiles, and even as domestic cleaning agents. The emission of VOCs are either from static sources (e.g., from production of products such as coal, oil, organic chemicals, plywood, artificial leather, synthetic materials, cosmetics, printing, paint, tobacco smoke, and cleaning products; and from composting units/plants, electroplating, chemical coating, incineration plants, and landfills) or from mobile sources (e.g., petrol and diesel exhaust emissions) [2,3]. In the presence of UV-light, some VOCs can react with nitrogen oxide and form photochemical smog which is harmful to human health and the environment $[4,5]$. Due to its negative impact on human and environmental health, environmental policies for the emission control of VOCs are becoming more and more stringent.

Volatile organic compounds are the main components of indoor air pollution (IAP) and they can cause carcinogenic, mutagenic, and teratogenic health problems such as skin allergies, dizziness, vomiting, damage to the liver, kidney, and central nervous system [6-8], and are suspected to be the main reason for sick building syndrome (SBS) $[9,10]$. Several techniques which have been investigated for the removal of VOCs from air [11] including thermal decomposition [12,13], catalytic decomposition/oxidation [14,15], 
bio-filtration [16-18], adsorption [19], non-thermal plasma [20-22], photo-catalysis [23,24], and plasma catalysis [20,25-27]. Generally, the exhaust gas has a large volume (high flow rate required) and low VOC concentrations (10-1000 ppm) [28]. For example, an indoor gas exhaust from a certain printing factory has a flow rate and VOC concentration of $800 \mathrm{Nm}^{3} / \mathrm{min}$ and $17 \mathrm{ppm}$, respectively [29]. To treat these flue gases directly (for example, by incineration), huge operating facilities with high energy consumption are required which increase both the instillation and operating costs [28].

Among the various technologies which have been proposed and used for the decomposition of VOCs, plasma catalysis (PC) which is the combination of non-thermal plasma (NTP) and catalysis has been proven efficient; particularly, for the removal of low concentration of VOCs ( $<1000 \mathrm{ppm}$ ) [30,31]. Non-thermal plasma is generated by applying a sufficiently high electric field which produces electrons, excited gas molecules, and free radicals that are suitable to convert environmental pollutants to ideal products. However, the commercialization of this technique has the following disadvantages such as: (a) formation of un-wanted toxic by-products, (b) low energy efficiency, and (c) incomplete oxidation of VOCs. Thus, the combination of NTP and catalysts takes advantage of the ability of plasma to activate catalysts at lower temperature and the high selectivity of the catalysts [32]. In most of the cases, active metals are supported on the surface of substrates such as $\gamma-\mathrm{Al}_{2} \mathrm{O}_{3}$, zeolite, and activated carbon which have a large surface area. The area of active sites on the surface of the support material can be improved either by increasing the amount of metal loading or by decreasing the size of metal catalyst (thus, less metal will be required to obtain certain surface area of active metal); of which the latter is more beneficial as precious metals are expensive [32]. On the other hand, from an engineering point of view, the rapid start up and turn off of the plasma devices makes this technique more suitable for smalland medium-scale applications. But the main drawback of using plasma catalysis for the treatment of very low concentrations of VOCs $(<100 \mathrm{ppm})$ in flue gas is that most of the discharge energy will be utilized for the excitement of oxygen and nitrogen [33]. This emphasize the necessity to explore different techniques which are more suitable for the removal of very low concentration of VOCs from a large volume of flue gas. In order to treat the large volume of gas with low VOC concentration and to improve the energy efficiency, the combination of adsorption and plasma catalysis has been proposed and investigated [34-36]. In such an adsorption-plasma catalysis (APC) process, the NTP discharge is either continuous [37] or cyclic [28,38,39].

Figure 1 shows the schematic diagram of the continuous process, where the catalyst/adsorbent material is placed either in the plasma discharge region (in-plasma catalysis, IPC) or downstream of the plasma discharge (post plasma catalysis, PPC) and the plasma is ignited permanently. The main disadvantage of the continuous treatment is that the plasma discharge is applied continuously irrespective of the variation in VOC concentration, and thus the energy consumption to decompose per VOC molecule is high.

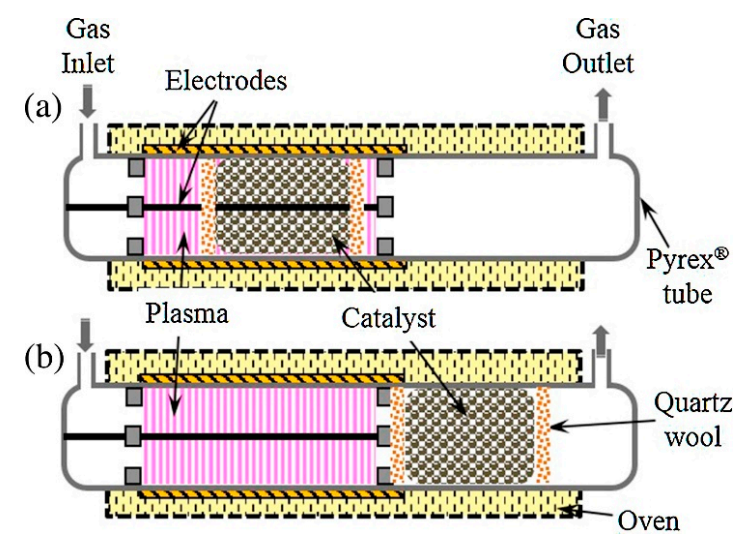

Figure 1. The working principle of the continuous adsorption-plasma catalytic process for volatile organic compounds (VOCs) removal (a) in-plasma catalysis and (b) post-plasma catalysis. Reprinted from Reference [40], with permission from Elsevier. 
Figure 2 shows schematically the working principle of the cyclic APC process for VOC removal. Briefly, in a cyclic APC process, the low-concentration VOCs in flue gas are first stored on catalysts/adsorbents at a storage stage (plasma off) and then the stored VOCs are oxidized to $\mathrm{CO}_{2}$ by plasma at a discharge stage (plasma on). In a cyclic APC process, adsorption of VOC on an adsorbent for a long time followed by the plasma discharge for the oxidation of adsorbed VOCs to $\mathrm{CO}_{2}$ during a shorter time improves the energy efficiency [34,41,42]. Thus, the ratio of energy deposited per treated VOC molecule is considerably reduced [43]. Also, the flow rate during the discharge stage of the cyclic APC technology can be chosen to be lower than the storage stage, which leads to higher energy density for the cyclic APC technology for the same discharge power.

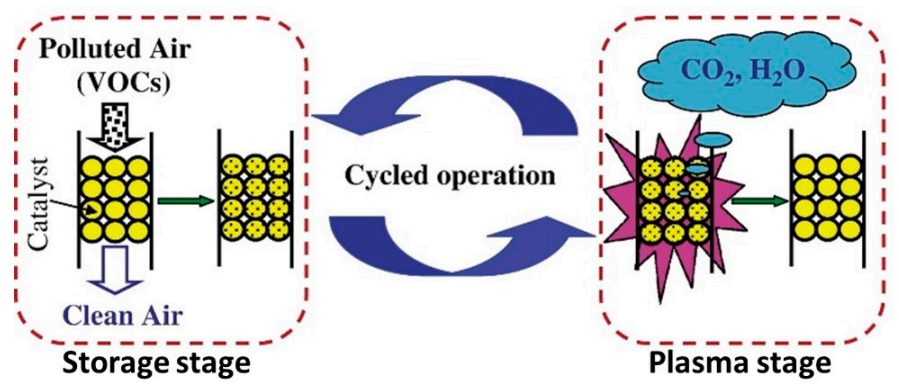

Figure 2. The working principle of the cyclic adsorption-plasma catalytic process for VOC removal. Reprinted from Reference [44], with permission from Elsevier.

The main advantages of the cyclic APC over continuous APC are as follows: (i) during the plasma discharge stage, $\mathrm{O}_{2}$ plasma can be used instead of air, because $\mathrm{O}_{2}$ plasma avoids the formation of byproducts such as $\mathrm{NO}_{x}, \mathrm{~N}_{2} \mathrm{O}$, etc., and is more efficient in regeneration of the adsorbent/catalyst, (ii) high $\mathrm{CO}_{2}$ selectivity, (iii) improved carbon balance, (iv) improved energy efficiency and higher power operation is possible, (v) concentration of dilute VOCs (compact system), (vi) adapts to the change in the flow rate and VOC concentration, and (vii) rapid operation.

The adsorbing and catalytic function of the adsorbents can be separated or integrated using a dual-functional material. The most commonly used adsorbents are either (i) physical adsorbents such as alumina, zeolite, and activated carbon or (ii) chemical adsorbents such as alkaline earth metals and metal loaded physical adsorbents. The adsorption of VOCs on adsorbent reduces the chemical barrier by $E_{b}-E_{a d s}$ ( $E_{b}$ is bond energy of the molecule; $E_{a d s}$ is the adsorption energy) and the reduction depends on the kind of adsorption (either physisorption or chemisorption) [45]. Physisorption is the Van Der Waals force of attraction on the surfaces and the physically adsorbed molecules can be desorbed by applying heat; whereas chemisorption is because of the chemical reactions that leads to the transfer of electrons and ions between the adsorbent surfaces and molecules. Thus, the presence of adsorbents in the plasma discharge region prolongs the residence time of VOCs, active species, and intermediate by-products resulting in increased collisional probabilities between them and thus enhanced $\mathrm{CO}_{2}$ selectivity [46].

Another not mentioned yet important advantage of combining adsorption and NTP is the increased lifetime of the used adsorbents. The very low concentration VOCs can be concentrated on the adsorbing material and then desorbed and decomposed to less toxic and/or more useful products. In most of the cases, the adsorbents are discarded or incinerated. With regard to the economic and practical point of view, it is appropriate to decompose the adsorbed VOCs and regenerate the adsorbent [47]. It has been already demonstrated in the literature that some adsorbents can be regenerated by different methods such as heating [48-50], microwave heating [51], pressure and temperature swing adsorption [52], and non-thermal plasma [28,53]. However, the use of techniques such as temperature or pressure swing adsorption and thermal regeneration requires high temperature or vacuum making the regeneration of the adsorbent expensive. For the desorption and decomposition of VOCs adsorbed on the adsorbents, NTP discharge can be used instead of a conventional thermal 
process in order to reduce both the size of the treatment equipment and the energy consumption [54]. The highly oxidizing environment of plasma promotes the oxidation of the adsorbed VOCs and simultaneously regenerates the adsorbent.

The APC requires an adsorbing/catalytic system which effectively adsorb VOCs and efficiently oxidize the adsorbed VOCs. The selection of adsorbent/catalyst is very crucial to achieve high energy efficiency to decompose diluted VOCs from air. The surface properties such as specific surface area $\left(\mathrm{S}_{\mathrm{BET}}\right)$ and pore size affects the adsorption capacity and plasma discharge. The energy efficiency of APC for the removal of VOC in air is enhanced by using adsorbent with high specific surface area as this increases the adsorbing time [55]. Depending on the pore size, the discharge volume can be effectively increased by packing porous material in the discharge zone of the dielectric barrier discharge (DBD) reactor. The dielectric constant of the adsorbents influences the discharge performance, which affects the number and kind of active species generated. Also, the hydrophobicity of the adsorbent is very important for the selective adsorption of VOCs from the ambient air with humidity [56-58].

Considering the superior and tunable surface properties, hydrophobicity and metal loadability, zeolites are one of the best adsorbents and catalysts for VOC degradation. Zeolites are traditional adsorbents due to their unique micropores, cavities, and channels. The pore diameter in zeolites is in the range of 5-20 $\AA$ which is suitable for the adsorption of various VOC molecules. Also, the zeolites can interact with plasma due to their strong natural electric field inside their framework $[59,60]$. The degradation of VOCs by continuous and cyclic APC using zeolites are accompanied by synergetic effects due to different mechanisms such as ultraviolet (UV) irradiation, generation of electron-hole pairs and their subsequent chemical reactions, changes in work function, adsorption, desorption, direct interaction of gas phase radicals with the catalyst surface and the adsorbed molecules, local heating and activation lattice oxygen and ozone $[8,61]$.

The main target of this work is to review the literature on adsorption and/or plasma catalysis using zeolites for the decomposition of dilute VOCs in flue gas. In this article, the important aspects for the practical use of APC with zeolites for the decomposition of VOCs such as decomposition efficiency, energy efficiency, stability of the adsorbents/catalysts, and post-processing of the by-products obtained after plasma treatment have been discussed. In the first part of the article, the different kind of zeolites which are used in combination with NTP for environmental applications are introduced. In the second part of this article, the pros and cons of using zeolites in combination with non-thermal plasma for VOC abatement and stability of zeolites in APC technique are discussed in detail. Finally, regarding the performance of zeolite adsorption plasma catalytic reactors, the effect of various process parameters such as reactor configuration, humidity, and flow rate of the flue gas, initial concentration of VOCs, and nature of discharge gas is investigated.

\section{Zeolites}

In recent years, zeolite, a solid acid has been investigated by a number of researchers and used widely in industries due to its high surface area, ordered pore size and structure, thermal stability, shape selectivity, hydrothermal stability, mobility of their cations to act as a catalyst, and the ability to tailor its properties such as wettability and auxiliary mesopore generation in the crystals. Weitkamp and Moshoeshoe et al. [62,63] wrote interesting reviews about the basic principles of zeolite chemistry, structure, properties, and their application in catalysis. Furthermore, a series of zeolite-supported metals as highly efficient catalysts have been well developed for the catalytic combustion of VOCs by combining the selective adsorption of zeolites with catalytically active metal centers [64]. The natural zeolites are known to mankind as aluminosilicate minerals for almost 250 years and most of the natural zeolites are the result of volcanic activities [65]. Zeolites are a three-dimensional framework of $\mathrm{SiO}_{4}$ and $\mathrm{AlO}_{4}$ tetrahedra which are bonded by a common oxygen in the corners. Natural zeolite such as Mordenite, after acid treatment which is an essential step in order to eliminate the impurities and to open the pores and thus increasing $\mathrm{S}_{\mathrm{BET}}$, can be used for environmental applications [66]. The main 
disadvantages of natural zeolites are (i) the presence of impurities, (ii) they are not optimized for catalysis, and (iii) a variation in chemical composition which is source/deposit dependent [62].

In order to overcome the shortcomings of natural zeolites, synthetic zeolites with various $\mathrm{Si} / \mathrm{Al}$ ratios (between 1 and $\infty$ ) and well-defined pore structure and dimensions are synthesized. The pioneering work of Barrer, Milton, and their co-workers [67-69] led to the synthesis of the first synthetic zeolites which made this porous material an important commercial heterogeneous catalyst. The general formula of zeolite is $\mathrm{M}_{\mathrm{x}} / \mathrm{n}\left[\left(\mathrm{AlO}_{2}\right)_{\mathrm{x}}\left(\mathrm{SiO}_{2}\right)_{\mathrm{y}}\right] \cdot \mathrm{mH}_{2}$ where $\mathrm{M}$ is the metal or hydrogen ion of valency " $n$ " occupying the exchangeable site in the zeolite framework [70]. Figure 3 shows the schematic of the tetrahedral arrangement of $\mathrm{SiO}_{4}$ and $\mathrm{AlO}_{4}$ which are the primary building units of zeolites. The overall charge of the aluminosilicate framework, which is formed by polymerization of $\mathrm{SiO}_{4}$ and $\mathrm{AlO}_{4}$, is negative due to the +4 charge on silicon and the +3 on aluminum. This negative charge is compensated by the presence of cations such as $\mathrm{Na}^{+}, \mathrm{K}^{+}, \mathrm{Ca}^{2+}$, and $\mathrm{Mg}^{2+}$ in pores or in rings, which are the exchangeable cations in the zeolite framework. As shown in Figure 4, the adjacent tetrahedral are linked via the common oxygen at their corners (which are called the secondary building units) which results in a three-dimensional macromolecule with channels and cages which are usually occupied by water or cations [71,72]. Figure 5 depicts the formation of four different commercial zeolites (such as Faujasite type (X and Y), ZSM-5, ZSM-12, and ZSM-22) from the primary and secondary building units and their micropore structure and dimensions.

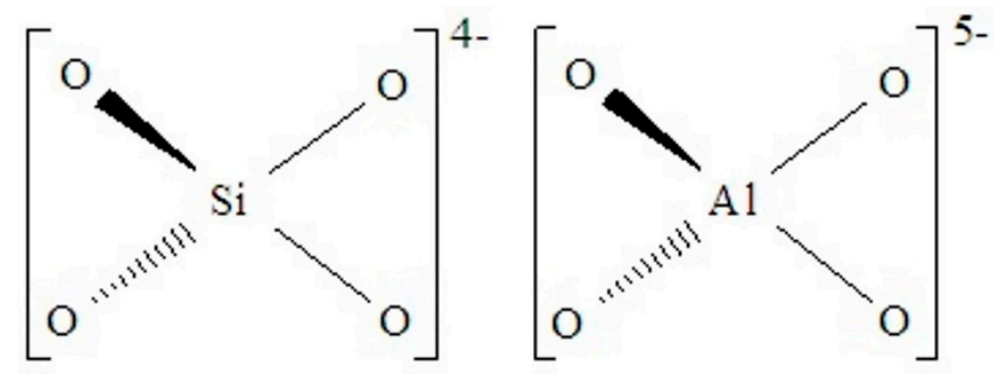

Figure 3. Tetrahedral arrangement of $\mathrm{SiO}_{4}$ and $\mathrm{AlO}_{4}$ which forms the primary building units of zeolite. Reproduced from Reference [63] under CC BY 4.0.

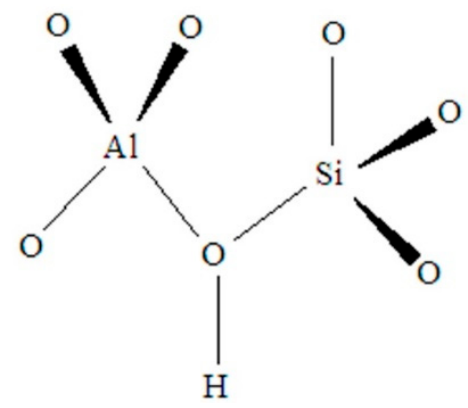

Figure 4. Tetrahedral arrangement of the $\mathrm{Si}-\mathrm{O}$ and $\mathrm{Al}-\mathrm{O}$ bonds forming a unit block of zeolite. Reproduced from Reference [63] under CC BY 4.0. 


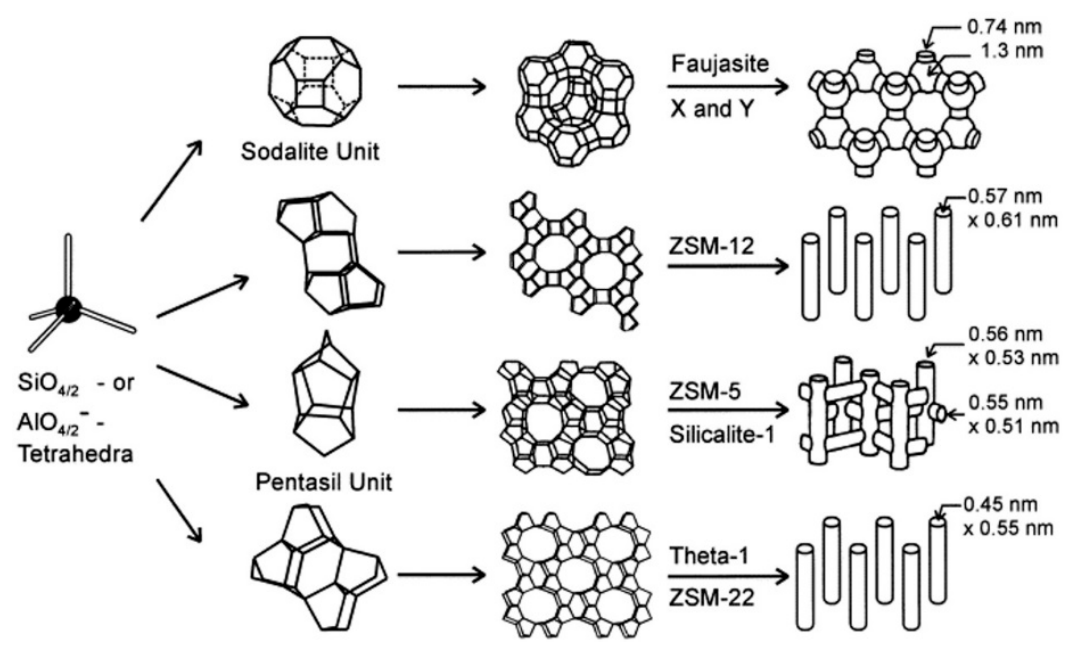

Figure 5. Structures of four commercial zeolites (from top to bottom: Faujasite or zeolites X, Y; zeolite ZSM-12; zeolite ZSM-5 or silicalite-1; zeolite Theta-1 or ZSM-22) and their micropore systems and dimensions. Reprinted from Reference [62], with permission from Elsevier.

Zeolites are classified based on the pore diameter and ring size as these properties have a major role in determining its adsorption properties [73]. Depending on the interconnections between the oxygen bridges and secondary block units, zeolites can be classified as 4-, 5-, 6-, 8-, 10 or 12- membered rings. A ring is made of tetrahedrons and an " $\mathrm{n}$ " number ring is made of n-tetrahedrons as shown in Figure 6. Zeolites such as MS-3A, MS-4A, MS-5A, and Mordenite contain eight numbers of rings with a pore diameter in the range of 3-5 ; whereas ZSM- 5 contains 10 rings with the pore diameter of $\sim 3-5 \AA$. On the other hand, Faujasite type $X$ and $Y$ zeolite have 12 rings with larger pore diameter of 7-8 $\AA$. Zeolites are also classified based on the $\mathrm{Si} / \mathrm{Al}$ ratio as low silica ( $\leq 2$, e.g., Na-X Faujasite), intermediate silica (2-5, e.g., Na-Y Faujasite, Mordenite), and high silica zeolites ( $>5$, e.g., ZSM-5, $\beta$-zeolites). The ratio of $\mathrm{Si} / \mathrm{Al}$ influences the hydrophobicity of the zeolite and the hydrophilicity decreases with the increase in this ratio [74].

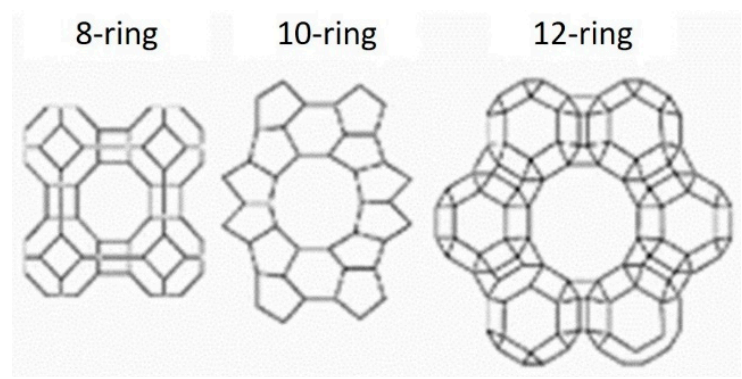

Figure 6. Schematic of " $n$ " rings that are frequently found in the zeolite framework. Reprinted from Reference [75], with permission from Springer nature.

The synthetic zeolites which have been widely used for environmental applications in combination with non-thermal plasma are as follows: (i) Zeolite A, (ii) Zeolite $X$ and $Y$ (Faujasite type), (iii) $\beta$-zeolite, and (iv) ZSM-5. Zeolite A is the first industrially used synthetic zeolite which is still in commercial use today. Figure 7 shows the schematic drawing of the structure of zeolite A. The well-known molecular sieves such as MS-4A, MS-5A, and MS-6A are type A zeolite. Zeolite A is formed by the linkage between the sodalite cages which are linked by four ring cages and the nominal $\mathrm{Si} / \mathrm{Al}$ ratio is 1:1 and the negative charge is balanced by sodium ions. 


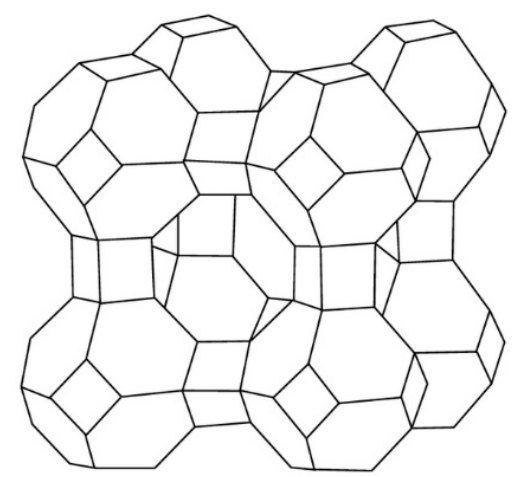

Figure 7. Schematic drawing of the structure of zeolite A. Reproduced from Reference [76] under CC BY 4.0.

Zeolite $\mathrm{X}$ and $\mathrm{Y}$ belongs to the family of aluminosilicates with Faujasite-type structure. Faujasite is a rare natural zeolite, whereas its synthetic counterpart Linde $X$ and Linde $Y$ are widely used in catalysis. Zeolite $X$ and $Y$ are formed by the linkage over six cornered surfaces and the hexagonal prisms. MS-13X zeolite which is a Faujasite-type zeolite has high adsorption capacity for VOCs due to its high $\mathrm{S}_{\mathrm{BET}}$. Figure 8 shows the three-dimensional structure of zeolite $13 \mathrm{X}$ and it consists of alumina tetrahedra and silica tetrahedron with oxygen bridge with a certain spatial structure forming a uniform crystal. The basic structural unit of $13 \mathrm{X}$ is a beta cage, and adjacent beta cages form the molecular sieve by the six-angle prism connection [77].

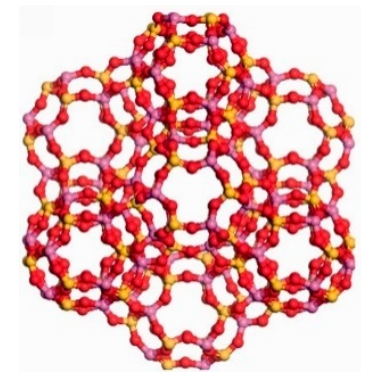

Figure 8. Schematic structure of Faujasite type zeolite. Reproduced from reference [77] under CC BY 4.0.

Zeolite beta is also one of the synthetic zeolites with high silica content and it is formed by the intergrowth hybrid of two different structures (polymorph A and B) with a stacking disorder (shown in Figure 9). Because of its high Si/ Al ratio, hydrophobic nature, and higher acidic strength, zeolite beta is usually preferred rather than Faujasite type zeolites in various chemical reactions.

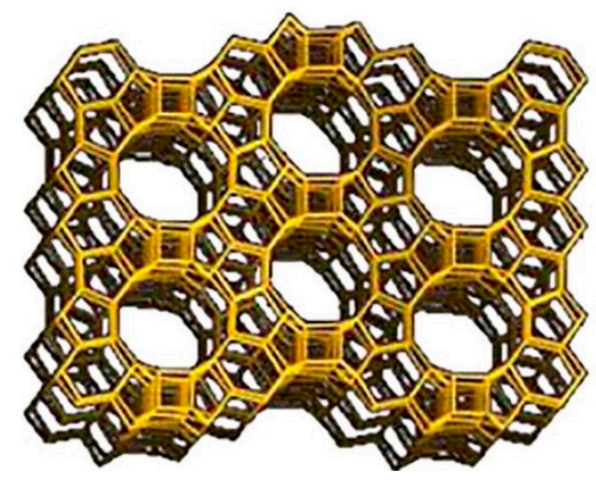

Figure 9. Schematic diagram of beta-zeolite. Reprinted from Reference [78], with permission from Elsevier. 
As shown in Figure 10, the ZSM-5 zeolite is formed from the pentasil unit, which are interconnected by an oxygen bridge resulting in 10-membered ring. The $\mathrm{Na}^{+}$cations can be removed from the ZSM-5 via ion-exchange and replaced by $\mathrm{H}^{+}$ions yields zeolites in its protonic form, i.e., HZSM-5 [79] which is used for molecular sieving [80,81]. The VOC molecules with dynamic diameter smaller than the channel openings of HZSM- 5 can access the zeolite's pore network and these adsorbed molecules can be eventually converted on the zeolite acid sites [80-83]. But the bulkier product molecules which cannot diffuse out of the pores being either converted to smaller molecules (resulting in product selectivity) or accumulated as coke (causing deactivation).

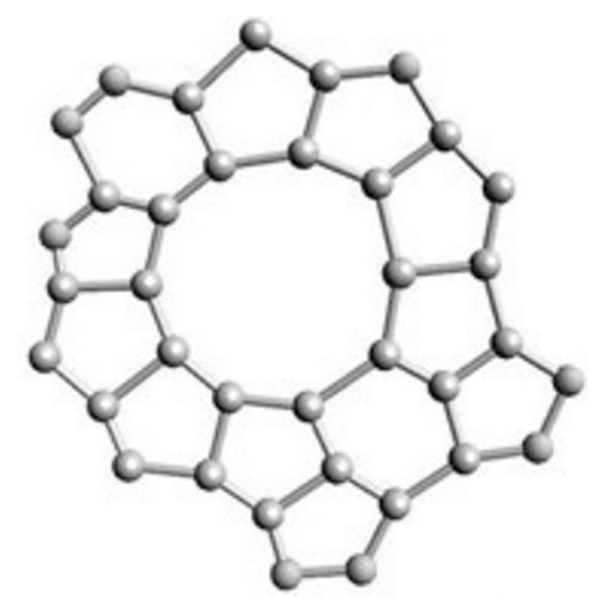

Figure 10. Schematic drawing of synthetic ZSM-5 zeolite. Reprinted from Reference [84], with permission from Elsevier.

\section{Adsorption Plasma Catalysis for VOC Abatement}

\subsection{Adsorption of VOCs on Zeolite}

The adsorption of VOCs on zeolite plays an important role in the complete oxidation of VOCs by increasing the residence time of VOCs in the plasma discharge region. The adsorption of VOCs on the adsorbents depends on the surface properties of the materials such as $\mathrm{S}_{\mathrm{BET}}$, pore volume, size, and structure. When the pore diameter is larger than the size of the VOC molecule, the VOCs could be adsorbed and enter the internal pore structure. When the pore diameter of the zeolite is smaller than the dynamic diameter of the molecule, they do not exhibit any adsorption of VOCs [85]. The size of the micropores of MS-3A, MS-4A, MS-5A, and MS-13X are approximately $0.3,0.4,0.5$, and $1 \mathrm{~nm}$ respectively; whereas the dynamic size of benzene molecule is $0.59 \mathrm{~nm}$ and it is well adsorbed in the intrinsic pores of MS-13X [86]. The 13X zeolite has a hexagonal system and the supercage structure contained four 12-membered ring orifices with tetrahedral orientation [87] which has a large proportion of micropore with the pore size of $1.03 \mathrm{~nm}$, which results in the excellent adsorption of aromatic VOCs such as benzene and toluene $[86,88]$.

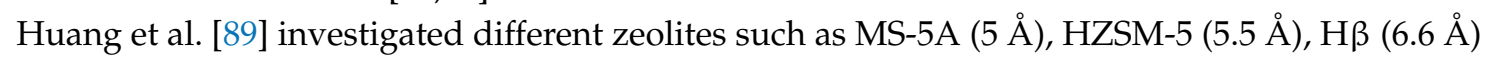
and HY (7.4 $\AA$ ) and reported that except MS-5A, other zeolites exhibited toluene adsorbing ability. The pore diameter of zeolite $5 \mathrm{~A}$ is smaller than the dynamic toluene molecule diameter resulting in no adsorption. As shown in Figure 11, the breakthrough time for toluene adsorption on other zeolites (such as HZSM-5, H $\beta$ and HY) follows the same order as that of the pore diameter [89]. The breakthrough time for toluene adsorption of HY zeolite is further increased by metal loading which will discussed in detail in the following section. Another work reported that the adsorption of benzene on different zeolites exhibited the same trend as that of their pore diameter MS-13X $(10 \AA) \approx$ HY $(7.4 \AA)>\operatorname{MOR}(6.7 \sim 7 \AA)>$ ferrierite $(4.3 \sim 5.5 \AA)$ [41].

The effect of both $\mathrm{S}_{\mathrm{BET}}$ and pore diameter of the zeolites on the adsorption of VOCs has been highlighted in the following works. Shiau et al. [54] reported that the adsorption of isopropyl alcohol 
on different molecular sieves such as MS-3A, MS-4A, MS-5A and MS-13X follow the same order as that of its specific surface area and pore diameter as shown in Table 1. Yi et al. [88] reported that $13 \mathrm{X}$ zeolite has better adsorption capacity for toluene when compared to the other adsorbents such as $\mathrm{Al}_{2} \mathrm{O}_{3}$ and MS-5A. This is because of the high $\mathrm{S}_{\mathrm{BET}}\left(626.439 \mathrm{~m}^{2} \cdot \mathrm{g}^{-1}\right)$ and suitable pore size and structure [87] of 13X zeolite for toluene adsorption.

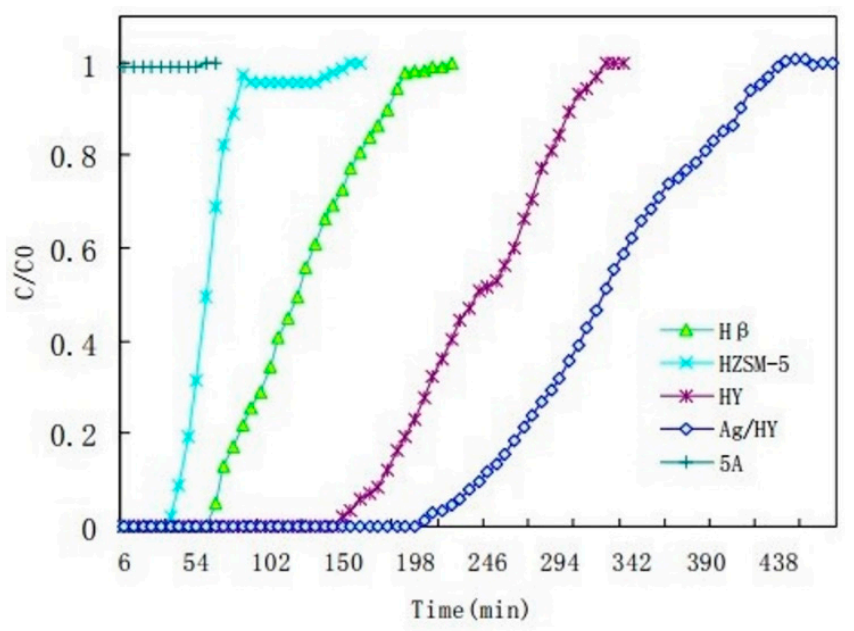

Figure 11. The breakthrough curves of toluene on different zeolites (flow rate: $300 \mathrm{~mL} / \mathrm{min}$ and toluene inlet concentration: 100 ppm). Reprinted from Reference [89], with permission from RCS publishing.

Table 1. Specific surface area, pore diameter, and adsorption capacity of different zeolite A [54].

\begin{tabular}{cccc}
\hline Zeolite & Specific Surface Area $\left(\mathbf{m}^{2} / \mathbf{g}\right)$ & Pore Diameter $(\AA)$ & Adsorption Capacity $(\mathbf{m g} / \mathbf{g})$ \\
\hline MS-3A & 224.95 & 3.52 & 17.75 \\
MS-4A & 290.54 & 4.79 & 19.21 \\
MS-5A & 391.94 & 5.33 & 21.27 \\
MS-10A & 439.31 & 9.66 & 126.61 \\
\hline
\end{tabular}

Thus, the adsorption capacity of zeolites for VOCs are roughly proportional to the $S_{\mathrm{BET}}$ and pore size as follows: NaY > MS-13X $(10 \AA) \approx \mathrm{HY}(7.4 \AA)$ > > MOR $(6.7-7.0 \AA)$ > ferrierite (4.3-5.5 $\mathrm{A})$ [32]. If the pore size of the zeolites are larger than the dynamic molecular size of VOCs, the VOCs are adsorbed in the microchannels of zeolites.

The adsorption capacity of zeolites can be increased or decreased by metal loading. The VOCs adsorption capacity of zeolites is enhanced by the presence of metal cation due to the strong interaction between the cation in the zeolite framework and VOC molecules. On the other hand, the adsorption capacity of zeolites can be lowered by metal loading, because the metal ions reduce the specific surface area and block some pores of zeolites, resulting in increased pore diffusion resistance. Thus, the proper selection of the metal ions for loading is important for the enhanced VOC adsorption on zeolites.

The ethylene adsorption capacity of zeolites is enhanced by the presence Ag cation due to the strong interaction between the charge compensating cation in the zeolite framework and the double bond of ethylene [51,90-94]. When compared to bare 13X zeolite, Ag/13X zeolite exhibited higher ethylene adsorption capacity because of the $\pi$-complexation between $\mathrm{Ag}(\mathrm{I})$ species and ethylene double bond $[93,95,96]$ in addition to the interaction between the adsorbed oxygen and ethylene. The metals with empty s-orbital and available electrons in the d-orbital could form $\pi$-complexation bonding. In case of bare $13 \mathrm{X}$ zeolite, the adsorption of ethylene on zeolite is via electrostatic interaction with $\mathrm{Na}^{+}$ions in 13X-zeolite and this physical adsorption is weak and reversible which is insufficient for the ethylene to be adsorbed to the inner pores of zeolite under flowing condition at atmospheric pressure and room temperature. Ethylene adsorption of zeolite is enhanced two orders of magnitude (from $2.66 \times 10^{-4}$ to $3.37 \times 10^{-2} \mathrm{~g}$ per gram of catalyst) by the incorporation of $\mathrm{Ag}$ [46]. When 
compared to HY, Ag loaded HY can adsorb more toluene which is due to the $\pi$-complexation of $\mathrm{Ag} / \mathrm{HY}$ with toluene [89].

Several studies showed that metal loading on zeolite enhances the VOC adsorption capacity despite the reduction in their specific surface area [38,44,97]. As shown in Table 2, the metal loading on HZSM-5 reduces the $\mathrm{S}_{\mathrm{BET}}$ as they occupy the cationic sites in zeolites which blocks the pores. Despite their reduced $\mathrm{S}_{\mathrm{BET}}$, Ag and Ag-Mn loaded HZSM-5 have a longer adsorption time when compared to bare HZSM-5 due to the ability of Ag to form $\pi$-complexation with toluene molecule [38]. Generally, the adsorption of toluene on HZSM-5 reduces with the loading of Mn. But, the mixed loading of $\mathrm{Ag} / \mathrm{Mn}$ shifts the toluene adsorption site to $\mathrm{Ag}$ due to the strong intermolecular force ( $\pi$-complexation) between Ag and toluene. Wang et al. [38] reported that during the adsorption of toluene on metal/HZSM-5, the partial oxidation of toluene has been observed on $\mathrm{Ag}, \mathrm{Mn}$, and Ag-Mn loaded HZSM-5 and the combination of Ag and Mn leads to further oxidation of these partial oxidation products to form $\mathrm{CO}_{2}$ as shown in the diffuse reflectance infrared Fourier transform (DRIFT) spectra bands at $2330 \mathrm{~cm}^{-1}$ and $2360 \mathrm{~cm}^{-1}$ of Ag-Mn/HZSM-5 catalysts with adsorbed toluene (Figure 12) [38].

Table 2. Specific surface area and toluene adsorption capacity of different metal loaded HZSM-5 zeolite (amount of catalyst $=1.6 \mathrm{~g}$ ) [38].

\begin{tabular}{ccc}
\hline Catalyst & $\mathbf{S}_{\text {BET }}\left(\mathbf{m}^{\mathbf{2}} \mathbf{g}^{-\mathbf{1}}\right)$ & Toluene Adsorption Amount (mmol) \\
\hline Ag/HZSM-5 & 367.6 & 0.29 \\
Mn/HZSM-5 & 398.5 & 0.22 \\
Ce/HZSM-5 & 380.6 & 0.21 \\
Ag-Mn/HZSM-5 & 350.0 & 0.27 \\
Ce-Mn/HZSM-5 & 344.0 & 0.21 \\
HZSM-5 & 486.6 & 0.26 \\
\hline
\end{tabular}
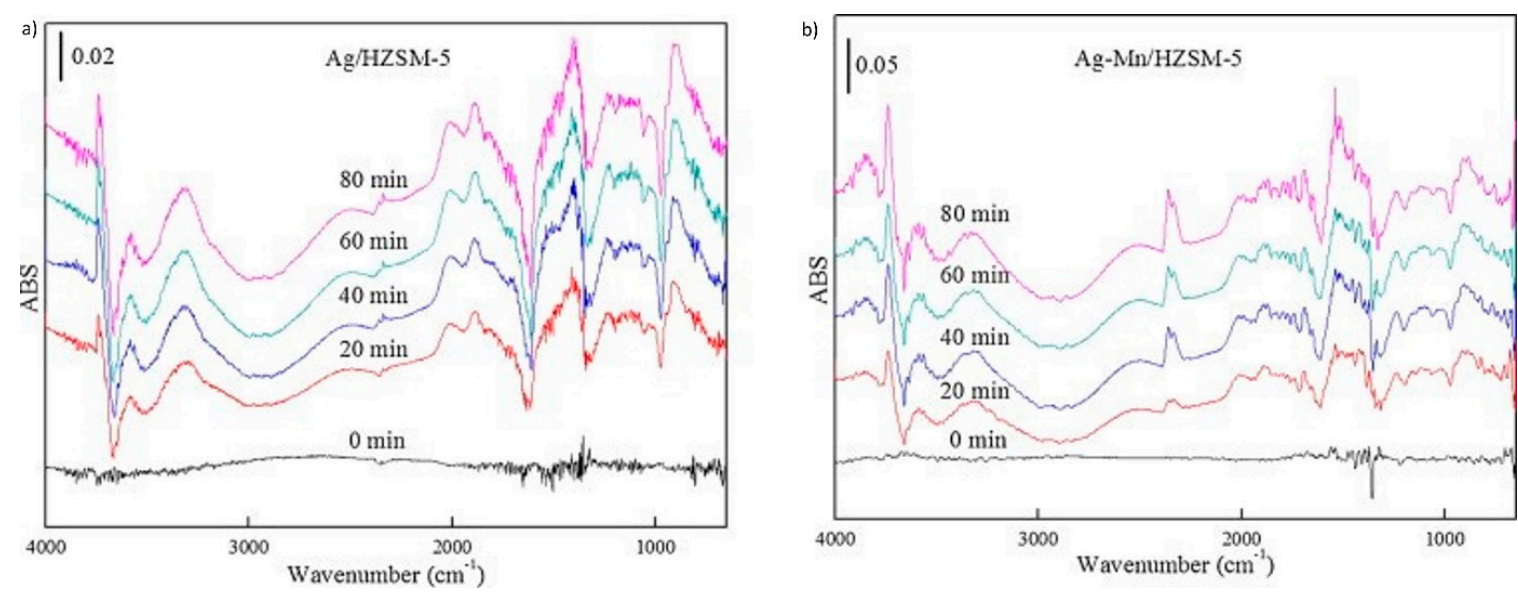

Figure 12. The diffuse reflectance infrared Fourier transform spectra (DRIFTS) of catalyst surface with adsorbed toluene (a) Ag/HZSM-5 and (b) Ag-Mn/HZSM-5 catalysts. Reprinted from Reference [38], with permission from Elsevier.

Among different transition metal loaded $(\mathrm{Cu}, \mathrm{Co}, \mathrm{Ce}$, and $\mathrm{Mg}) 13 \mathrm{X}$ zeolites, $\mathrm{Co} / 13 \mathrm{X}$ zeolite showed less decrease in the toluene adsorption capacity (as shown in Figure 13). Although the same of amount of metal has been loaded, the excellent adsorption of toluene on $\mathrm{Co} / 13 \mathrm{X}$ is due to the ability of $\mathrm{Co}^{3+}$ to form $\pi$-complexation with toluene which is stronger when compared to other metal species such as $\mathrm{Mg}, \mathrm{Ce}$, and $\mathrm{Cu}$ [88]. Another work reported that among the different packing materials $\left(\mathrm{CuO} / \mathrm{MnO}_{2}, \mathrm{CeO}_{2} / \mathrm{HZSM}-5\right.$ and $\left.\mathrm{Ag} / \mathrm{TiO}_{2}\right)$ tested for the adsorption of chlorobenzene, $\mathrm{CeO}_{2} / \mathrm{HZSM}-5$ exhibited rather high adsorption due to its high $\mathrm{S}_{\mathrm{BET}}$ and pore volume of the support [97]. 


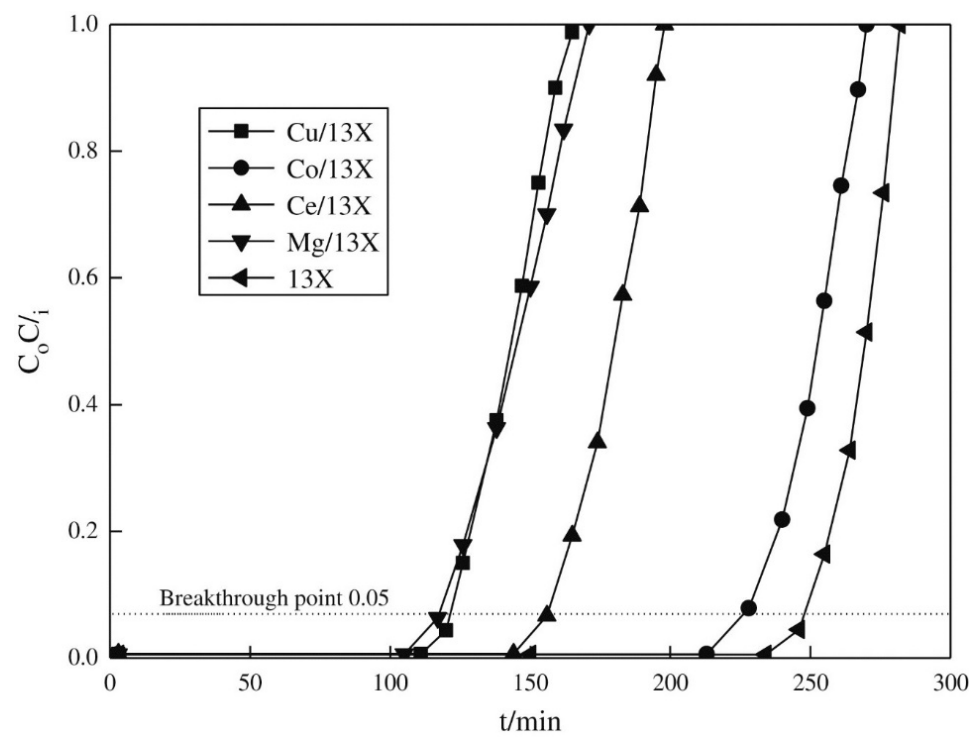

Figure 13. Adsorption breakthrough curves of 13X supported catalysts. Reprinted from Reference [88], with permission from John Wiley and Sons.

The co-incorporation of $\mathrm{Ag}$ and transition metal oxide in zeolites substantially increases the VOC adsorption capability due to the new active sites provided by the transition metals. Trinh et al. [95] reported that except $\mathrm{Fe}_{\mathrm{x}} \mathrm{O}_{\mathrm{y}}$, the addition of other transition metals (such as $\mathrm{Cu}, \mathrm{Mn}$, and $\mathrm{Co}$ ) enhances the ethylene adsorption capacity of $\mathrm{Ag} / 13 \mathrm{X}$ zeolite due to the formation of $\pi$-complexation [98]. Among the different bimetallic catalysts, $\mathrm{Ag}-\mathrm{Co} / 13 \mathrm{X}$ showed the maximum enhancement in ethylene adsorption. Zhao et al. [44] reported that among the different packing materials tested (such as HZSM-5, Ag/HZSM-5, Cu/HZSM-5, and AgCu/HZSM-5), AgCu/HZSM-5 showed higher breakthrough capacity for formaldehyde (as shown in Table 3) due to the synergistic effect of $\mathrm{Ag}$ and $\mathrm{Cu}$. The adsorption of formaldehyde happens on both the metal sites (due to $\pi$-complexation) and zeolite on Ag/HZSM-5 and AgCu/HZSM-5; while the adsorption happens only on zeolite in Cu/HZSM-5 and HZSM-5. The co-incorporation of $\mathrm{Ag}$ and $\mathrm{Cu}$ increases the amount of $\mathrm{Cu}^{3+}$ ions and the formation of $\mathrm{Ag}-\mathrm{Cu}$ species on AgCu/HZSM-5 catalyst which increases formaldehyde breakthrough capacity [99]. Qin et al. [100] investigated the metal supported $\mathrm{HZSM}-5 / \mathrm{Al}_{2} \mathrm{O}_{3}$ for the toluene decomposition in a cyclic APC system. The $\mathrm{S}_{\mathrm{BET}}$ of the HZSM- $5 / \mathrm{Al}_{2} \mathrm{O}_{3}$ is higher than the metal loaded HZSM-5 $/ \mathrm{Al}_{2} \mathrm{O}_{3}$. However, the breakthrough capacity of $\mathrm{Ag}-\mathrm{Mn}$ loaded $\mathrm{HZSM}-5 / \mathrm{Al}_{2} \mathrm{O}_{3}$ is better when compared to the bare support due to the presence of $\mathrm{Ag}^{+}$active sites which are capable of forming $\pi$-complexation with the toluene molecule $[96,100]$.

Table 3. Formaldehyde breakthrough capacity of different metal loaded HZSM-5 zeolites [44].

\begin{tabular}{cc}
\hline Sample & Breakthrough Capacity $(\mu \mathrm{mol} / \mathrm{mL}-\mathrm{cat})$ \\
\hline HZSM-5 & 8.5 \\
Ag/HZSM-5 & 18.5 \\
Cu/HZSM-5 & 11.8 \\
AgCu/HZSM-5 & 38.9 \\
\hline
\end{tabular}

High silica zeolite $\left(\mathrm{HZSM}-5\right.$ with $\left.\mathrm{SiO}_{2} / \mathrm{Al}_{2} \mathrm{O}_{3}=360\right)$ shows preferential adsorption of VOCs in humid air due to its hydrophobic nature [39,101,102]. Liu and Fan et al. [39,101] investigated different metal loaded HZSM-5 for the adsorption of dilute benzene in humid air $\left(1.5 \mathrm{vol} \% \mathrm{H}_{2} \mathrm{O}\right)$ and the breakthrough capacity are as follows: AgMn/HZSM-5 (131 $\mu \mathrm{mol} / \mathrm{cat})>\mathrm{Ag} / \mathrm{HZSM}-5(94 \mu \mathrm{mol} / \mathrm{cat})>$ Mn/HZSM-5 (78 $\mu \mathrm{mol} / \mathrm{cat})>$ HZSM-5 $(45 \mu \mathrm{mol} / \mathrm{cat})$. Ag/HZSM-5 has a longer breakthrough time due to the $\pi$-complexation of Ag with benzene $[39,101]$ and the adsorption capacity of AgMn/HZSM- 5 is much stronger due to the presence of more adsorption sites [39]. 
A wide range of humidity tolerance of the adsorbent is also one of the important factors for the cyclic APC process. Zhao et al. [44] reported that the $\mathrm{HCHO}$ breakthrough capacity of AgCu/HZSM-5 was almost constant over a wide range of relative humidity (20-93\%) due to the hydrophobic nature of high silica HZSM-5 which results in the selective adsorption of formaldehyde on AgCu/HZSM-5 catalyst; whereas the $\mathrm{HCHO}$ breakthrough capacity is slightly higher in dry conditions. HiSiv zeolites are high silica Faujasite zeolites $\left(\mathrm{SiO}_{2} / \mathrm{Al}_{2} \mathrm{O}_{3}\right.$ : HiSiv $1000<6.5$, HiSiv $\left.<10\right)$ known for their hydrophobic nature due to the high silica content and they are used for environmental applications due to their selectivity for organics in the presence of water. Kuroki et al. [47] reported that the mixture of HiSiv 1000 and HiSiv 3000 zeolite enhances the adsorption of a xylene mixture (o-, p-, and m-xylene) due to the capability of HiSiv 1000 zeolite to adsorb larger molecules $(0.6-0.9 \mathrm{~nm})$. However, HiSiv 3000 alone is not suitable for the adsorption of the xylene mixture as HiSiv 3000 zeolites are known for the adsorption of molecules which are smaller $(<0.6 \mathrm{~nm})$.

\subsection{Plasma Catalysis of Adsorbed VOCs on Zeolite}

One of the key issues finding an appropriate catalyst for cyclic APC technique is to find a catalyst which is not only good for VOC adsorption and has good humidity tolerance but also a catalyst which has the ability to completely oxidize the adsorbed VOCs. An overview of published papers on abatement of VOCs using zeolites in combination with non-thermal plasma discharge is given in Table 4. The decomposition of $\mathrm{O}_{3}$ to form highly reactive $\mathrm{O}^{\bullet}$ is one of the important reactions which governs the decomposition efficiency of adsorbed VOCs on zeolites because the rate of reaction of $\mathrm{O}^{\bullet}$ with VOC is much higher than that of ozone. The decomposition of VOCs by ozone has been known to follow one of the following two mechanisms:

(i) Langmuir-Hinshelwood (L-H) mechanism [103]:

$$
\begin{gathered}
\mathrm{O}_{3}+* \rightarrow \mathrm{O}_{2}+* \mathrm{O}_{\text {ads }} \\
* \mathrm{O}_{\text {ads }}+\mathrm{VOC}_{\mathrm{ads}} \rightarrow \mathrm{CO}_{\mathrm{x}}+\mathrm{H}_{2} \mathrm{O}+*
\end{gathered}
$$

where $*$ is the active site on the catalyst and $* \mathrm{O}_{\text {ads }}$ is the active oxygen species adsorbed on the catalyst. Metal loaded zeolites (for example, MS-13X) have the ability to decompose ozone to form active oxygen species which react with the VOCs adsorbed on zeolite. In this model, both the reactants should be adsorbed on the surface and followed by migration to active site.

(ii) Eley-Rideal (E-R) mechanism:

$$
* \mathrm{VOC}_{\mathrm{ads}}+\mathrm{O}_{3} \rightarrow \mathrm{CO}_{\mathrm{x}}+\mathrm{H}_{2} \mathrm{O}+*
$$

where $* \mathrm{VOC}_{\mathrm{ads}}$ is the VOC adsorbed on the catalyst. Metal unloaded zeolite (bare zeolite) has no ability to decompose ozone to form active oxygen (for example, H-Y zeolite). Unlike the VOC adsorbed on zeolite, which can be oxidized by ozone, ozone on bare zeolite has less ability to oxidize $\mathrm{CO}$ to form $\mathrm{CO}_{2}$ and thus resulting in lower $\mathrm{CO}_{2}$ selectivity [74]. In this model, only one reactant is adsorbed on the surface and the other exists in the gas phase. Also, the diffusion length of short-lived species such as $\mathrm{O}$ and $\mathrm{OH}$ and electrons are as small as $100 \mu \mathrm{m}$ at atmospheric pressure. But ozone has a longer diffusion length of $10 \mathrm{~mm}$ due to it long lifetime and can thus reach the inner area of the micropores in zeolite [74].

The adsorption of VOCs on zeolite increases the residence time of VOCs in the plasma discharge region resulting in enhanced mineralization efficiency of cyclic APC technique. Yi et al. [61] investigated three different plasma reactor configurations such as (i) NTP alone, (ii) plasma catalysis (PC), and (iii) cyclic APC for the decomposition of toluene using Co/13X zeolite as a packing material. Toluene removal efficiency of cyclic APC was 92.7\%; whereas a removal efficiency of $100 \%$ was achieved using NTP alone and PC. However, for APC, the mineralization efficiency and $\mathrm{CO}_{2}$ selectivity were improved by $23.4 \%$ and $35.3 \%$, respectively, when compared to NTP alone; whereas, the improvement 
was only $18 \%$ and $10 \%$, respectively, for PC. Since the product selectivity towards the gaseous products $\mathrm{CO}_{\mathrm{x}}\left(\mathrm{CO}+\mathrm{CO}_{2}\right)$ directly corresponds to the extent of mineralization, which is an important evaluation parameter for air pollution treatment. Thus, the higher mineralization efficiency of APC is due to the increase in the residence time of toluene and plasma generated active species in the plasma discharge region which completely oxidizes the adsorbed toluene and the by-products formed show that cyclic APC is suitable for air pollution treatment $[104,105]$.

Yi et al. [88] investigated the cyclic APC using different metal loaded $(\mathrm{Cu}, \mathrm{Mg}, \mathrm{Ce}, \mathrm{Co}) 13 \mathrm{X}$ zeolite for the decomposition of toluene. The metal loading on $13 \mathrm{X}$ zeolite enhances the $\mathrm{CO}$ and $\mathrm{CO}_{2}$ yield, $\mathrm{CO}_{\mathrm{x}}$ selectivity, and carbon balance. This is due to the dissociation of $\mathrm{O}_{3}$ produced by the NTP discharge on the metal active sites $\left(^{*}\right)$ which played a significant role on the complete oxidation of toluene following the equations $[103,106]$ :

$$
\begin{gathered}
\mathrm{O}_{3}+* \rightarrow \mathrm{O}_{2}+* \mathrm{O} \\
\mathrm{O}_{3}+* \mathrm{O} \rightarrow \mathrm{O}_{2}+* \mathrm{O}_{2} \\
* \mathrm{O}_{2} \rightarrow \mathrm{O}_{2}+*
\end{gathered}
$$

Of the different metal loaded $13 \mathrm{X}$ zeolites studied, $\mathrm{Cu}$ and $\mathrm{Co}$ showed excellent $\mathrm{CO}_{2}$ selectivity, because the active sites of $\mathrm{Co}$ and $\mathrm{Cu}$ catalysts are $\mathrm{Co}_{3} \mathrm{O}_{4}$ and $\mathrm{CuO}_{2}$, respectively, which have large oxygen adsorption capacity and easily convert oxygen to $\mathrm{O}^{-}$and $\mathrm{O}^{2-}$ ion [88]. Oda et al. [107,108] investigated the combination of NTP and metal loaded ZSM- 5 zeolite for the decomposition of TCE. They reported that the TCE removal efficiency using zeolites such as Na-ZSM-5 and Cu-ZSM-5 was $80 \%$ without the plasma. Due to the large specific surface area of ZSM-5 zeolites, this removal is mainly due to adsorption. As the plasma decomposition of TCE is also associated with its desorption, the TCE removal efficiency is never $100 \%$ even at higher discharge power [108]. A good absorbance of TCE at room temperature was exhibited by Cu-ZSM- 5 which enhanced the removal efficiency of TCE to $>95 \%$ even in the presence of weak plasma [107].

Nishimura et al. [46] investigated the use of $\mathrm{Ag} / 13 \mathrm{X}$ zeolite in a packed bed dielectric barrier discharge (PBDBD) reactor for the removal of ethylene [46] and reported 100\% removal efficiency with and without plasma discharge. Thus, the ethylene removal in the absence of plasma is attributed to the adsorption of ethylene on zeolite ( $\pi$-complexation) and the enhanced ethylene removal in the presence of plasma is because of the widened range of plasma generation due to Ag loading on zeolite [32,41]. Also, the formation of unwanted by-products such as $\mathrm{HCHO}, \mathrm{O}_{3}$, and $\mathrm{NO}_{x}$ is greatly suppressed by the $\mathrm{Ag} / 13 \mathrm{X}$. The concentration of $\mathrm{CO}$ in the outlet is also reduced either due to the adsorption of $\mathrm{CO}$ on $\mathrm{Ag} / 13 \mathrm{X}$ or via the decomposition reaction with the surface reactive oxygen produced by $\mathrm{O}_{3}$ (Equations (4)-(6)). Similarly, another work reported that the formation of $\mathrm{O}_{3}$ is reduced in the $\mathrm{Ag} / \beta$-zeolite ( $20 \mathrm{ppm}$ ), when compared to the bare zeolite (350 ppm in transient state and $\sim 30 \mathrm{ppm}$ in steady state) due to the decomposition of $\mathrm{O}_{3}$ in metal active sites which increased the rate of acetone degradation when compared to the bare zeolite [109]. Kim et al. [8,110] reported that the metal loaded $\mathrm{H}-\mathrm{Y}$ zeolite also enhances the carbon balance by retarding the formation of carbonaceous products on the surface of the catalyst and the largest enhancement of carbon balance (about $30 \%$ ) is observed by supporting $2 \% \mathrm{Ag}$ on $\mathrm{H}-\mathrm{Y}$ zeolite.

In $\mathrm{Ag} / \mathrm{H}-\mathrm{Y}$ zeolite, ozone was adsorbed and decomposed both by the active sites of the zeolite substrate and by metal loaded on zeolite, and thus exhibiting an enhanced toluene removal efficiency and carbon balance. For example, Ag loading on $\mathrm{H}-\mathrm{Y}$ zeolite increases the carbon balance from $83 \%$ to 98.1\% [89]. Also, the formation of organic byproducts was retarded using Ag/H-Y zeolite due to the complete toluene oxidation by the active oxygen species obtained by the decomposition of $\mathrm{O}_{3}$. Thus, the decomposition of toluene can be achieved by the impact of plasma active species in the gas phase. But the further oxidation of intermediates and by-products formed are effective only by the active $\mathrm{O}^{\bullet}$ species produced by the decomposition of ozone on the surface of the catalyst. 
Hu et al. [111] investigated the use of a series surface/packed bed discharge reactor (SSPBD) powered by a bipolar pulsed power supply in combination with metal oxide loaded $13 \mathrm{X}$ zeolite $\left(\mathrm{TiO}_{2}\right.$, $\mathrm{MnO}_{2}$, and $\mathrm{MnO}_{2}-\mathrm{TiO}_{2}$ ) for the decomposition of benzene. The highest benzene decomposition efficiency and $\mathrm{CO}_{x}$ selectivity of $83.7 \%$ and $68.1 \%$ were obtained using $\mathrm{MnO}_{2}-\mathrm{TiO}_{2}$ / zeolite packed reactor $(10.33 \mathrm{~W})$ because of the generation of $\mathrm{OH}$ radicals due to the charge transformation between $\mathrm{Ti}^{4+}$ and $\mathrm{Mn}^{4+}$ on the surface of $\mathrm{MnO}_{2}-\mathrm{TiO}_{2} /$ zeolite catalyst which resulted in the separation of the photogenerated electron and hole. Also, the concentration of $\mathrm{O}_{3}$ is greatly reduced due to the $\mathrm{O}_{3}$ decomposition ability of $\mathrm{MnO}_{2}$ [112-115]. Also, the formation of some intermediate by-products such as $\mathrm{CO}, \mathrm{HCOOH}$, and $\mathrm{N}_{2} \mathrm{O}$ were also significantly suppressed.

It is well known from literature that $\mathrm{MnO}_{\mathrm{x}}$ efficiently oxidizes $\mathrm{O}_{3}$ [112-115] and Mn/HZSM-5 enhances the rate of benzene decomposition in cyclic APC [39]; whereas $\mathrm{CO}_{2}$ selectivity of $\sim 100 \%$ was achieved using Ag/HZSM-5 as packing material. This shows that Ag is necessary to promote the complete benzene oxidation [39,101,102]. Thus, the promotional effect of $\mathrm{Mn}_{\text {for }} \mathrm{O}_{3}$ decomposition and $\mathrm{Ag}$ for complete benzene oxidation is obtained using AgMn/HZSM-5 zeolite [39]. Similar work has been performed for the decomposition of toluene by Wang et al. [38] and they reported that during the NTP regeneration of the toluene adsorbed catalyst, the mineralization efficiency of Ag-Mn/HZSM-5 is higher than the individual metal loaded HZSM-5 (such as Ag/HZSM-5, Mn/HZSM-5, Ce/HZSM-5).

The affinity of metal oxides which are loaded on zeolites towards the adsorbed VOCs plays an important role in determining the time required for a plasma discharge which in turn influences the energy cost of the process. Zhao et al. [44] studied the abatement of the adsorbed formaldehyde on different metal loaded $(\mathrm{Cu}, \mathrm{Ag}, \mathrm{AgCu})$ and bare zeolites (HZSM-5). As shown in Figure 14, the evolution of $\mathrm{CO}_{2}$ on AgCu/HZSM-5 and Ag/HZSM-5 is slower than that of Cu-HZSM- 5 and bare HZSM- 5 due to the difference in the adsorption sites towards $\mathrm{HCHO}$ for different zeolites under investigation. Despite the longer discharge time required for the complete decomposition of the adsorbed formaldehyde, the $\mathrm{CO}_{2}$ selectivity and carbon balance of $\mathrm{AgCu} / \mathrm{HZSM}-5$ are $~ 100 \%$ suggesting that there is no other by-product formation [44].
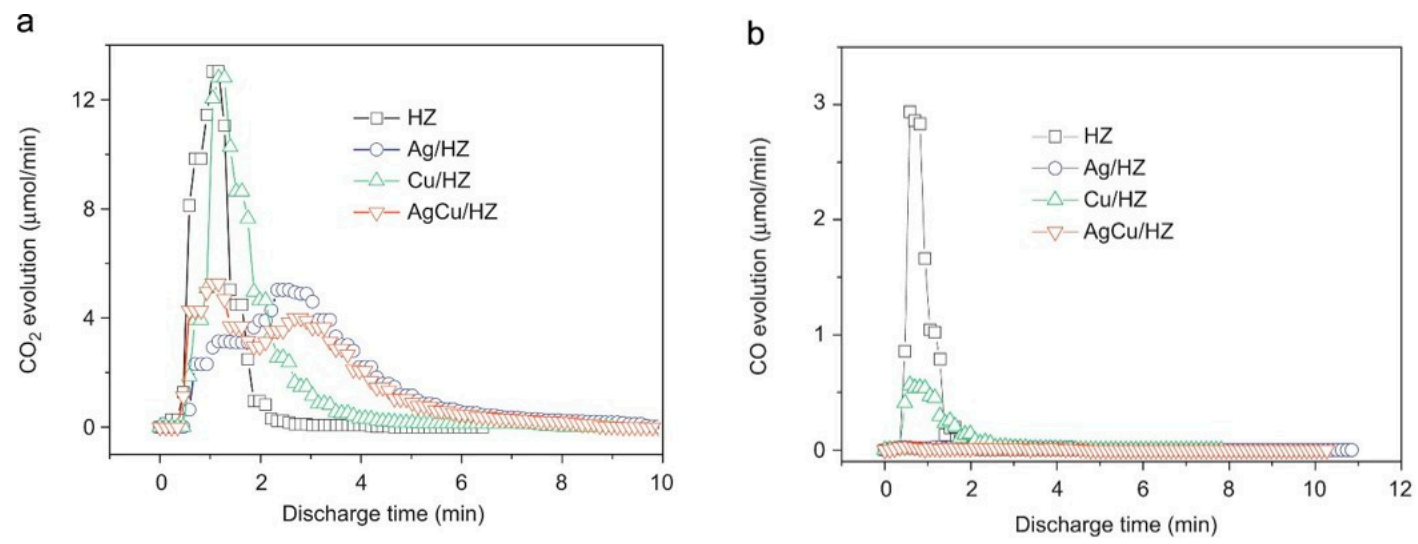

Figure 14. (a) $\mathrm{CO}_{2}$ and (b) $\mathrm{CO}$ evolutions with discharge time in plasma catalytic oxidation of stored $\mathrm{HCHO}$ over $\mathrm{HZ}, \mathrm{Ag} / \mathrm{HZ}, \mathrm{Cu} / \mathrm{HZ}$, and $\mathrm{AgCu} / \mathrm{HZ}$ catalysts (storage stage: simulated air at $300 \mathrm{~mL} / \mathrm{min}$, $50 \%$ relative humidity $(\mathrm{RH}), \mathrm{GHSV}=12,000 \mathrm{~h}^{-1}, \mathrm{C}_{\mathrm{HCHO}}=24.4 \mathrm{ppm}(\mathrm{HZ}), 27.2 \mathrm{ppm}(\mathrm{Ag} / \mathrm{HZ}), 26.7 \mathrm{ppm}$ $(\mathrm{Cu} / \mathrm{HZ})$ and $26.6 \mathrm{ppm}(\mathrm{AgCu} / \mathrm{HZ}), \mathrm{t}=40 \mathrm{~min}$; discharge stage: $\mathrm{O}_{2}$ at $\left.60 \mathrm{~mL} / \mathrm{min}, \mathrm{P}_{\text {discharge }}^{\mathrm{APC}}=2.3 \mathrm{~W}\right)$. Reprinted from Reference [44], with permission from Elsevier.

Despite the lower affinity towards ethylene, the oxidation of ethylene by $\mathrm{AgFe} / 13 \mathrm{X}$ zeolite is faster when compared to other transition metal $(\mathrm{Co}, \mathrm{Mn}$, and $\mathrm{Cu}$ ) loaded $\mathrm{Ag} / 13 \mathrm{X}$ zeolite, which is evident from the temporal evolution of $\mathrm{CO}_{2}$. But, the desorption of ethylene and $\mathrm{CO}_{2}$ production are the least in $\mathrm{AgCo} / 13 \mathrm{X}$ zeolite. Also, the emission of by-products such as $\mathrm{O}_{3}$ and $\mathrm{CH}_{4}$ was suppressed by the $\mathrm{Ag}-\mathrm{Fe} / 13 \mathrm{X}$ zeolite when compared with other bimetallic $13 \mathrm{X}$-zeolite. Thus, the affinity of the metal oxide loaded zeolite towards the adsorbed VOCs plays an important role in the desorption and 
oxidation of the desorbed VOCs [95] as the rate of oxidation reaction is higher in the gaseous phase [93]. The increase in the amount of adsorbent from $4.8 \mathrm{~g}$ (HiSiv 3000) to $8 \mathrm{~g}$ (HiSiv3000 = $2.5 \mathrm{~g}$ and HiSiv1000 $=5.5 \mathrm{~g}$ ), decreases the conversion efficiency of $\mathrm{p}$-xylene due to the fact that the conversion is faster in gaseous phase and the increase in the amount of adsorbent reduces the desorption of p-xylene [47], and thus the reduced conversion efficiency.

The metal loading on zeolite not only influences the oxidation state and the crystallinity of the catalyst, but also the pore volume and $\mathrm{S}_{\mathrm{BET}}$ of the support. Thus, the optimum level of metal loading is critical for the best catalytic performance. Yi et al. [88] reported that the 5\% Co/13X zeolite exhibits the best toluene adsorption and good plasma catalytic activity. When the Co loading is too low (1\%), the number of active sites available for the $\pi$-complexation is too low, resulting in the weak chemical adsorption of toluene. When Co loading exceeds 15\%, not only the pores of zeolite are blocked but also the active metal species can be significantly agglomerated which reduces the surface area of active sites, resulting in decreased catalytic performance [88].

The characteristics of the plasma discharge can also be affected by the amount of metal loading on zeolite $[32,41,102]$. For environmental protection applications, the plasma active region should be widely spread as the localized plasma consumes much energy without enhancing the removal efficiency. Thus, a uniformly distributed plasma is desirable for high energy and conversion efficiency. Kim et al. [32] reported that microscopic ICCD camera snapshots revealed that the metal loading on zeolite increases the number of micro-discharges and reduces the peak current. The number of micro-discharges in a DBD plasma reactor determines the amount of active radicals produced, and thus the VOC decomposition efficiency. As shown in Figure 15, without metal loading, the plasma is confined mainly in the vicinity of zeolite pellets; whereas, with metal loading, the plasma intensity is increased and expanded over a wide area due to the formation of surface streamers. Although the initial decomposition of VOCs occurs on the surface of the support such as zeolites, further decomposition of intermediates occurs on the active sites such as metals on zeolite [110] resulting in different $\mathrm{CO}_{2}$ selectivity, carbon balance and formation of by-products. Also, the amount of metal loading on zeolite plays a significant role in the complete oxidation of the adsorbed VOCs. Fan et al. [102] reported that the carbon balance during the decomposition of benzene $(\mathrm{P}=4.7 \mathrm{~W})$ is $\sim 100 \%$ for $0.8 \mathrm{wt} \% \mathrm{Ag} / \mathrm{HZSM}-5$ and decreases with an increase in Ag loading on HZSM-5 zeolite. This decrease in carbon balance is due to the strong interaction between the adsorbed benzene and $\mathrm{Ag}^{+}$which makes it more difficult to desorb and oxidize the adsorbed benzene [102]. Thus, the loading of metals on zeolites showed enhanced VOC removal efficiency and $\mathrm{CO}_{2}$ selectivity due to the following reasons: (i) enhanced catalytic activity of the metal loaded catalyst (more active sites) and (ii) the formation of a uniform discharge over metal loaded zeolite when compared to the bare zeolite [41].

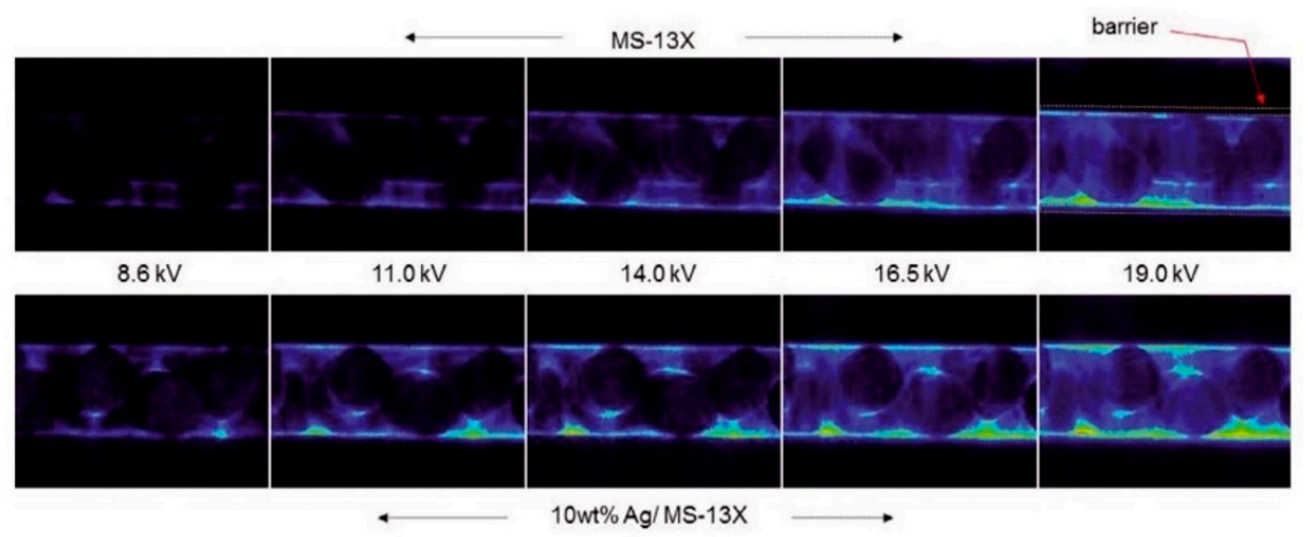

Figure 15. ICCD camera snapshots of the discharge plasma over molecular sieve 13X zeolite (MS-13X) with or without Ag loading; (frequency $=50 \mathrm{~Hz}, 2 \times$ lens, $2 \mathrm{~mm}$ gap, exposure time $=100 \mathrm{~ms}$ ). Reprinted from Reference [32], (c) EDP sciences, 2011. 
It is well known from literature that greater the $\mathrm{S}_{\mathrm{BET}}$, greater the catalytic activity [116]. However, Youn et al. [117] reported that Fe/ZSM-5 $\left(\mathrm{S}_{\mathrm{BET}}=362.3 \mathrm{~m}^{2} / \mathrm{g}\right.$ and pore volume $\left.=0.17 \mathrm{~cm}^{3} / \mathrm{g}\right)$ showed higher toluene oxidation in comparison with $\mathrm{Fe} /$ Beta $\left(\mathrm{S}_{\mathrm{BET}}=587.8 \mathrm{~m}^{2} / \mathrm{g}\right.$ and pore volume $=0.90 \mathrm{~cm}^{3} / \mathrm{g}$ ) in an APC technique. This is because the number of micro-discharges per pore volume of $\mathrm{Fe} / \mathrm{ZSM}-5$ is higher than of $\mathrm{Fe} /$ Beta which is evident from the Lissajous figure (as shown in Figure 16). This behavior enhanced both toluene oxidation $\left(100 \%\right.$ carbon balance) and $\mathrm{CO}_{\mathrm{x}}$ selectivity [117]. With the increase in Fe content, the product selectivity of $\mathrm{CO}_{\mathrm{x}}$ increases and ethylene reduces due to the oxidation ability of the Fe/zeolite [117].

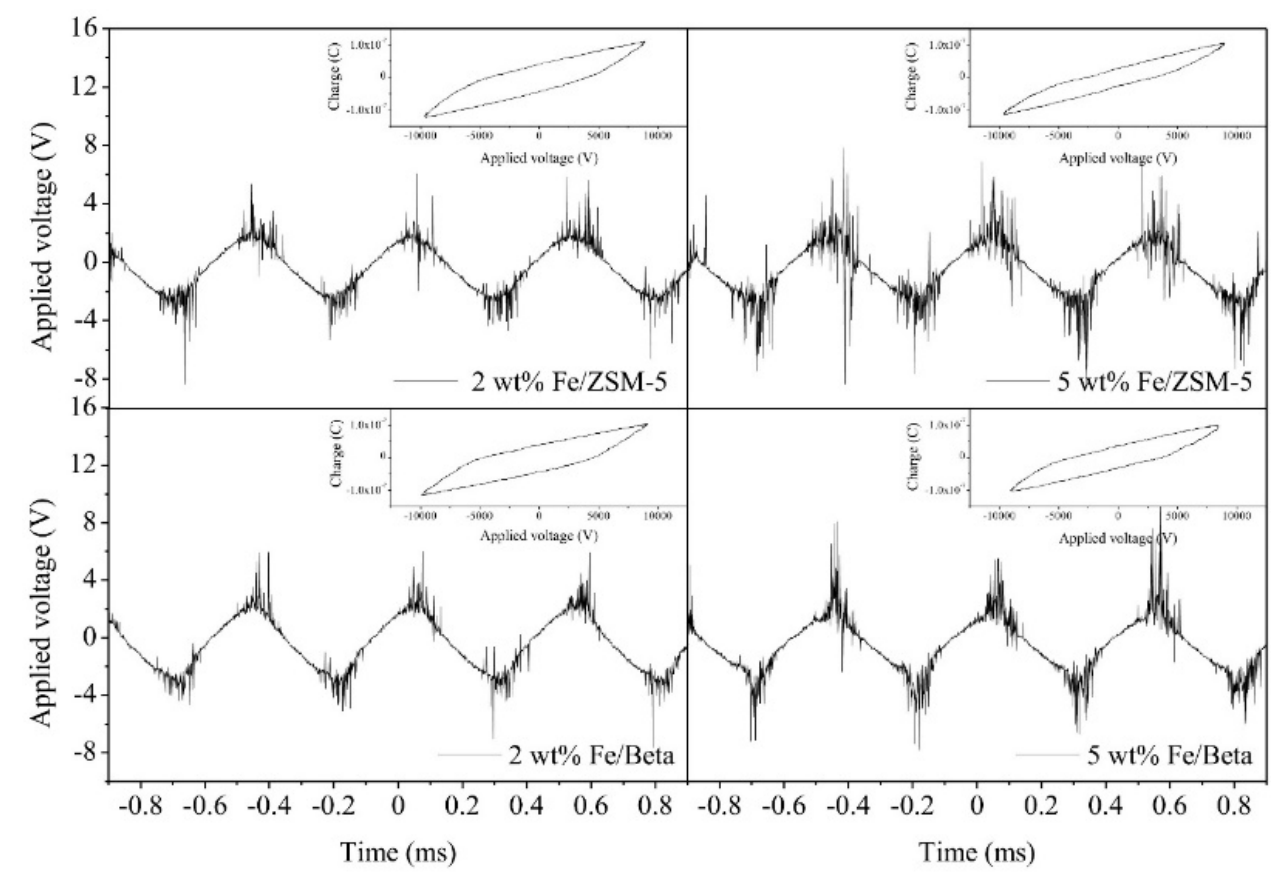

Figure 16. Discharge properties (current pattern and Lissajous plot) of Fe/ZSM-5 and Fe/Beta in toluene oxidation using a dielectric barrier discharge (DBD) plasma-catalyst hybrid system. Reprinted from Reference [117], with permission from Elsevier.

As already mentioned, the number of micro-discharges in a DBD plasma reactor determines the amount of active radicals produced. Apart from the metal loading, the number of micro-discharges also depends on the dielectric constant of a packing material. The discharge characteristics of the zeolite packed plasma reactor can be improved by mixing zeolite with other support materials with higher dielectric constant such as $\mathrm{Al}_{2} \mathrm{O}_{3}, \mathrm{TiO}_{2}$, and $\mathrm{BaTiO}_{3}[100,118]$. As the dielectric constant of $\mathrm{Al}_{2} \mathrm{O}_{3}(9 \sim 11)$ is higher than HZSM-5 (1.5 5), the $\mathrm{Al}_{2} \mathrm{O}_{3}$ packed plasma reactor has a higher electric field strength when compared to a HZSM-5 packed reactor $[119,120]$. As shown in Figure 17, the number of micro-discharges produced in an $\mathrm{Al}_{2} \mathrm{O}_{3}$ packed plasma reactor is higher than that of $\mathrm{HZSM}-5$ resulting in an increased number of active species produced [100] which is directly related to the enhanced VOC removal efficiency. The dielectric constant of the zeolites is also dependent on the Si/Al ratio and it is inversely proportional to the $\mathrm{Si} / \mathrm{Al}$ ratio. Kim et al. [121] studied $\mathrm{Ag} / \mathrm{HY}$ zeolites with different $\mathrm{Si} / \mathrm{Al}$ ratio such as $2.6,15$, and 40 and reported that the propagation of the surface streamers are less when the dielectric constant is more than 15 , and thus reduced plasma catalytic activity. Qin et al. [100] investigated the mixed packing material $\left(\mathrm{Al}_{2} \mathrm{O}_{3} / \mathrm{HZSM}-5\right)$ for toluene decomposition in the cyclic APC system. The high $\mathrm{S}_{\mathrm{BET}}$ and suitable pore size of HZSM-5 keep the adsorbed toluene in the discharge region; whereas, the $\mathrm{Al}_{2} \mathrm{O}_{3}$ produces more active species for an effective toluene oxidation. 

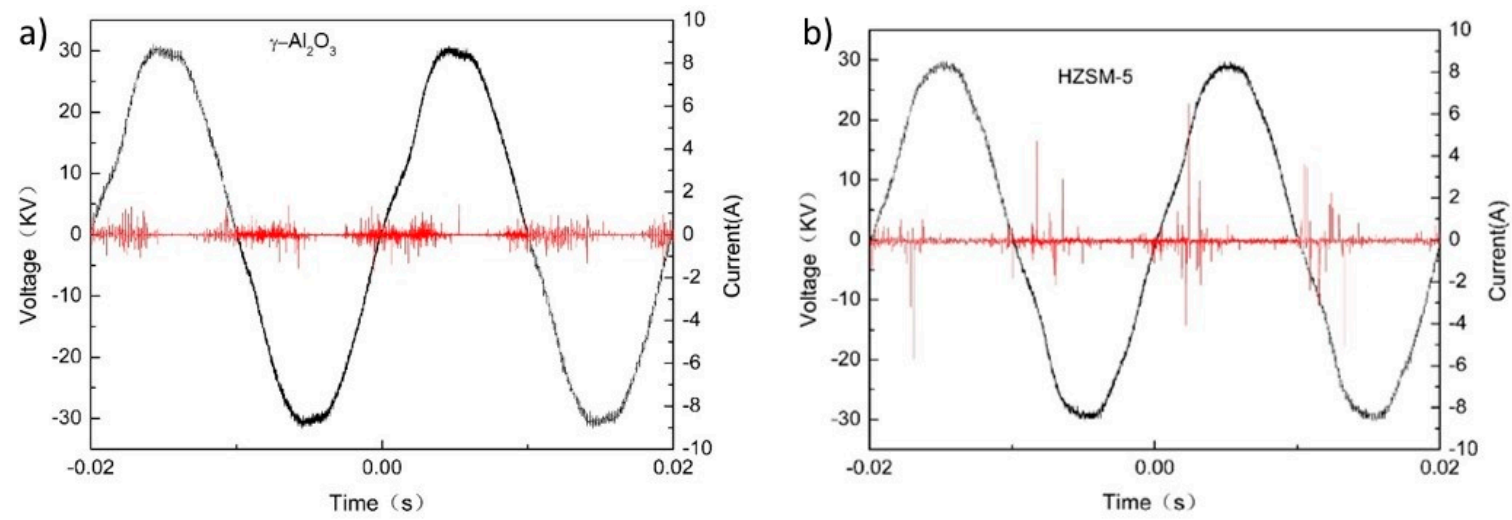

Figure 17. Voltage-current diagrams of (a) $\gamma-\mathrm{Al}_{2} \mathrm{O}_{3}$ and a (b) HZSM-5 packed NTP reactor. Reprinted from Reference [100], with permission from Elsevier.

Another work investigated the use of mixture of zeolites (such as MS-3A, MS-4A, MS-5A, and MS-13X) and ferroelectric material $\left(\mathrm{BaTiO}_{3}\right)$ for the decomposition of dilute benzene in flue gas [86]. The zeolite $/ \mathrm{BaTiO}_{3}$ hybrid reactor yields 1.4-2.1 times more $\mathrm{CO}_{2}$ than the conventional $\mathrm{BaTiO}_{3}$ reactor except for an MS-13X hybrid reactor which is due to the adsorption of $\mathrm{CO}_{2}$ on MS-13X. In the physical mixture of packing materials, apart from the dielectric constant, the relative size of ferroelectric pellets and adsorbing packing material such as $\mathrm{Al}_{2} \mathrm{O}_{3}$ and zeolite also plays an important role in the intensification of plasma. Ogata et al. [55] studied the reaction field and the role of solid surface under plasma for the decomposition of benzene in air. The strong plasma density is necessary to induce catalysis in the plasma media [55] and this phenomenon has been demonstrated by using the combination of $\mathrm{BaTiO}_{3}>$ porous $\mathrm{Al}_{2} \mathrm{O}_{3}$ (a mixture of $2 \mathrm{~mm} \mathrm{BaTiO}$ and $1 \mathrm{~mm} \mathrm{Al}_{2} \mathrm{O}_{3}$ ) and $\mathrm{BaTiO}_{3}<$ $\mathrm{Al}_{2} \mathrm{O}_{3}$ (a mixture of $1 \mathrm{~mm} \mathrm{BaTiO}$ and $2 \mathrm{~mm} \mathrm{Al}_{2} \mathrm{O}_{3}$ ) as shown in Figure 18. Since the high-energy plasma is produced around the contact points of $\mathrm{BaTiO}_{3}$ as shown in Figure 18, the combination of $\mathrm{BaTiO}_{3}>\mathrm{Al}_{2} \mathrm{O}_{3}$ is more effective for the plasma catalysis when compared to $\mathrm{BaTiO}_{3}<\mathrm{Al}_{2} \mathrm{O}_{3}$.

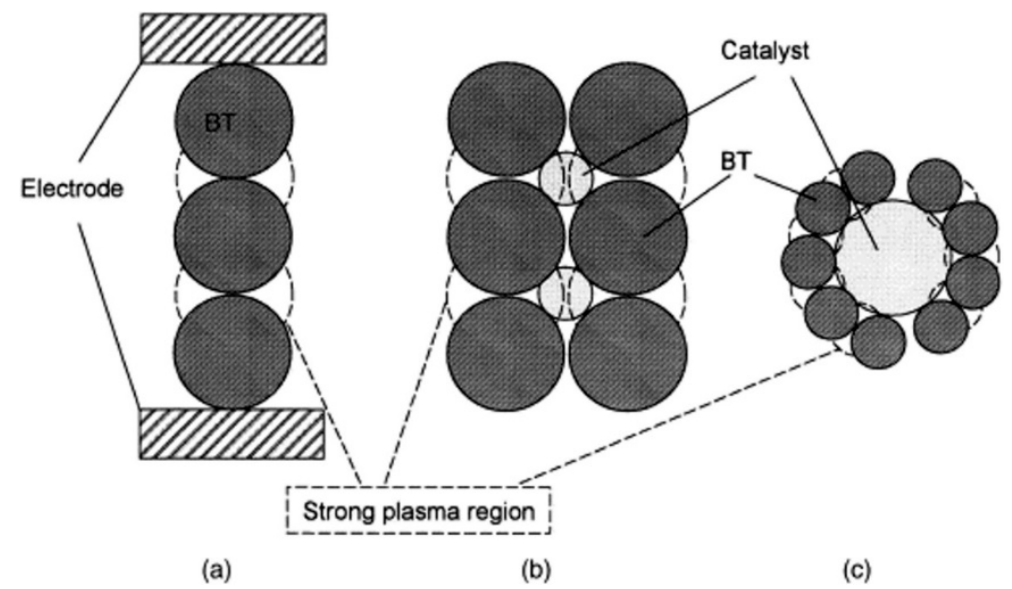

Figure 18. Representation of plasma discharge in (a) a conventional reactor packed with $\mathrm{BaTiO}_{3}$ (BT) alone and the reactors packed with a mixture of $\mathrm{BaTiO}_{3}$ (BT) and adsorbent $\mathrm{Al}_{2} \mathrm{O}_{3}$ catalyst (b) $\mathrm{BT}>\mathrm{Al}_{2} \mathrm{O}_{3}$ and (c) $\mathrm{BT}<\mathrm{Al}_{2} \mathrm{O}_{3}$. Reprinted from Reference [55], with permission from Elsevier.

The mineralization efficiency can be further improved by loading metal on the mixed packing materials. The highest $\mathrm{CO}_{2}$ selectivity was obtained with $\mathrm{AgMn} / \mathrm{ZSM}-5 / \mathrm{BaTiO}_{3}$ for toluene decomposition [118] because the introduction of $\mathrm{Ag}-\mathrm{Mn}$ : (i) favors the formation of $\pi$-complexation bonds with toluene which aided the reaction pathway to produce $\mathrm{CO}_{2}$ and (ii) favors the oxidation of $\mathrm{CO}$ to $\mathrm{CO}_{2}$. The AgMn/ZSM-5/ $\mathrm{BaTiO}_{3}$ enhances the toluene removal efficiency to $100 \%$, reduces the concentration of $\mathrm{O}_{3}$ by decomposing $\mathrm{O}_{3}$ to $\mathrm{O}_{2}$ and oxygen active species, which oxidize $\mathrm{CO}$ to $\mathrm{CO}_{2}$ 
and resulting in a $83 \%$ mineralization efficiency. $\mathrm{AgMn} / \mathrm{ZSM}-5 / \mathrm{BaTiO}_{3}$ also reduces the production of $\mathrm{N}_{2} \mathrm{O}$.

Apart from the dielectric constant and metal loading on zeolites, the plasma discharge characteristics are also influenced by the textural properties of zeolites. When the size of the micropores are much smaller than the dynamic molecular size of VOCs, the adsorption of VOCs is restricted and also the formation of micro-discharges inside the pores is limited resulting in only surface discharges, and thus the decomposition efficiency is reduced [85]. But, the VOCs adsorbed on the external pores of zeolites are easily oxidized when compared to VOCs adsorbed in the inner pores [86]. Ogata et al. [55] reported that the ratio of the surface and the bulk pore volume is important for the decomposition of adsorbed VOCs because it is difficult for the plasma micro-discharges to reach the inner pores when the size of the catalyst is large. On the other hand, when the size of the by-products produced is bigger than the pore diameter, carbon deposition would appear [89].

Huang et al. [89] investigated different zeolites for the plasma driven catalytic abatement of toluene and reported that the mineralization efficiency follows the same order of the pore diameter. Although the pore diameter of MS-5A zeolite is too small to adsorb toluene, it still exhibited high toluene removal efficiency in combination with plasma due to the strong collision of electrons and radicals in the micro pores. For the zeolites that exhibited good toluene adsorption such as $\mathrm{H}-\mathrm{Y}, \mathrm{H} \beta$ and HZSM-5, the toluene removal was due to the combined effect of the collision of electrons and radicals and the adsorption of toluene on the zeolite surface [89]. The highest mineralization was achieved by the zeolite $\mathrm{H}-\mathrm{Y}$ due to its larger pore size. The natural columbic electric field in the microporous structure of zeolites can strengthen the plasma discharge and enhances the VOC removal efficiency. Also, there was no formation of organic compounds on the surface of MS-5A zeolites after plasma treatment; whereas organic deposits were found on $\mathrm{H}-\mathrm{Y}, \mathrm{H} \beta$ and HZSM- 5 zeolites. This is because the pore size of $5 \mathrm{~A}$ zeolite is too small for the organic intermediates to access the internal pores.

On the other hand, the porous material with high $\mathrm{S}_{\mathrm{BET}}$ expands the discharge region because the streamers can be generated in the pores [88]. USY zeolite has very high surface area $\left(715 \mathrm{~m}^{2} \mathrm{~g}^{-1}\right)$ and it is known for its VOC adsorption capacity. Hamada et al. [122] reported that the deposition of $\mathrm{Mn}_{\mathrm{x}} \mathrm{O}_{\mathrm{y}}$ on Y-zeolite enhances the removal efficiency of benzene and avoids the formation of organic by-products which might deactivate the catalyst. This is mainly due to the high $\mathrm{S}_{\mathrm{BET}}$ of Y-zeolite and $\mathrm{O}_{3}$ decomposing ability of $\mathrm{MnO}_{2}$ in $\mathrm{Mn} / \mathrm{USY}$ catalyst.

The combination of non-thermal plasma and HZSM-5 has also been investigated for the decomposition of chlorinated VOCs such as dichloromethane (DCM) and chlorobenzene. Wallis et al. [123] investigated the combination of zeolites (such as HZSM-5, calcined HZSM-5, NaZSM-5, $\mathrm{NaA}$, and $\mathrm{NaX}$ ) and NTP discharge for the destruction of DCM in air. Among the different zeolites tested, HZSM- 5 showed the highest DCM destruction efficiency of $36 \%$; whereas the calcined HZSM- 5 exhibited lower conversion due to the reduction in Brønsted acid sites as these sites play an important role in the oxidation of chlorinated hydrocarbons [97,124,125]. The HZSM-5 did not exhibit any reduction in $\mathrm{NO}_{\mathrm{x}}$ concentration; whereas calcined HZSM- 5 reduces the production of $\mathrm{NO}_{\mathrm{x}}$ by $15 \%$. The DCM decomposition efficiency of sodium zeolites such as NaZSM-5, NaA, and NaX are similar but not as high as HZSM-5 zeolites [123]. However, NaA is capable of reducing the concentration of unwanted by-products such as $\mathrm{CO}$ and $\mathrm{HCOCl}$, and $\mathrm{Na}$-zeolites are also good for deNO $\mathrm{N}_{\mathrm{x}}$ up to $53 \%$ due to its basic sites.

Jiang et al. [125] studied the metal loaded HZSM-5 for the decomposition of chlorobenzene. As shown in Figure 19, for lower specific input energy, the removal efficiency of chlorobenzene was higher in the presence of $\mathrm{CeO}_{2} / \mathrm{HZSM}-5$ in the discharge region when compared to NTP alone. The dominant factors that influenced the oxidizability of $\mathrm{CeO}_{2} / \mathrm{HZSM}-5$ are its relatively high specific surface area, strong acidity, and redox properties. $\mathrm{CeO}_{2} / \mathrm{HZSM}-5$ exhibited better $\mathrm{CO}_{2}$ and $\mathrm{CO}_{\mathrm{x}}$ selectivity due to the presence of more oxygen vacancies and reactive oxygen on the surface of deposited $\mathrm{CeO}_{2}$ crystallites, in addition to the Brønsted acid sites of HZSM-5 which oxidize some of the intermediates on the catalyst surfaces $[97,125]$. The concentration of ozone in the exhaust of 
$\mathrm{CeO}_{2} / \mathrm{HZSM}-5$ packed reactor is lower than the DBD reactor, because of decomposition of ozone on the catalyst surface to produce active oxygen atom by the following the mechanism mentioned in Equations (1) and (2) [125].
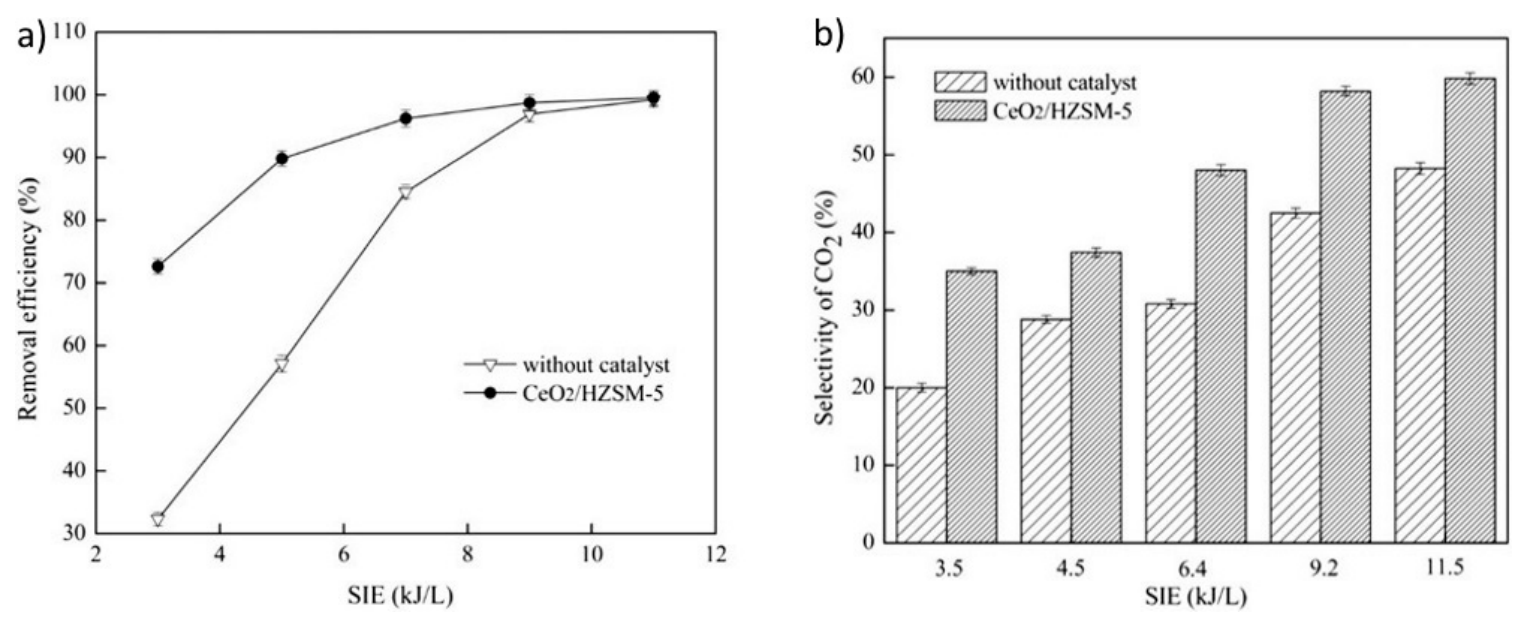

Figure 19. Influence of $\mathrm{CeO}_{2} / \mathrm{HZSM}-5$ on (a) chlorobenzene removal efficiency and (b) selectivity of $\mathrm{CO}_{2}$. Reprinted from Reference [125], with permission from Elsevier.

The plasma catalysis using metal loaded zeolites can also be used as a pretreatment technology for biotrickling filter in order to convert the recalcitrant VOC compounds such as chlorobenzene into water soluble compounds [97]. Zhu et al. [97] reported that the synergy between the NTP and catalysts $\left(\mathrm{CeO}_{2} / \mathrm{HZSM}-5\right)$ increased the chlorobenzene removal efficiency by $40 \%$ at low discharge voltages $(5-6 \mathrm{kV})$ [97] which is preferable for a pretreatment technology. The water solubility and the biodegradability of the by-products are important for using the plasma catalysis system as a pretreatment process because the water-soluble carbon-based by-products can be easily used as carbon source by microbes. More water soluble and highly biodegradable by-products were produced by a $\mathrm{CeO}_{2} / \mathrm{HZSM}-5$ packed plasma reactor [97].

A number of studies have been conducted on the application of plasma catalysis for the treatment of single VOCs. However, a knowledge gap still exists in understanding the use of plasma catalysis for the treatment of VOC mixtures. Mustafa et al. [126] investigated the removal of a mixture of aliphatic, aromatic, and chlorinated VOCs such as toluene, benzene, ethyl acetate, trichloroethylene, tetrachloroethylene, and carbon disulfide by combining NTP and HZSM-5. A removal efficiency of $100 \%$ was achieved for all the compounds except $\mathrm{CS}_{2}(80.18 \%)$ in the presence of HZSM-5 in the discharge zone at an input power of $16 \mathrm{~W}$. The HZSM-5 has a large adsorbing capacity which extends the retention time of VOCs in the discharge zone and promotes the collisional probability of the adsorbed VOCs and the plasma generated active species, resulting in enhanced VOC removal efficiency. Treatment of VOC mixtures enhances the utilization efficiency of energy and the active species due to the reaction between partial oxidation products of different VOCs. The combination of NTP and HZSM-5 inhibits the formation of certain by-products such as cyclohexane $\left(\mathrm{C}_{6} \mathrm{H}_{12}\right)$, pentadecane $\left(\mathrm{C}_{15} \mathrm{H}_{32}\right)$, benzenonitrile $\left(\mathrm{C}_{7} \mathrm{H}_{5} \mathrm{~N}\right)$, 2,2-dimethyltetradecane $\left(\mathrm{C}_{16} \mathrm{H}_{34}\right)$, and 1-propene-1-thiol $\left(\mathrm{C}_{3} \mathrm{H}_{6} \mathrm{~S}\right)$. These compounds were otherwise found as solid deposits in the plasma reactor.

Typically, the exhaust gas containing VOCs are large in volume with high flow rates and the reactor for treating these effluents should have a low-pressure loss. It has been reported that by using a honeycomb structured zeolite adsorbent in a closed loop DBD reactor, 93\% toluene removal efficiency has been obtained (toluene initial concentration $=25 \mathrm{ppm}$ and flow rate $=150 \mathrm{~L} / \mathrm{min}$ ) [33]. Also, the combination of densification of VOCs by adsorption followed by a plasma discharge has the adaptability for the change in the wide range of flow rates and VOC concentrations which is difficult with the flow type reactor (NTP alone or PC). Honeycombs can be produced in different shapes with different zeolite types, allowing customization of their adsorption behavior [127]. The main advantages 
of honeycomb zeolites are: (i) a lower pressure loss which is suitable for many industrial applications which involve high flue gas flow rate and (ii) an increased surface area for a given volume (as shown in Figure 20) [128].

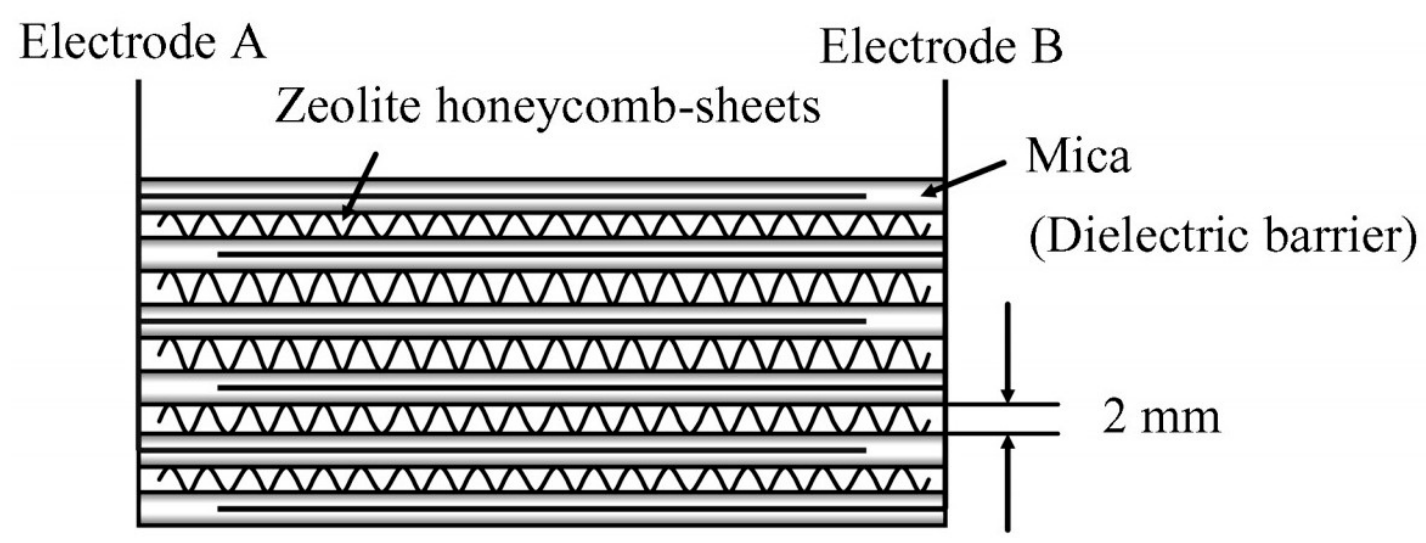

Figure 20. Illustration of the adsorption/plasma combined element with insertion of corrugated honeycomb sheets between discharge electrodes. Reprinted from Reference [37], with permission from Elsevier.

Hydrophobic honeycomb zeolites exhibited high toluene adsorbing capacity in humid air due to their high $\mathrm{S}_{\mathrm{BET}}$, pore size and their hydrophobicity retards the adsorption of water which can negatively influence the plasma performance. Inoue et al. [37] investigated the combination of an adsorption/in plasma catalytic reactor filled with hydrophobic dealuminated honeycomb Y-type zeolite as a packing material and a catalytic reactor filled with $\mathrm{MnO}_{\mathrm{x}}$ placed in the downstream of the reactor for the decomposition of low concentrations of different VOCs (100 ppm) from humid air at high flow rates $\left(60 \mathrm{~m}^{3} / \mathrm{h}\right)$. In this particular hybrid system, the VOC decomposition takes places due to different reactions such as (i) on the surface of the adsorbent, (ii) in the gas phase, and (iii) on the catalyst due to the active oxygen produced via ozone decomposition. Among the different VOCs studied, the molecules with a $\mathrm{C}-\mathrm{O}$ bond are easily decomposable with this system. The decomposition efficiency of different VOCs are as follows: alcohol and ether > aromatic and non-aromatic cyclic compounds $>$ ketones.

\subsection{Stability of Zeolite in Adsorption-Plasma Catalysis}

The main difference between conventional PC and cyclic APC techniques lies in the regeneration of the adsorbents/catalysts. From an economic and application point of view, it is important that the performance of the adsorbents/catalysts is restored completely after plasma assisted regeneration. For the cyclic APC process, high catalytic reaction under the plasma discharge is required for the regeneration of adsorbents. This is achieved by air or $\mathrm{O}_{2}$ plasma which simultaneously decomposes VOCs and regenerates the adsorbent. However, deactivation of the catalysts/adsorbents occurs in continuous usage due to the deposition of carbon containing molecules on zeolites which deteriorates the surface properties of zeolite and poisons the active sites. Thus, it is important that the researchers study the performance of the adsorbents/catalyst in continuous usage for longer time.

The stability of Ag/HZSM-5 for the adsorption of very low concentration of benzene (4.7 ppm) in humid air $(\mathrm{RH}=50 \%)$ followed by $\mathrm{O}_{2}$ plasma over five cycles of APC technique has been investigated [101]. It has been reported that Ag/HZSM-5 exhibited good stability and the carbon balance and $\mathrm{CO}_{2}$ selectivity were kept around $100 \%$ for five cycles of cyclic APC of benzene. The stability of AgCu/HZSM-5 was investigated for the cyclic APC removal of low concentration of formaldehyde (26 ppm) by $\mathrm{O}_{2}$ plasma. As shown in Figure 21, the stability of AgCu/HZSM-5 was maintained for five cycles with the carbon balance and $\mathrm{CO}_{2}$ selectivity of $\sim 100 \%$ [44]. 
a

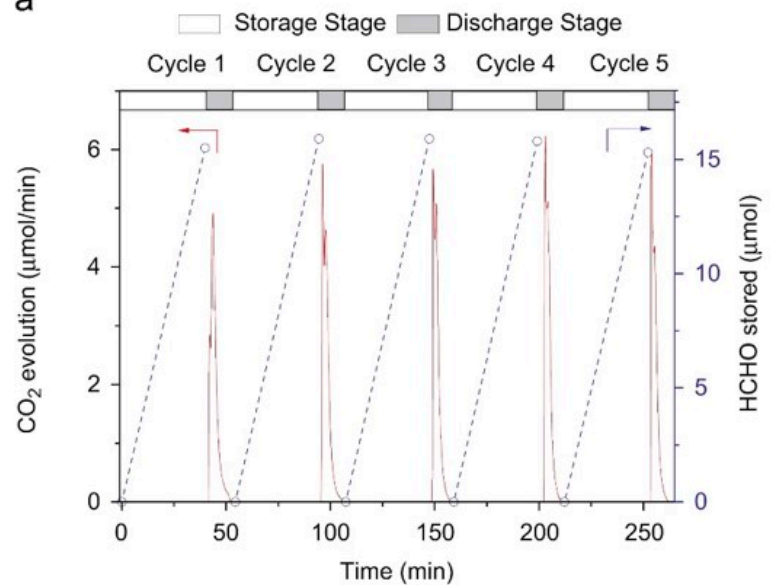

b

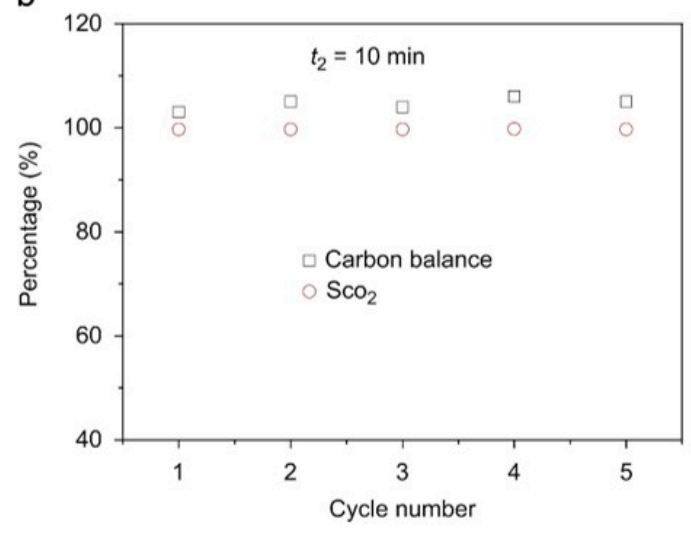

Figure 21. Comparison of (a) $\mathrm{CO}_{2}$ evolution and $\mathrm{HCHO}$ storage and (b) carbon balance and $\mathrm{CO}_{2}$ selectivity in five 'adsorption-plasma discharge' cycles. Reprinted from Reference [44], with permission from Elsevier.

The performance of Ag loaded $\beta$-zeolite reactor was investigated for four cycles of cyclic APC abatement of acetone ( $300 \mathrm{ppm})$ by $\mathrm{O}_{2}$ plasma and it has been reported that the performance of the reactor was not significantly reduced [109]. However, the concentration peaks of the by-products were getting broader probably due to the oxidation of the low volatile and non-volatile by-products which were deposited on the surface of the catalyst. Kuroki et al. [28] also investigated the stability of honeycomb zeolite for 10 cycles of adsorption of low concentration of toluene (30 ppm) and air plasma for regeneration and reported that a regeneration efficiency of more than $80 \%$ was obtained for 10 cycles.

Yi et al. [61] investigated the stability of Co/13X zeolite in cyclic APC and PC technique for the decomposition of toluene (150 ppm) by air NTP discharge. In APC and PC, the toluene removal efficiency was not significantly affected by continuous usage for five adsorption-plasma cycles and $3 \mathrm{~h}$, respectively. But, the adsorption of toluene, mineralization efficiency, and $\mathrm{CO}_{2}$ selectivity were reduced. For $\mathrm{PC}$, mineralization efficiency and $\mathrm{CO}_{2}$ selectivity were reduced by $8.1 \%$ and $16.4 \%$, respectively. For APC, the adsorption was significantly reduced from $0.51 \mathrm{mmol}$ in the first cycle to $0.382 \mathrm{mmol}$ in the fifth cycle and the mineralization efficiency and $\mathrm{CO}_{2}$ selectivity were also reduced. The main reasons for the deactivation of $\mathrm{Co} / 13 \mathrm{X}$ zeolites in continuous usage are due to the [61]: (i) retention of carbon containing molecules in the zeolite even after plasma discharge which might poison the active sites, (ii) significant reduction in $\mathrm{S}_{\mathrm{BET}}$ and pore diameter and (iii) retention of $\mathrm{H}_{2} \mathrm{O}$ produced during the decomposition of toluene.

Qin et al. [100] investigated a cyclic APC for seven cycles of toluene decomposition $\left(1632 \mathrm{mg} \cdot \mathrm{m}^{-3}\right)$ by air plasma and reported the deactivation of $\mathrm{Al}_{2} \mathrm{O}_{3} / \mathrm{HZSM}-5$ support and the Ag-Mn loaded $\mathrm{Al}_{2} \mathrm{O}_{3} / \mathrm{HZSM}-5$. The main reasons for the deactivation are as follows: (i) formation/residual of organic intermediates on the catalyst surface, which results in reduced $\mathrm{S}_{\mathrm{BET}}$ and pore volumes, and (ii) change in the active components. For example, the following intermediates are found on the surface of deactivated HZSM-5: undecomposed toluene, 4-benzyl-1,2-dimethylbenzene, 2,2'-bimethylbiphenyl, benzaldehyde, and ethyl(propa-2-yloxl)acetate. The relative amount of $\mathrm{Ag}^{+}$on the deactivated catalyst is reduced resulting in the deactivation of the catalyst as $\mathrm{Ag}^{+}$is responsible for the $\pi$-complexation with toluene molecule.

During the air plasma catalytic removal of chlorobenzene $\left(1250 \mathrm{mg} \cdot \mathrm{m}^{-3}\right)$, the stability of $\mathrm{CeO}_{2} / \mathrm{HZSM}-5$ was maintained for the first $75 \mathrm{~h}$. After this, the deactivation of $\mathrm{CeO}_{2} / \mathrm{HZSM}-5$ was noticed which may be due to halide and small organic matter deposition which blocks the active sites [125]. The distribution of elements before and after the reaction on the $\mathrm{CeO}_{2} / \mathrm{HZSM}-5$ using energy dispersive $\mathrm{X}$-ray spectroscopy analysis (Figure 22) shows the presence of $\mathrm{C}$ and $\mathrm{Cl}$ elements 
after the reaction, confirming that a certain amount of organic and chlorinated matter was deposited or adsorbed on $\mathrm{CeO}_{2} / \mathrm{HZSM}-5$. This is due to the long reaction time and the continuous addition of chlorobenzene that results in insufficient oxidation of intermediates which were deposited on the surface of $\mathrm{CeO}_{2} / \mathrm{HZSM}-5$ covering the active sites, further reducing the decomposition efficiency [125].
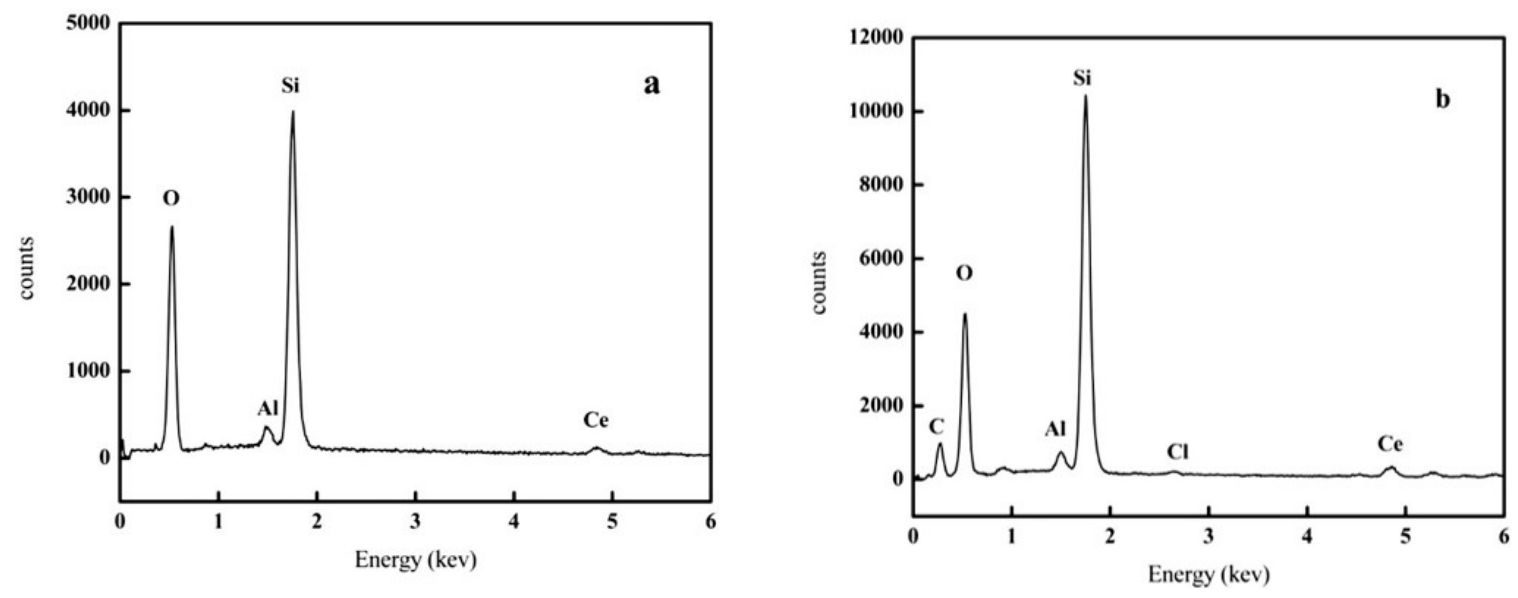

Figure 22. Energy dispersive X-ray spectroscopy spectrum of $\mathrm{CeO}_{2} / \mathrm{HZSM}-5$ (a) before and (b) after plasma catalytic reaction. Reprinted from Reference [125], with permission from Elsevier.

For the APC process, high catalytic reaction under the plasma is required for the complete regeneration of adsorbents/catalysts and this is achieved by an $\mathrm{O}_{2}$ plasma that generates more active species and radicals which oxidize and decompose VOCs and simultaneously regenerates packing materials.

\section{Effect of Process Parameters}

\subsection{Effect of Humidity}

The presence of water in the flue gas has both a beneficial and detrimental effect: (i) moderate humidity $(0.2 \mathrm{vol} \%$ to $0.4 \mathrm{vol} \%)$ promotes the decomposition of VOCs by the formation of $\mathrm{OH} \bullet$ radicals, (ii) however, in the presence of excess humidity ( $>0.4 \mathrm{vol} \%)$ water molecules can adsorb on the surface of the adsorbent/catalyst and block the catalytically active sites and therefore inhibiting the VOC removal [39]. But the effect of presence of water in a flue gas on the adsorption of toluene on a hydrophobic honeycomb zeolite was negligible [29]. Fan et al. [102] reported that the effect of different relative humidity of the flue gas ( $\mathrm{RH}=0 \%$ to $60 \%$ at $25{ }^{\circ} \mathrm{C}$ ) is weak on the decomposition of benzene due to the high hydrophobic nature HZSM-5 zeolite.

The main disadvantage of the presence of $\mathrm{H}_{2} \mathrm{O}$ on the on the surface of adsorbent/catalyst and in the plasma discharge region are as follows: (i) water changes the physical and chemical properties of the discharge by quenching the activated chemical species and limits the electron density in the plasma, (ii) water reduces the total charge of a micro-discharge and decreases the plasma volume, and (iii) water covering the catalyst surface results in the hindrance of ozone adsorption and decomposition for the formation of active oxygen species. Hamada et al. [122] investigated the effect of adding water $(1 \%)$ to the flue gas on the performance of a Mn/USY packed silent discharge reactor and reported that the addition of water has a negative impact on the decomposition of benzene because it inhibits the formation of ozone and lowers the catalytic activity of Mn-USY.

\subsection{Effect of Initial Concentration}

Inoue et al. [37] investigated the performance of the newly developed hybrid plasma reactor (adsorption on hydrophobic dealuminated honeycomb Y-type zeolite and $\mathrm{MnO}_{2}$ in the downstream of plasma reactor) in real conditions to treat exhaust gases from painting and adhesive industry. They 
reported that this hybrid reactor is more suitable for treating the flue gas when the initial VOCs concentration is less than the critical VOC concentration $V_{C R T}$ and it can respond well to temporary rises in VOC concentrations by adsorption and decomposition (e.g., in applications of the printing industry). On the other hand, when concentrations of VOCs are continuously higher than the $\mathrm{V}_{\mathrm{CRT}}$, the adsorption function of zeolite is not very effective because the adsorption sites are already saturated by VOCs (e.g., in applications of the adhesive industry). When the initial concentrations of VOCs are as low as the $\mathrm{V}_{\mathrm{CRT}}(\sim 300 \mathrm{ppm})$, a conversion efficiency of $80 \%$ was achieved [37].

\subsection{Effect of Discharge Gas}

The main difference between the conventional adsorption and a cyclic APC technique lies in the regeneration step [32]. In conventional adsorption, the adsorbent is regenerated either by heating or by supplying hot water vapor and the resulting high concentration of VOCs has to be further oxidized either by thermal or catalytic oxidation. However, for an APC process, high catalytic reaction under the plasma is required for the regeneration of adsorbents/catalysts, and this is achieved by air or $\mathrm{O}_{2}$ plasma which decomposes VOCs and simultaneously regenerates the adsorbent/catalyst. Kim et al. [129] reported first the complete oxidation of adsorbed benzene on $\mathrm{Ag} / \mathrm{TiO}_{2}$ using oxygen plasma without the formation of by-products such as $\mathrm{CO}$ and $\mathrm{NO}_{x}$ and regeneration of the adsorbent.

During discharge, oxygen as background gas enhances the oxidation of adsorbed VOCs and inhibits the formation of unwanted by-products such as $\mathrm{NO}_{\mathrm{x}}$ [130]. In air as a background gas, $\mathrm{N}_{2}$ competes with VOCs for the active oxygen species resulting in reduced VOC conversion efficiency. Kim et al. [8] reported that $\mathrm{O}_{2}$ driven PC reactor in cyclic operation retards the formation of $\mathrm{N}_{\mathrm{x}} \mathrm{O}_{\mathrm{y}}$. Thus, $\mathrm{O}_{2}$ plasma is suitable for the complete regeneration of the zeolites. The presence of oxygen in a plasma has the following effect on the plasma discharge: photoionization, streamer properties, electron attachment, transition of filamentary to glow discharge in DBD [8], which are more suitable for the complete VOC oxidation. Despite the advantages of using oxygen plasma to avoid the formation of $\mathrm{NO}_{\mathrm{x}}$ and to produce highly oxidizing environment, using air as a discharge gas is far more economical in application point of view. Although, the formation of $\mathrm{NO}_{x}$ (such as $\mathrm{N}_{2} \mathrm{O}$ and $\mathrm{NO}_{2}$ ) are unavoidable while using air plasma, the concentration of $\mathrm{NO}_{x}$ produced can be reduced by minimizing the discharge time and maximizing adsorption time in the APC process [44]. When air was used as the desorption gas, part of toluene has been decomposed before desorption from the hydrophobic honeycomb zeolite because toluene was more easily decomposed in air than $\mathrm{N}_{2}[28,29]$. Shiau et al. [54] reported that the desorption of isopropyl alcohol is higher when $\mathrm{N}_{2}$ is used as a desorbing gas when compared to $\mathrm{O}_{2}$ because air or $\mathrm{O}_{2}$ plasma generates more active species and radicals which oxidize and decompose IPA resulting in reduced desorption of IPA and enhanced IPA conversion.

\subsection{Effect of Gas Flow Rate}

The gas flow rate during the NTP discharge in cyclic APC techniques plays an important role in the desorption and oxidation of the adsorbed VOCs because the flow rate influences the exposure time of the desorbed VOCs to the plasma. On the other hand, increasing the flow rate produces more active species that enhance the VOC decomposition. Kuroki et al. [29] reported that the increase in air flow rate from 1 to $4 \mathrm{~L} / \mathrm{min}$ increases the toluene desorption ratio from $49 \%$ to $72 \%$. This is due to the decrease in exposure time of the desorbed toluene to the plasma discharge and suppressed decomposition of desorbed toluene with increased air flow rate [29]. Nevertheless, the selectivity of $\mathrm{CO}_{2}$ increases and $\mathrm{CO}$ decreases with increase in flow rate.

As shown in Figure 23, the gas flow rate during the plasma discharge process plays an important role determining the plasma operating time and thus the energy efficiency of the process. Youn et al. [117] reported that the time required for toluene desorption and oxidation could be reduced by reducing the air flow rate. This is due to an increased specific energy density with the reduced flow rate for the same input power which provides more energy for desorption and oxidation [117]. 


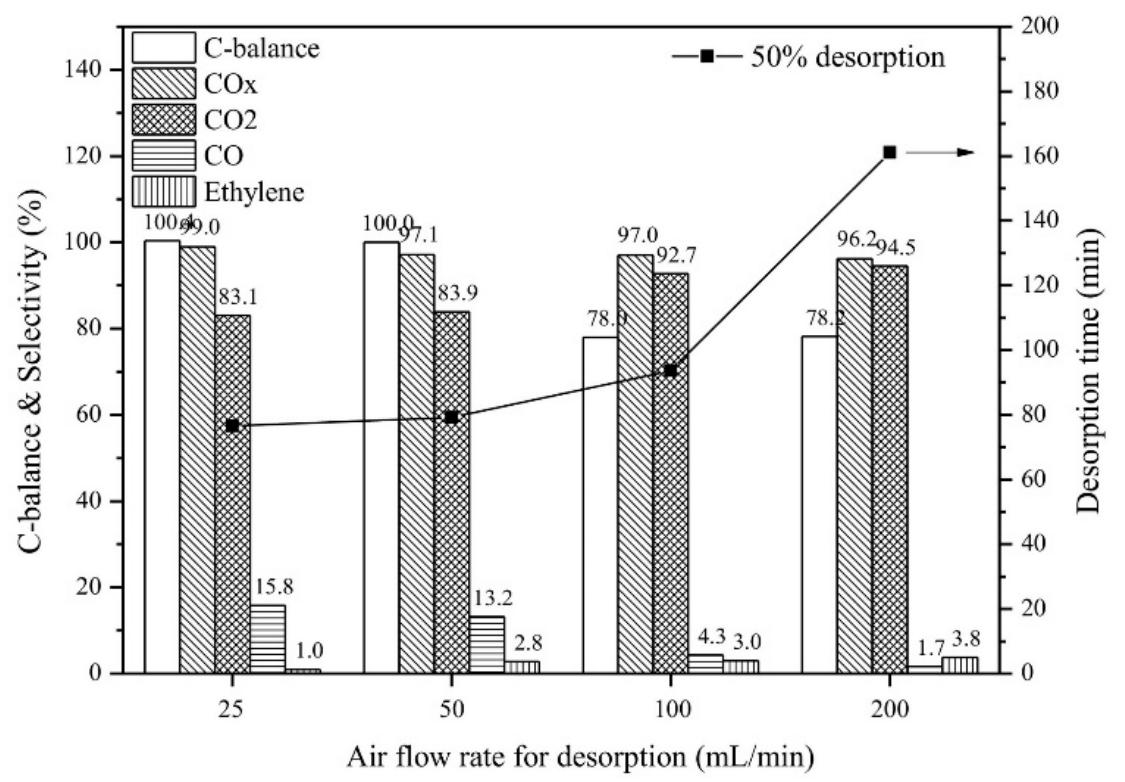

Figure 23. Effect of air flow rate on the performance of $2 \mathrm{wt} \% \mathrm{Fe} / \mathrm{ZSM}-5$ packed DBD reactor for toluene oxidation. Reprinted from Reference [117], with permission from Elsevier.

\subsection{Reactor Configuration}

\subsubsection{Desorption Method}

Yi et al. [131] investigated a closed and ventilated plasma reactor for the removal of toluene in a cyclic APC process. This work reported that the closed reactor is suitable for low concentration of VOCs as the residence time of VOCs in the discharge zone is prolonged; whereas, a ventilated discharge is more suitable for high concentration of VOCs because more reactive species $\left(\mathrm{O}^{\bullet}, \mathrm{OH}^{\bullet}\right.$ and $\mathrm{O}_{2}{ }^{\bullet}$ ) are generated. For example, the adsorption of toluene on MS-5A is low and the closed reactor during the plasma discharge has enough reactive species per toluene for the conversion, yielding better carbon balance and $\mathrm{CO}_{x}$ selectivity. On the other hand, toluene adsorption on MS-13X zeolite is very high and the average number of reactive species available for every toluene molecule is not enough in a closed reactor resulting in poor oxidation. Thus, a ventilated discharge is more suitable for the higher concentration of VOCs as this produces more oxygen reactive species.

Kuroki et al. [28] investigated the effect of a plasma desorption method (closed and conventional open) on toluene decomposition and regeneration of honeycomb zeolites. This work concludes that the regeneration efficiency and desorption efficiency of the closed system is superior than the conventional open system [28]. The formation of $\mathrm{NO}_{2}$ is suppressed in the closed system. The optimum closing time for the higher toluene desorption and zeolite regeneration efficiency is $1 \mathrm{~min}$; whereas higher closing time is required if complete toluene oxidation is desired [28].

\subsubsection{Position of Catalysts}

The position of the zeolite in the plasma reactor influences the rate of oxidation reactions, decomposition efficiency and eventually, the mineralization efficiency. Trinh et al. [93] investigated three plasma reactor configurations such as one stage (in-plasma), two stage (post-plasma), and hybrid reactors (zeolites are placed towards the tail of the plasma discharge zone) for the decomposition of ethylene on 13X zeolite (as shown in the Figure 24). During the plasma discharge, the by-products produced in one- and two-stage reactors are mainly $\mathrm{CO}_{\mathbf{X}}$; whereas $\mathrm{HCHO}$ and desorbed ethylene were also found in the hybrid reactor. The formation of $\mathrm{HCHO}$ and ethylene desorption suggests the fast oxidation reaction in the gas phase in the hybrid reactor. As shown in Figure 25, in a two-stage plasma catalytic reactor, there is no formation of $\mathrm{CO}_{2}$ in the first $10 \mathrm{~min}$ because the ozone produced in the plasma reactor diffused and decomposed on the catalytic surface to form atomic oxygen which reacts 
with the adsorbed ethylene to form $\mathrm{CO}_{2}$. Also, the $\mathrm{O}_{3}$ production is low in the one stage reactor due to the small gas volume, and thus the oxidation of ethylene is mainly by the diffusion of short-lived species into the micropores of zeolites that have adsorbed ethylene. When compared to the one- and two-stage plasma reactors, fast temporal evolution of $\mathrm{CO}_{2}$ is observed (Figure 25) with the hybrid plasma reactor due to the synergetic effect of both reactors utilizing the $\mathrm{O}_{3}$ formed in the blank part of the reactor and the short-lived species formed in the packed part of the reactor.

Oh et el. [36] studied the influence of the amount of toluene adsorbed on a zeolite on the toluene decomposition efficiency depending on the position of the zeolite in the plasma reactor. When the zeolite is placed in the tail of the plasma reactor, the decomposition efficiency of toluene increases with the adsorption capacity; whereas, the decomposition efficiency is not influenced by the adsorption capacity when zeolite is placed in the head of the plasma reactor [36]. These results suggest that the decomposition of toluene adsorbed in the micropores of zeolites by a direct plasma exposure is not easy; while the ozone produced in a plasma forms active atomic oxygen which effectively oxidizes toluene. Other works reported that the positioning of zeolite in the tail of the plasma reactor increases the conversion efficiency between $10 \%$ and $20 \%$ depending on the type of zeolite (NaY, H-Y, Ferrierite and Mordenite) [36,132].

Teramoto et al. [74] reported that the decomposition efficiency is 3.7 times and 1.2-1.5 times higher when compared to the conventional NTP reactor when a zeolite is placed in the tail (downstream) and in the beginning (upstream) of the plasma reactor, respectively. This is because the amount of ozone increases towards the tail of the reactor and according to the Equation (3), $\mathrm{O}_{3}$ is important for the decomposition of adsorbed VOCs by metal unloaded zeolites. Thus, the decomposition efficiency is suppressed when a zeolite is placed in the upstream of the plasma reactor [74].

Hamada et al. [122] investigated the use of a surface discharge reactor in combination with $\mathrm{Mn}$ loaded USY zeolite for benzene decomposition. For low input power range, the decomposition of ozone can be achieved by placing Mn/USY zeolite in the downstream of the plasma reactor, which enhanced benzene decomposition efficiency. For higher input power range, where the concentration of ozone produced is reduced by heating, it is more effective to place Mn/USY zeolite in the discharge zone as they can make use of reactive species with shorter lifetime in addition to $\mathrm{O}_{3}$.
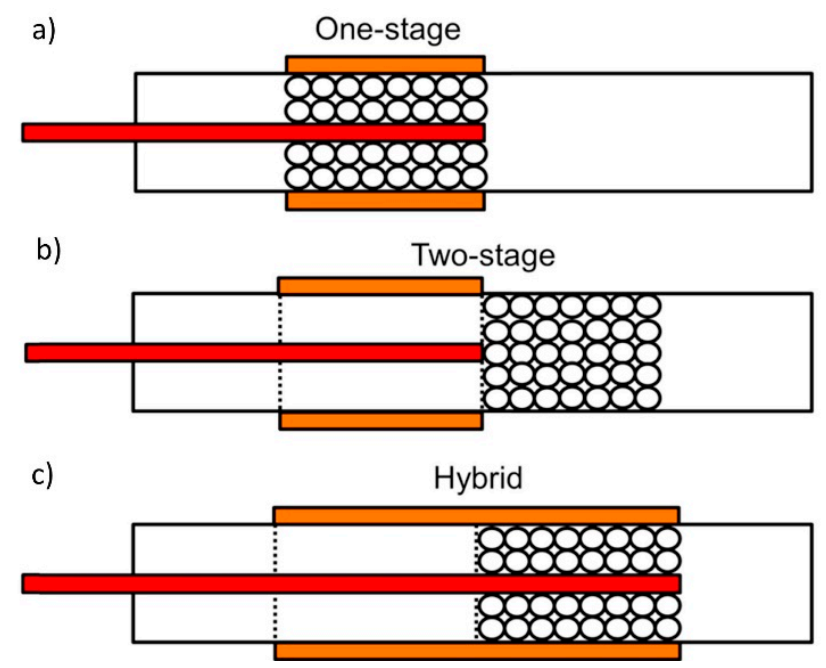

Figure 24. Different configurations of non-thermal plasma reactors. (a) One-stage, (b) two-stage, and (c) hybrid plasma reactors. Reprinted from Reference [93], with permission from Elsevier. 


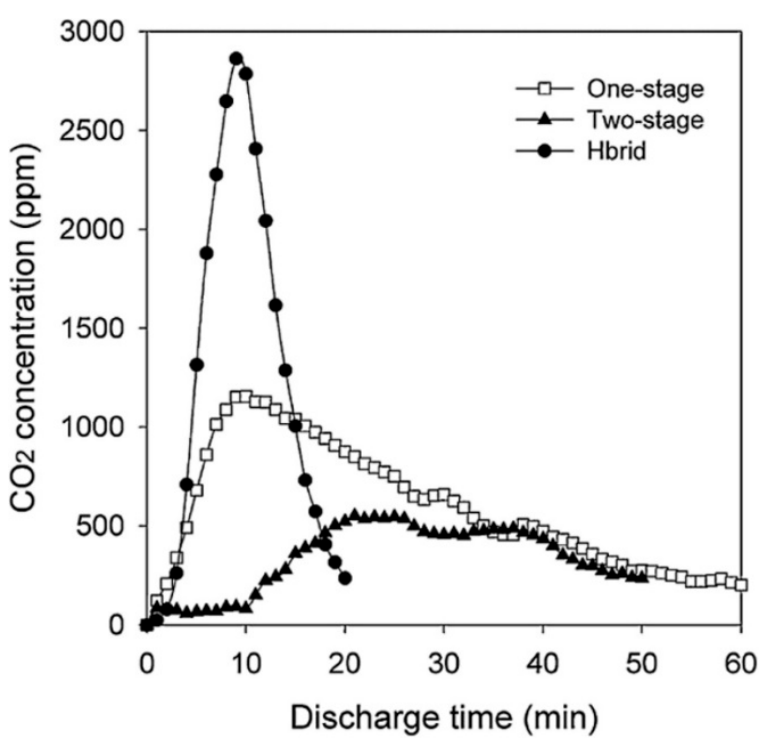

Figure 25. The evolution of $\mathrm{CO}_{2}$ concentration for different reactor configurations (adsorption time: $100 \mathrm{~min}$, applied voltage: $20 \mathrm{kV}$ ). Reprinted from Reference [93], with permission from Elsevier.

\subsection{Energy Cost}

The energy efficiency of a cyclic APC technique can be three times higher (increased by $1.39 \mathrm{gkw}^{-1} \mathrm{~h}^{-1}$ ) than NTP alone and plasma catalysis under the same experimental conditions for the decomposition of toluene on $\mathrm{Co} / 13 \mathrm{X}$ zeolite [61]. This is because the flow rate during the plasma discharge of APC and discharge time were significantly reduced in cyclic APC resulting in enhanced energy density and energy efficiency, respectively. Liu et al. [39] reported that the energy efficiency of APC is almost six times higher $\left(19.72 \mathrm{gkW}^{-1} \mathrm{~h}^{-1}\right)$ when compared to the continuous plasma catalysis $\left(3.05 \mathrm{gkW}^{-1} \mathrm{~h}^{-1}\right)$ for benzene decomposition using AgMn/HZSM-5 zeolite.

The energy cost (EC) of a cyclic APC technique can be decreased by increasing the ratio of adsorption time $\left(t_{1}\right)$ and discharge time $\left(t_{2}\right)$ according to the following equation [44]:

$$
\mathrm{EC}^{\mathrm{APC}}=\frac{\mathrm{P}_{\text {discharge }}^{\mathrm{APC}} \mathrm{t}_{2}}{\mathrm{t}_{1}}
$$

Fan et al. [101] reported the energy cost of the cyclic APC technique for the decomposition of VOCs was as low as $3.7 \times 10^{-3} \mathrm{kWh} \mathrm{m}^{-3}$ for the remediation of $4.7 \mathrm{ppm}$ benzene from humid air $(50 \% \mathrm{RH})$ using $\mathrm{Ag} / \mathrm{HZSM}-5$. In the cyclic treatment, the duration of the plasma discharge for the complete oxidation of adsorbed VOCs depends on two important factors: (i) the amount of VOCs adsorbed during the storage step and (ii) the applied voltage [95]. Zhao et al. [44] studied the effect of the adsorption time of formaldehyde on $\mathrm{AgCu} / \mathrm{HZSM}-5$ zeolite on the discharge time for the complete oxidation of adsorbed formaldehyde. As shown in Figure 26, the storage time has no effect on the discharge time and a discharge time of $10 \mathrm{~min}$ is required for the complete oxidation of adsorbed formaldehyde to $\mathrm{CO}_{2}$. The energy cost of the cyclic APC process for a storage time of $690 \mathrm{~min}$ has been calculated to be $1.9 \times 10^{-3} \mathrm{kWh} \mathrm{m}^{-3}$; whereas the energy cost can be reduced to the order of $10^{-5}$ to $10^{-4} \mathrm{kWh} \mathrm{m}^{-3}$, considering the possible long adsorption time of $\mathrm{AgCu} / \mathrm{HZSM}-5$ zeolite [44]. On the other hand, another work reported that when the storage period of benzene on Ag/HZSM-5 increased from 1 to $14 \mathrm{~h}$, a small increase in the discharge time from 9 to $24 \mathrm{~min}$ was required to achieve $100 \%$ conversion of benzene to $\mathrm{CO}_{2}$ [102]. 


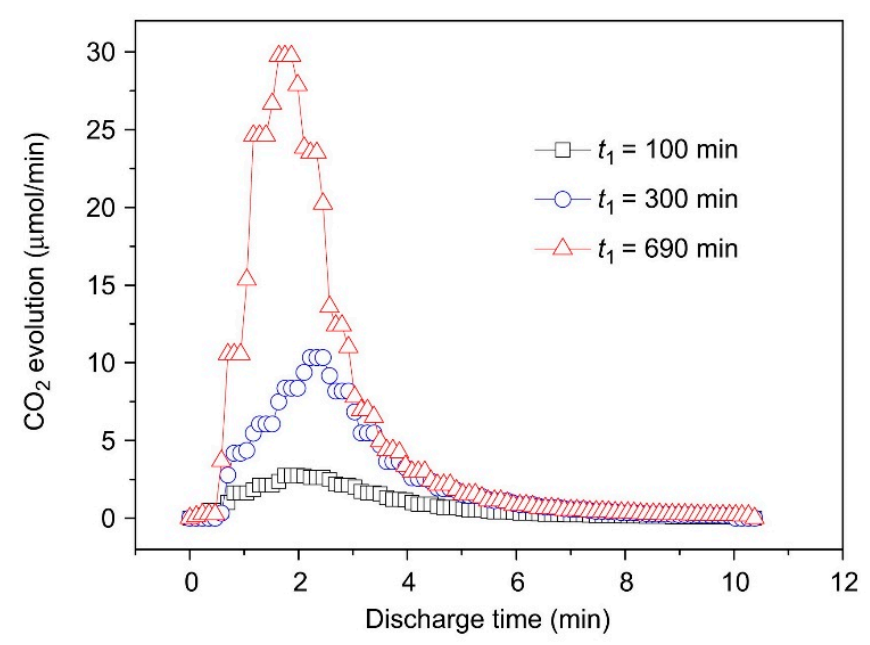

Figure 26. $\mathrm{CO}_{2}$ evolution with discharge time in cyclic $\mathrm{APC}$ of $\mathrm{HCHO}$ over $\mathrm{AgCu} / \mathrm{HZ}$ at various storage periods (100, 300 and $690 \mathrm{~min}$ ) (storage stage: simulated air at $300 \mathrm{~mL} / \mathrm{min}, 50 \% \mathrm{RH}$; discharge stage: $\mathrm{O}_{2}$ at $6 \mathrm{~mL} / \mathrm{min}, \mathrm{P}_{\text {discharge }}^{\mathrm{APC}}=2.3 \mathrm{~W}$ ). Reprinted from reference [44], with permission from Elsevier.

The energy efficiency of a HZSM-5 packed plasma reactor is $29.45 \%$ higher when compared to a plasma alone reactor at $16 \mathrm{~W}$ which can also be attributed to the adsorption capability of HZSM- 5 zeolite and outcompetes other reactors [126]. The presence of $\mathrm{CeO}_{2} / \mathrm{HZSM}-5$ in the discharge region enhances the energy efficiency by 1.25 times when compared to NTP alone (at $3.5 \mathrm{~kJ} / \mathrm{L}$ ) for chlorobenzene removal which is an obvious economic benefit [125]. Ogata et al. [55] reported that despite the large adsorption capacity of MS-13X, the energy efficiency of a MS-13X hybrid reactor was lower than the reactors packed with MS-3A, MS-4A, and MS-5A. This is because MS-13X does not completely desorb the large amount of adsorbed benzene to the gas phase and the energy efficiency was calculated based on the $\mathrm{CO}_{\mathrm{x}}$ formed and the inlet benzene, resulting in reduced energy efficiency.

The combination of adsorption, catalysis, and non-thermal plasma using zeolites suppresses the formation of by-products such as $\mathrm{NO}_{x}, \mathrm{CO}$, and $\mathrm{O}_{3}$. Trinh et al. [109] reported that using silver coated $\beta$-zeolite for the removal of acetone in a cyclic APC technique improves the energy efficiency and suppresses the formation of un-wanted by-products. But, the formation of unwanted by-products such as $\mathrm{CO}, \mathrm{N}_{2} \mathrm{O}$, and $\mathrm{NO}_{2}$ increases with increase in discharge power which is required for a faster conversion mechanism [39]. The formation of $\mathrm{NO}_{2}$ may poison the active sites of Ag in AgMn/HZSM-5. Zhao et al. [44] reported that the optimum discharge power for the conversion of adsorbed HCHO to $\mathrm{CO}_{2}$ is $2.3 \mathrm{~W}$ because with the decrease in the discharge power to $1.4 \mathrm{~W}$, the conversion of $\mathrm{HCHO}$ reduces to $76 \%$; whereas there is no further improvement in the performance with a further increase of discharge power. 
Table 4. Overview of published papers on abatement of VOCs using zeolites in combination with non-thermal plasma discharge.

\begin{tabular}{|c|c|c|c|c|c|c|c|c|c|c|c|}
\hline VOCs & Zeolite & $\underset{\left(\mathrm{m}^{2} / \mathrm{g}\right)}{\mathrm{S}_{\mathrm{BET}}}$ * & $\begin{array}{l}\text { Pore Size } \\
\text { (Å) * }\end{array}$ & Type of Discharge & Carrier Gas & $\begin{array}{l}\text { Flow Rate } \\
(\mathrm{L} / \mathrm{min})^{*}\end{array}$ & $\begin{array}{c}\text { Initial VOC } \\
\text { Concentration } \\
(\mathrm{ppm})^{*}\end{array}$ & $\begin{array}{c}\text { Amount of } \\
\text { Adsorption/Removal } \\
\text { Efficiency }\end{array}$ & $\begin{array}{c}\text { Energy } \\
\text { Density and } \\
\text { Frequency }\end{array}$ & By-Products & Ref. \\
\hline \multirow{2}{*}{ Acetone } & \multirow{2}{*}{$\begin{array}{c}3 \mathrm{wt} \% \\
\mathrm{Ag} / \beta \text {-zeolite } \\
(15 \mathrm{~g})\end{array}$} & \multirow{2}{*}{-} & \multirow{2}{*}{ - } & $\begin{array}{l}\text { PBDBD (IPC) } \\
\mathrm{t}_{1}=100 \mathrm{~min}\end{array}$ & $\mathrm{~N}_{2}$ & 2 & 300 & $2.45 \mathrm{mmol}$ & - & - & \multirow[b]{2}{*}{ [109] } \\
\hline & & & & $\begin{array}{c}\text { PBDBD (IPC) } \\
\mathrm{t}_{2}=15 \mathrm{~min}\end{array}$ & $\mathrm{O}_{2}$ & 2 & - & $97 \%$ & $\begin{array}{c}28 \mathrm{~W} \\
(400 \mathrm{~Hz})\end{array}$ & $\begin{array}{c}\mathrm{CH}_{4} \text { (less), } \\
\mathrm{HCHO}, \\
\mathrm{CH}_{3} \mathrm{CHO}\end{array}$ & \\
\hline \multirow{8}{*}{ Benzene } & \multirow{2}{*}{ Ferrierite } & \multirow{2}{*}{270} & \multirow[t]{2}{*}{ - } & $\begin{array}{c}\text { SD (IPC) } \\
\text { adsorption }\end{array}$ & $\mathrm{N}_{3}$ & $4-5$ & 200 & - & - & \multirow{2}{*}{ - } & \multirow{8}{*}{ [8] } \\
\hline & & & & $\begin{array}{c}\text { SD (IPC) } \\
\text { Closed discharge }\end{array}$ & $50 \% \mathrm{O}_{2} / \mathrm{N}_{2}$ & $5-8$ & - & $57 \%$ & $130 \mathrm{~J} / \mathrm{L}$ & & \\
\hline & \multirow{2}{*}{ MS-13X } & \multirow{2}{*}{540} & \multirow{2}{*}{ - } & $\begin{array}{c}\text { SD (IPC) } \\
\text { adsorption }\end{array}$ & $\mathrm{N}_{2}$ & $4-5$ & 200 & - & - & \multirow{2}{*}{ - } & \\
\hline & & & & $\begin{array}{c}\text { SD (IPC) } \\
\text { Closed discharge }\end{array}$ & $50 \% \mathrm{O}_{2} / \mathrm{N}_{2}$ & $5-8$ & - & $43 \%$ & $89 \mathrm{~J} / \mathrm{L}$ & & \\
\hline & \multirow{2}{*}{ H-Y zeolite } & \multirow{2}{*}{ - } & \multirow{2}{*}{ - } & $\begin{array}{c}\text { SD (IPC) } \\
\text { adsorption }\end{array}$ & $\mathrm{N}_{2}$ & 10 & 200 & - & - & \multirow{2}{*}{-} & \\
\hline & & & & $\begin{array}{c}\text { SD (IPC) } \\
\text { Closed discharge }\end{array}$ & $50 \% \mathrm{O}_{2} / \mathrm{N}_{2}$ & $5-8$ & - & $84 \%$ & $140 \mathrm{~J} / \mathrm{L}$ & & \\
\hline & \multirow{2}{*}{$\begin{array}{l}2 \% \mathrm{Ag} / \mathrm{H}-\mathrm{Y} \\
\text { zeolite }\end{array}$} & \multirow{2}{*}{520} & \multirow{2}{*}{ - } & $\begin{array}{c}\text { SD (IPC) } \\
\text { adsorption }\end{array}$ & $\mathrm{N}_{2}$ & 10 & 200 & - & - & \multirow{2}{*}{ - } & \\
\hline & & & & $\begin{array}{c}\text { SD (IPC) } \\
\text { Closed discharge }\end{array}$ & $50 \% \mathrm{O}_{2} / \mathrm{N}_{2}$ & $5-8$ & - & $89 \%$ & $160 \mathrm{~J} / \mathrm{L}$ & & \\
\hline Benzene & $\mathrm{TiO}_{2}-\mathrm{MnO}_{2} /$ zeolite & $=$ & - & $\begin{array}{l}\text { SSPBD (IPC) } \\
\text { Continuous }\end{array}$ & Air & 0.5 & 400 & $81 \%$ & $\begin{array}{c}10.33 \mathrm{~W} \\
(50 \mathrm{~Hz} ; 1 \mathrm{nF})\end{array}$ & $\mathrm{CO}$ & [111] \\
\hline Benzene & $\begin{array}{c}\text { Mn/USY } \\
\text { zeolite }\end{array}$ & 715 & - & $\begin{array}{c}\text { SD (IPC) } \\
\text { Continuous }\end{array}$ & $20 \% \mathrm{O}_{2} / \mathrm{N}_{2}$ & 1 & 200 & $95 \%$ & $\begin{array}{c}12 \mathrm{~W} \\
(60 \mathrm{~Hz})\end{array}$ & $\mathrm{CO}$ & [122] \\
\hline \multirow{4}{*}{ Benzene } & Ferrierite & - & - & \multirow{4}{*}{$\begin{array}{c}\text { SD (IPC) } \\
\text { Continuous }\end{array}$} & $50 \% \mathrm{O}_{2} / \mathrm{N}_{2}$ & \multirow{4}{*}{$5-8$} & \multirow{4}{*}{200} & $58 \%$ & $\begin{array}{l}130 \mathrm{~J} / \mathrm{L} \\
(500 \mathrm{~Hz})\end{array}$ & - & \multirow{4}{*}{ [41] } \\
\hline & $\begin{array}{c}10 \% \\
\mathrm{Ag} / \text { Mordenite }\end{array}$ & - & - & & $50 \% \mathrm{O}_{2} / \mathrm{N}_{2}$ & & & $97 \%$ & $\begin{array}{l}130 \mathrm{~J} / \mathrm{L} \\
(500 \mathrm{~Hz})\end{array}$ & - & \\
\hline & $10 \% \mathrm{Ag} / \mathrm{HY}$ & - & - & & $60 \% \mathrm{O}_{2} / \mathrm{N}_{2}$ & & & $96 \%$ & $\begin{array}{l}154 \mathrm{~J} / \mathrm{L} \\
(500 \mathrm{~Hz})\end{array}$ & - & \\
\hline & $\begin{array}{c}10 \% \\
\text { Ag/MS-13X }\end{array}$ & - & - & & $60 \% \mathrm{O}_{2} / \mathrm{N}_{2}$ & & & $88 \%$ & $\begin{array}{l}154 \mathrm{~J} / \mathrm{L} \\
(500 \mathrm{~Hz})\end{array}$ & - & \\
\hline
\end{tabular}


Table 4. Cont.

\begin{tabular}{|c|c|c|c|c|c|c|c|c|c|c|c|}
\hline VOCs & Zeolite & $\underset{\left(\mathrm{m}^{2} / \mathrm{g}\right)}{\mathrm{S}_{\mathrm{BET}}}$ * & $\begin{array}{l}\text { Pore Size } \\
(\AA \AA)\end{array}$ & Type of Discharge & Carrier Gas & $\begin{array}{l}\text { Flow Rate } \\
\text { (L/min)* }\end{array}$ & $\begin{array}{c}\text { Initial VOC } \\
\text { Concentration } \\
(\mathrm{ppm})^{*}\end{array}$ & $\begin{array}{c}\text { Amount of } \\
\text { Adsorption/Removal } \\
\text { Efficiency }\end{array}$ & $\begin{array}{c}\text { Energy } \\
\text { Density and } \\
\text { Frequency }\end{array}$ & By-Products & Ref. \\
\hline \multirow{3}{*}{ Benzene } & Ferrierite & 270 & $4.3-5.3$ & \multirow{3}{*}{$\begin{array}{c}\text { SD (IPC) } \\
\text { Continuous }\end{array}$} & \multirow{3}{*}{ Synthetic air } & 4 & \multirow{3}{*}{200} & $78 \%$ & \multirow{3}{*}{$\begin{array}{l}200 \mathrm{~J} / \mathrm{L} \\
(500 \mathrm{~Hz})\end{array}$} & \multirow{3}{*}{-} & \multirow{3}{*}{ [110] } \\
\hline & $\begin{array}{c}2 \mathrm{wt} \% \\
\mathrm{Ag} / \mathrm{H}-\mathrm{Y}\end{array}$ & 520 & 7.4 & & & 10 & & $75 \%$ & & & \\
\hline & $\begin{array}{c}2 \text { wt \% } \\
\mathrm{Ag} / \mathrm{H}-\mathrm{Y} \& 0.5 \\
\text { wt } \% \\
\mathrm{Pt} / \gamma-\mathrm{Al}_{2} \mathrm{O}_{3} \\
\end{array}$ & - & - & & & 10 & & $86 \%$ & & & \\
\hline \multirow{2}{*}{ Benzene } & Ag/HZSM-5 & 334 & - & $\begin{array}{l}\text { DBD (IPC) } \\
\mathrm{t}_{1}=60 \mathrm{~min}\end{array}$ & $\begin{array}{c}\text { Humid air } \\
(\mathrm{RH}=50 \%)\end{array}$ & 0.6 & 4.7 & $7.6 \mu \mathrm{mol}$ & - & - & \multirow[t]{2}{*}{101} \\
\hline & & & & $\begin{array}{l}\text { DBD (IPC) } \\
\mathrm{t}_{2}=13 \mathrm{~min}\end{array}$ & $\mathrm{O}_{2}$ & 0.06 & - & $100 \%$ & $\begin{array}{c}4.7 \mathrm{~W} \\
(2 \mathrm{kHz})\end{array}$ & $\mathrm{CO}$ & \\
\hline \multirow{4}{*}{ Benzene } & $\begin{array}{c}\text { HZSM-5 } \\
(0.05 \mathrm{~g})\end{array}$ & 341 & - & \multirow{4}{*}{$\begin{array}{c}\text { DBD (IPC) } \\
\text { adsorption up to } \\
5 \% \text { of initial } \\
\text { benzene }\end{array}$} & \multirow{4}{*}{$\begin{array}{l}\text { Humid air }(1.5 \\
\left.\text { vol } \% \mathrm{H}_{2} \mathrm{O}\right)\end{array}$} & \multirow{4}{*}{$100 \mathrm{SSCM}$} & \multirow{4}{*}{20} & $45 \mu \mathrm{mol} / \mathrm{cat}$ & \multirow{4}{*}{ - } & \multirow{4}{*}{-} & \multirow{4}{*}{ [39] } \\
\hline & $\begin{array}{c}0.7 \mathrm{wt} \% \\
\mathrm{Ag} / \mathrm{HZSM}-5 \\
(0.05 \mathrm{~g})\end{array}$ & 341 & - & & & & & $78 \mu \mathrm{mol} / \mathrm{cat}$ & & & \\
\hline & $\begin{array}{c}2.4 \mathrm{wt} \% \\
\text { Mn/HZSM-5 } \\
(0.05 \mathrm{~g}) \\
\end{array}$ & 334 & - & & & & & $94 \mu \mathrm{mol} / \mathrm{cat}$ & & & \\
\hline & $\begin{array}{c}0.8 \mathrm{wt} \% \mathrm{Ag} \\
2.4 \mathrm{wt} \% \\
\text { Mn/HZSM-5 } \\
(0.05 \mathrm{~g}) \\
\end{array}$ & 336 & - & & & & & $131 \mu \mathrm{mol} / \mathrm{cat}$ & & & \\
\hline Chloro-benzene & $\begin{array}{c}12 \mathrm{wt} \% \\
\mathrm{CeO}_{2 / \mathrm{HZSM}-5} \\
(0.3 \mathrm{~g})\end{array}$ & - & - & $\begin{array}{c}\text { DBD (IPC) } \\
\text { Continuous }\end{array}$ & Dry air & - & $1250 \mathrm{mg} / \mathrm{m}^{3}$ & $96 \%$ & $\begin{array}{c}7 \mathrm{kV} \\
(10 \mathrm{kHz})\end{array}$ & - & [125] \\
\hline Chloro-benzene & $\begin{array}{c}12 \mathrm{wt} \% \\
\mathrm{CeO}_{2} / \mathrm{HZSM}-5 \\
(0.3 \mathrm{~g})\end{array}$ & 315.8 & - & $\begin{array}{l}\text { DBD (IPC) } \\
\text { Continuous }\end{array}$ & Air & 1 & $1250 \mathrm{mg} / \mathrm{m}^{3}$ & $72.6 \%$ & $\begin{array}{c}5 \mathrm{kV} \\
(10 \mathrm{kHz})\end{array}$ & $\mathrm{CO}$ & [97] \\
\hline \multirow{5}{*}{ Dichloro-methane } & $\begin{array}{l}\text { HZSM-5 } \\
\left(140^{\circ} \mathrm{C}\right)\end{array}$ & 338 & 5.4 & \multirow{5}{*}{$\begin{array}{l}\text { PBDBD (PPC) } \\
\text { Continuous }\end{array}$} & \multirow{5}{*}{ Air } & \multirow{5}{*}{1} & \multirow{5}{*}{500} & $36 \%$ & \multirow{5}{*}{$\begin{array}{c}0.9 \mathrm{~W} \\
(10.25-13.25 \\
\mathrm{kHz})\end{array}$} & $\begin{array}{l}\text { CO, NOx, } \\
\text { HCOCl }\end{array}$ & \multirow{5}{*}{ [123] } \\
\hline & $\begin{array}{l}\text { Calcined } \\
\text { HZSM-5 } \\
\left(140^{\circ} \mathrm{C}\right) \\
\end{array}$ & 338 & 5.4 & & & & & $30 \%$ & & $\begin{array}{l}\mathrm{CO}, \mathrm{NOx} \\
\mathrm{HCOCl}\end{array}$ & \\
\hline & $\begin{array}{l}\text { NaZSM-5 } \\
\left(140{ }^{\circ} \mathrm{C}\right)\end{array}$ & 338 & 5.4 & & & & & $32 \%$ & & $\begin{array}{c}<\mathrm{NOx} \\
\mathrm{HCOCl}, \mathrm{CO}\end{array}$ & \\
\hline & $\begin{array}{l}\mathrm{NaA} \\
\left(140^{\circ} \mathrm{C}\right)\end{array}$ & - & 4 & & & & & $32 \%$ & & $\begin{array}{c}<\mathrm{HCOCl}, \mathrm{CO} \\
<\mathrm{NOx}\end{array}$ & \\
\hline & $\begin{array}{c}\mathrm{NaX} \\
\left(140^{\circ} \mathrm{C}\right)\end{array}$ & - & 10 & & & & & $32 \%$ & & $\begin{array}{c}<\mathrm{NOx} \\
\mathrm{HCOCl}, \mathrm{CO}\end{array}$ & \\
\hline
\end{tabular}


Table 4. Cont.

\begin{tabular}{|c|c|c|c|c|c|c|c|c|c|c|c|}
\hline VOCs & Zeolite & $\underset{\left(\mathrm{m}^{2} / \mathrm{g}\right)}{\mathrm{S}_{\mathrm{BET}}}$ * & $\begin{array}{l}\text { Pore Size } \\
\text { (A) * }\end{array}$ & Type of Discharge & Carrier Gas & $\begin{array}{l}\text { Flow Rate } \\
(\mathrm{L} / \mathrm{min})^{*}\end{array}$ & $\begin{array}{c}\text { Initial VOC } \\
\text { Concentration } \\
(\mathrm{ppm})^{*}\end{array}$ & $\begin{array}{c}\text { Amount of } \\
\text { Adsorption/Removal } \\
\text { Efficiency }\end{array}$ & $\begin{array}{c}\text { Energy } \\
\text { Density and } \\
\text { Frequency }\end{array}$ & By-Products & Ref. \\
\hline \multirow{2}{*}{ Ethylene } & \multirow{2}{*}{$\begin{array}{c}\mathrm{Ag}-\mathrm{Fe} \\
(1.5-0.5 \%) / 13 \mathrm{X} \\
(45 \mathrm{~g})\end{array}$} & \multirow[t]{2}{*}{ - } & \multirow[t]{2}{*}{ - } & $\begin{array}{c}\text { PBDBD (IPC) } \\
\mathrm{t}_{1}=60 \mathrm{~min}\end{array}$ & \multirow{2}{*}{$\begin{array}{c}21 \% \mathrm{O}_{2}+79 \% \\
\mathrm{~N}_{2}\end{array}$} & \multirow{2}{*}{1} & 270 & $662.2 \mu \mathrm{mol}$ & - & - & \multirow{2}{*}{ [95] } \\
\hline & & & & $\begin{array}{c}\text { PBDBD (IPC) } \\
\mathrm{t}_{2}=30 \mathrm{~min}\end{array}$ & & & - & $100 \%$ & $\begin{array}{c}15 \mathrm{kV} \\
(400 \mathrm{~Hz}) \\
\end{array}$ & - & \\
\hline \multirow{2}{*}{ Ethylene } & \multirow{2}{*}{$\begin{array}{c}\mathrm{Ag} / 13 \mathrm{X} \\
(30 \mathrm{~g})\end{array}$} & \multirow{2}{*}{699.6} & \multirow[t]{2}{*}{ - } & $\begin{array}{l}\text { PBDBD (IPC) } \\
\mathrm{t}_{1}=100 \mathrm{~min}\end{array}$ & \multirow{2}{*}{$\begin{array}{c}21 \% \mathrm{O}_{2}+79 \% \\
\mathrm{~N}_{2}\end{array}$} & \multirow{2}{*}{1} & 200 & $817.5 \mu \mathrm{mol}$ & - & - & \multirow{2}{*}{ [93] } \\
\hline & & & & $\begin{array}{l}\text { PBDBD (IPC) } \text { dist }_{2} \\
\quad=20 \mathrm{~min}\end{array}$ & & & - & $42 \%$ & $\begin{array}{c}20 \mathrm{kV} \\
(400 \mathrm{~Hz}) \\
\end{array}$ & $\mathrm{CO}$ & \\
\hline Ethylene & $\begin{array}{c}10 \mathrm{wt} \% \\
\mathrm{Ag} / \mathrm{MS}-13 \mathrm{X} \\
(10 \mathrm{~g})\end{array}$ & - & - & $\begin{array}{l}\text { PBDBD (IPC) } \\
\text { Continuous }\end{array}$ & $\begin{array}{c}10 \% \mathrm{O}_{2}, 10 \% \\
\mathrm{CO}_{2} / \mathrm{N}_{2}\end{array}$ & 5 & 200 & $100 \%$ & $\begin{array}{l}0-90 \mathrm{~J} / \mathrm{L} \\
(10 \mathrm{kHz})\end{array}$ & $\mathrm{CO}$ & [46] \\
\hline \multirow{2}{*}{ Formaldehyde } & \multirow{2}{*}{$\begin{array}{c}3.6 \mathrm{wt} \% \mathrm{Ag} \\
2.1 \mathrm{wt} \% \\
\mathrm{Cu} / \mathrm{HZSM}-5\end{array}$} & \multirow{2}{*}{299} & \multirow[t]{2}{*}{ - } & $\begin{array}{c}\text { PBDBD (IPC) } \\
\mathrm{t}_{1}=40 \mathrm{~min}\end{array}$ & $\begin{array}{l}\text { Humid air } \\
(\mathrm{RH}=50 \%)\end{array}$ & 0.3 & 26.6 & $14 \mu \mathrm{mol}$ & - & - & \multirow{2}{*}{ [44] } \\
\hline & & & & $\begin{array}{l}\text { PBDBD (IPC) } \\
\text { Open discharge }\end{array}$ & $\mathrm{O}_{2}$ & 0.06 & - & $100 \%$ & $\begin{array}{c}2.3 \mathrm{~W} \\
(2 \mathrm{kHz})\end{array}$ & - & \\
\hline Hexafluro-ethane & $\mathrm{BaTiO}_{3 / \text { zeolite }}$ & - & - & $\begin{array}{l}\text { PBDBD (PPC) } \\
\text { Continuous }\end{array}$ & $\mathrm{N}_{2}$ & 0.025 & 3000 & $100 \%$ & $\begin{array}{c}8 \mathrm{kV} \\
(60 \mathrm{~Hz}) \\
\end{array}$ & - & [133] \\
\hline \multirow{2}{*}{ Iso-propyl alcohol } & \multirow{2}{*}{ MS-10A } & \multirow{2}{*}{439.31} & \multirow{2}{*}{9.66} & $\begin{array}{c}\text { PBDBD (IPC) } \\
\mathrm{t}_{1}=60 \mathrm{~min}\end{array}$ & $\mathrm{~N}_{2}$ & 1 & 400 & - & - & - & \multirow[t]{2}{*}{ [54] } \\
\hline & & & & $\begin{array}{c}\text { PBDBD (IPC) } \\
\text { Open discharge } \\
\end{array}$ & $\mathrm{N}_{2}$ & 2 & - & - & $\begin{array}{c}9.66 \mathrm{~W} \\
(300 \mathrm{~Hz}) \\
\end{array}$ & - & \\
\hline Methane & $13 x$ & - & - & $\begin{array}{l}\text { PBDBD (IPC) } \\
\text { Continuous }\end{array}$ & - & - & $<1000$ & $26 \%$ & $\begin{array}{l}173-200 \\
\mathrm{Wh} / \mathrm{m}^{3} \\
(20 \mathrm{kHz})\end{array}$ & $\mathrm{NO}_{\mathrm{x}}$ & [104] \\
\hline Trichloro-ethylene & Cu-ZSM-5 & - & - & $\begin{array}{c}\text { DBD (IPC) } \\
\text { Continuous }\end{array}$ & Dry air & 0.4 & 1000 & $>95 \%$ & $\begin{array}{c}1 \mathrm{~W} \\
(50 \mathrm{~Hz})\end{array}$ & - & [107] \\
\hline \multirow{4}{*}{ Toluene } & \multirow{2}{*}{ ZSM-5- $\mathrm{BaTiO}_{3}$} & \multirow{2}{*}{165} & \multirow[t]{2}{*}{-} & $\begin{array}{c}\text { PBDBD (IPC) } \\
\text { Adsorption till } \\
\text { breakthrough } \\
\end{array}$ & $\begin{array}{l}\text { Humid air } \\
\qquad(19 \%)\end{array}$ & \multirow{4}{*}{0.6} & $1632 \mathrm{mg} / \mathrm{m}^{3}$ & $6.75 \mathrm{mg} / \mathrm{g}$ & - & & \multirow{4}{*}{ [118] } \\
\hline & & & & $\begin{array}{l}\text { PBDBD (IPC) } \\
\mathrm{t}_{2}=120 \mathrm{~min}\end{array}$ & Air & & - & $100 \%$ & $\begin{array}{l}22 \mathrm{kV} \\
(50 \mathrm{~Hz})\end{array}$ & $\mathrm{N}_{2} \mathrm{O}$ & \\
\hline & \multirow{2}{*}{\multicolumn{2}{|c|}{ AgMn-ZSM-5-BaTiO 3139}} & - & $\begin{array}{c}\text { PBDBD (IPC) } \\
\text { Adsorption till } \\
\text { breakthrough } \\
\end{array}$ & $\begin{array}{l}\text { Humid air } \\
\qquad(19 \%)\end{array}$ & & $1632 \mathrm{mg} / \mathrm{m}^{3}$ & $12.5 \mathrm{mg} / \mathrm{g}$ & - & & \\
\hline & & & & $\begin{array}{l}\text { PBDBD (IPC) } \\
\mathrm{t}_{2}=120 \mathrm{~min}\end{array}$ & Air & & - & $100 \%$ & $\begin{array}{l}22 \mathrm{kV} \\
(50 \mathrm{~Hz})\end{array}$ & $<\mathrm{N}_{2} \mathrm{O}$ & \\
\hline
\end{tabular}


Table 4. Cont.

\begin{tabular}{|c|c|c|c|c|c|c|c|c|c|c|c|}
\hline VOCs & Zeolite & $\underset{\left(\mathrm{m}^{2} / \mathrm{g}\right)}{\mathrm{S}_{\mathrm{BET}}}$ & 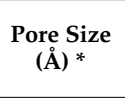 & Type of Discharge & Carrier Gas & $\begin{array}{l}\text { Flow Rate } \\
(\mathrm{L} / \mathrm{min})^{*}\end{array}$ & $\begin{array}{c}\text { Initial VOC } \\
\text { Concentration } \\
(\mathrm{ppm})^{*}\end{array}$ & $\begin{array}{c}\text { Amount of } \\
\text { Adsorption/Removal } \\
\text { Efficiency }\end{array}$ & $\begin{array}{c}\text { Energy } \\
\text { Density and } \\
\text { Frequency }\end{array}$ & By-Products & Ref. \\
\hline \multirow{5}{*}{ Toluene } & $\mathrm{Na}-\mathrm{Y}$ & 750 & 7.4 & \multirow{5}{*}{$\begin{aligned} \text { DBD }(\text { PPC }) \\
\mathrm{t}_{\text {total }}=160 \mathrm{~min} \\
\mathrm{t}_{1}=30 \mathrm{~min} \\
\mathrm{t}_{2}=10 \mathrm{~min}\end{aligned}$} & \multirow{5}{*}{$\begin{array}{l}\text { Humid air } \\
\left(0.5 \% \mathrm{H}_{2} \mathrm{O}\right)\end{array}$} & \multirow{5}{*}{$500 \mathrm{~cm}^{3} / \mathrm{min}$} & \multirow{5}{*}{200} & 52 & \multirow{5}{*}{$\begin{array}{c}5 \mathrm{~W} \\
(24 \mathrm{kHz})\end{array}$} & \multirow{5}{*}{$\mathrm{CO}, \mathrm{HCOOH}$} & \multirow{5}{*}{ [74] } \\
\hline & $\mathrm{H}-\mathrm{Y}(1)$ & 650 & 7.4 & & & & & 55 & & & \\
\hline & $\mathrm{H}-\mathrm{Y}(2)$ & 520 & 7.4 & & & & & 50 & & & \\
\hline & Mordenite & 460 & $6.7 \times 7.0$ & & & & & 35 & & & \\
\hline & Ferrierite & 270 & $4.3 \times 5.5$ & & & & & 20 & & & \\
\hline \multirow{2}{*}{ Toluene } & \multirow{2}{*}{$\mathrm{NaY}$} & \multirow{2}{*}{-} & \multirow{2}{*}{-} & $\begin{array}{c}\text { SD (IPC) } \\
t_{1}=160 \mathrm{~min}\end{array}$ & \multirow{2}{*}{$\begin{array}{l}\text { Synthetic } \\
\text { humid air } \\
\left(0.5 \% \mathrm{H}_{2} \mathrm{O}\right)\end{array}$} & \multirow{2}{*}{0.5} & 200 & $6.5 \times 10^{-4} \mathrm{~mol} / \mathrm{g}$ & - & - & \multirow{2}{*}{ [36] } \\
\hline & & & & $\begin{array}{c}\text { SD (IPC) } \\
\text { Open discharge }\end{array}$ & & & - & $50 \%$ & $\begin{array}{c}5 \mathrm{~W} \\
(50 \mathrm{~Hz})\end{array}$ & - & \\
\hline \multirow{10}{*}{ Toluene } & $13 x$ & - & - & $\begin{array}{c}\text { DBD (IPC) } \\
\mathrm{t}_{1}=282 \text { mins }\end{array}$ & Air & 0.4 & 150 & $0.57 \mathrm{mmol}$ & - & - & \multirow{10}{*}{ [131] } \\
\hline & & & & $\begin{array}{c}\text { DBD (IPC) } \\
\text { closed discharge } \\
\left(\mathrm{t}_{2}=1 \mathrm{~h}\right)\end{array}$ & - & - & - & $95 \%$ & $20 \mathrm{~W}$ & - & \\
\hline & & & & $\begin{array}{c}\text { DBD (IPC) } \\
\text { ventilated } \\
\text { discharge } \\
\left(\mathrm{t}_{2}=1 \mathrm{~h}\right)\end{array}$ & $\begin{array}{c}\text { Synthetic air } \\
\left(80 \% \mathrm{~N}_{2}+20 \%\right. \\
\left.\mathrm{O}_{2}\right)\end{array}$ & 0.1 & - & $95 \%$ & $20 \mathrm{~W}$ & - & \\
\hline & \multirow{4}{*}{$\mathrm{Co} / 13 \mathrm{X}$} & \multirow{4}{*}{386.214} & \multirow{4}{*}{ - } & \multirow{4}{*}{$\begin{array}{c}\text { DBD (IPC) } \\
\text { ventilated } \\
\text { discharge } \\
\left(\mathrm{t}_{2}=1 \mathrm{~h}\right)\end{array}$} & \multirow{2}{*}{$\mathrm{O}_{2}$} & 0.02 & - & $93.9 \%$ & $20 \mathrm{~W}$ & - & \\
\hline & & & & & & 0.03 & - & $93.5 \%$ & $20 \mathrm{~W}$ & - & \\
\hline & & & & & Air $\left(80 \% \mathrm{~N}_{2}+\right.$ & 0.1 & - & $92.7 \%$ & $20 \mathrm{~W}$ & - & \\
\hline & & & & & & 0.15 & - & $89.8 \%$ & $20 \mathrm{~W}$ & - & \\
\hline & \multirow{3}{*}{ MS 5A } & \multirow{3}{*}{-} & \multirow{3}{*}{-} & $\begin{array}{l}\text { DBD (IPC) } \\
\mathbf{t}_{1}=30 \mathrm{~min}\end{array}$ & Air & 0.4 & 150 & $0.021 \mathrm{mmol}$ & - & - & \\
\hline & & & & $\begin{array}{c}\text { DBD (IPC) } \\
\text { closed discharge } \\
\left(\mathrm{t}_{2}=1 \mathrm{~h}\right)\end{array}$ & - & & - & $95 \%$ & $20 \mathrm{~W}$ & - & \\
\hline & & & & $\begin{array}{c}\text { DBD (IPC) } \\
\text { ventilated } \\
\text { discharge } \\
\left(\mathrm{t}_{2}=1 \mathrm{~h}\right)\end{array}$ & $\begin{array}{c}\text { Synthetic air } \\
\left(80 \% \mathrm{~N}_{2}+20 \%\right. \\
\left.\mathrm{O}_{2}\right)\end{array}$ & 0.1 & - & $91 \%$ & $20 \mathrm{~W}$ & - & \\
\hline \multirow{2}{*}{ Toluene } & \multirow{2}{*}{$\begin{array}{l}\text { HZSM-5 } \\
(1.6 \mathrm{~g})\end{array}$} & \multirow{2}{*}{486.587} & \multirow{2}{*}{-} & $\begin{array}{c}\text { DBD (IPC) } \\
t_{1}=8 \mathrm{~h}\end{array}$ & $\begin{array}{l}\text { Humid air } \\
(\mathrm{RH}=40 \%)\end{array}$ & 3 & 3 & $0.25 \mathrm{mmol}$ & - & - & \multirow{2}{*}{ [38] } \\
\hline & & & & $\begin{array}{c}\text { DBD (IPC) } \\
\text { Open discharge }\end{array}$ & Synthetic air & 0.8 & - & $100 \%$ & $2.4 \mathrm{~W}$ & - & \\
\hline
\end{tabular}


Table 4. Cont.

\begin{tabular}{|c|c|c|c|c|c|c|c|c|c|c|c|}
\hline VOCs & Zeolite & $\underset{\left(\mathrm{m}^{2} / \mathrm{gET}\right)}{\mathrm{S}_{\mathrm{B}}}$ & $\begin{array}{l}\text { Pore Size } \\
\text { (A) * }\end{array}$ & Type of Discharge & Carrier Gas & $\begin{array}{l}\text { Flow Rate } \\
(\mathrm{L} / \mathrm{min})^{*}\end{array}$ & $\begin{array}{c}\text { Initial VOC } \\
\text { Concentration } \\
(\mathrm{ppm})^{*}\end{array}$ & $\begin{array}{c}\text { Amount of } \\
\text { Adsorption/Removal } \\
\text { Efficiency }\end{array}$ & $\begin{array}{l}\text { Energy } \\
\text { Density and } \\
\text { Frequency }\end{array}$ & By-Products & Ref. \\
\hline & Ag-Mn/HZSM-5 & 350.051 & - & $\begin{array}{c}\text { DBD (IPC) } \\
\mathrm{t}_{1}=8 \mathrm{~h}\end{array}$ & $\begin{array}{l}\text { Humid air } \\
(\mathrm{RH}=40 \%)\end{array}$ & 3 & 3 & $0.27 \mathrm{mmol}$ & - & - & \\
\hline & $(1.6 \mathrm{~g})$ & & & $\begin{array}{c}\text { DBD (IPC) } \\
\text { Open discharge } \\
\end{array}$ & Synthetic air & 0.8 & - & $100 \%$ & $2.4 \mathrm{~W}$ & - & \\
\hline \multirow{5}{*}{ Toluene } & \multirow{5}{*}{$\begin{array}{l}\text { Honeycomb } \\
\text { zeolite }\end{array}$} & \multirow{5}{*}{-} & \multirow{5}{*}{ - } & $\begin{array}{l}\text { DBD (IPC) } \\
t_{1}=60 \mathrm{~min}\end{array}$ & Dry air & 2 & 30 & $3.5 \mathrm{~mL}$ & - & - & \multirow{5}{*}{ [29] } \\
\hline & & & & \multirow{4}{*}{$\begin{array}{c}\text { DBD (IPC) } \\
\text { Open discharge }\end{array}$} & $\begin{array}{c}\text { Dry } \\
\text { air-forward } \\
\text { flow }\end{array}$ & \multirow{4}{*}{1} & \multirow{4}{*}{-} & $83 \%$ & $\begin{array}{c}20 \mathrm{~W} \\
(420 \mathrm{~Hz})\end{array}$ & - & \\
\hline & & & & & $\begin{array}{l}\text { Dry } \\
\text { air-reverse } \\
\text { flow }\end{array}$ & & & $51 \%$ & $\begin{array}{c}20 \mathrm{~W} \\
(420 \mathrm{~Hz})\end{array}$ & - & \\
\hline & & & & & $\begin{array}{l}\mathrm{N}_{2}-\text { forward } \\
\text { flow }\end{array}$ & & & $68 \%$ & $\begin{array}{c}20 \mathrm{~W} \\
(420 \mathrm{~Hz})\end{array}$ & - & \\
\hline & & & & & $\begin{array}{l}\mathrm{N}_{2} \text {-reverse } \\
\text { flow }\end{array}$ & & & $37 \%$ & $\begin{array}{c}20 \mathrm{~W} \\
(420 \mathrm{~Hz})\end{array}$ & - & \\
\hline \multirow{4}{*}{ Toluene } & \multirow[t]{2}{*}{ MS-13X } & \multirow[t]{2}{*}{626.439} & \multirow{4}{*}{26.6} & $\begin{array}{c}\text { DBD (IPC) } \\
\text { Adsorption till } \\
\text { breakthrough }\end{array}$ & Air & 0.4 & 150 & $0.57 \mathrm{mmol}$ & - & - & \multirow{4}{*}{88} \\
\hline & & & & $\begin{array}{c}\text { DBD (IPC) } \\
\text { Open discharge } \\
\end{array}$ & Synthetic air & 0.1 & - & $94 \%$ & $20 \mathrm{~W}$ & - & \\
\hline & \multirow[t]{2}{*}{$5 \% \mathrm{Co} / 13 \mathrm{X}$} & \multirow[t]{2}{*}{386.214} & & $\begin{array}{c}\text { DBD (IPC) } \\
\text { Adsorption till } \\
\text { breakthrough } \\
\end{array}$ & Air & 0.4 & 150 & $0.51 \mathrm{mmol}$ & - & - & \\
\hline & & & & $\begin{array}{c}\text { DBD (IPC) } \\
\text { Open discharge }\end{array}$ & Synthetic air & 0.1 & - & $92.7 \%$ & $20 \mathrm{~W}$ & - & \\
\hline \multirow{3}{*}{ Toluene } & \multirow{3}{*}{$\begin{array}{l}\text { Honeycomb } \\
\text { zeolite }(5.2 \mathrm{~g})\end{array}$} & \multirow{3}{*}{-} & \multirow{3}{*}{-} & $\begin{array}{l}\text { DBD (IPC) } \\
\mathrm{t}_{1}=60 \mathrm{~min}\end{array}$ & \multirow{3}{*}{ Air } & 2 & 30 & $3.6 \mathrm{~mL}$ & - & - & \multirow{3}{*}[28]{} \\
\hline & & & & $\begin{array}{c}\text { DBD (IPC) } \\
\mathrm{t}_{2}=5 \text { mins (with } 1 \\
\text { min closing time) } \\
\text { Reverse flow }\end{array}$ & & 1 & \multirow[t]{2}{*}{-} & Reg Eff $=82.3 \%$ & \multirow{2}{*}{$\begin{array}{c}20 \mathrm{~W} \\
\text { Pulsed hv } \\
(420 \mathrm{~Hz})\end{array}$} & \multirow[t]{2}{*}{$\mathrm{NO}, \mathrm{NO}_{2}$} & \\
\hline & & & & $\begin{array}{c}\mathrm{DBD}(\mathrm{IPC}) \mathrm{t}_{2}=4 \\
\text { mins } \\
\text { Reverse flow }\end{array}$ & & & & Reg Eff $=78.3 \%$ & & & \\
\hline \multirow{2}{*}{ Toluene } & \multirow{2}{*}{ Co/13X } & \multirow[t]{2}{*}{386.214} & \multirow{2}{*}{37.78} & $\begin{array}{c}\text { DBD (IPC) } \\
\mathrm{t}_{1}=\text { till equilibrium }\end{array}$ & \multirow{2}{*}{ Synthetic air } & 0.4 & 150 & $0.51 \mathrm{mmol}$ & - & - & \multirow{2}{*}[61]{} \\
\hline & & & & $\begin{array}{c}\mathrm{DBD}(\mathrm{IPC}) \\
\mathrm{t}_{2}=1 \mathrm{~h}\end{array}$ & & 0.1 & - & $92.7 \%$ & $20 \mathrm{~W}$ & - & \\
\hline
\end{tabular}


Table 4. Cont.

\begin{tabular}{|c|c|c|c|c|c|c|c|c|c|c|c|}
\hline VOCs & Zeolite & $\underset{\left(\mathrm{m}^{2} / \mathrm{g}\right)}{\mathrm{S}_{\mathrm{BET}}}$ * & $\begin{array}{l}\text { Pore Size } \\
\text { (A) * }\end{array}$ & Type of Discharge & Carrier Gas & $\begin{array}{l}\text { Flow Rate } \\
(\mathrm{L} / \mathrm{min})^{*}\end{array}$ & $\begin{array}{c}\text { Initial VOC } \\
\text { Concentration } \\
\text { (ppm)* }\end{array}$ & $\begin{array}{c}\text { Amount of } \\
\text { Adsorption/Removal } \\
\text { Efficiency }\end{array}$ & $\begin{array}{c}\text { Energy } \\
\text { Density and } \\
\text { Frequency }\end{array}$ & By-Products & Ref. \\
\hline \multirow{5}{*}{ Toluene } & $5 \mathrm{~A}$ & - & 5 & \multirow{5}{*}{$\begin{array}{l}\text { PBDBD (IPC) } \\
\text { Continuous }\end{array}$} & \multirow{5}{*}{ Dry air } & \multirow{5}{*}{0.3} & \multirow{5}{*}{100} & $79.8 \%$ & \multirow{5}{*}{$\begin{array}{c}3.3-3.7 \mathrm{~W} \\
(2 \mathrm{kHz})\end{array}$} & \multirow{5}{*}{-} & \multirow{5}{*}{89} \\
\hline & HZSM-5 & - & 5.5 & & & & & $80.8 \%$ & & & \\
\hline & $\mathrm{H} \beta$ & - & 6.6 & & & & & $98.4 \%$ & & & \\
\hline & $\mathrm{H}-\mathrm{Y}$ & - & 7.4 & & & & & $85.2 \%$ & & & \\
\hline & $\mathrm{Ag} / \mathrm{H}-\mathrm{Y}$ & - & - & & & & & $97 \%$ & & & \\
\hline Toluene & CuCeZr/ZSM-5 & 295 & 3.7 & $\begin{array}{l}\text { PBDBD (IPC) } \\
\text { Continuous }\end{array}$ & Dry air & 1 & 1400 & $77 \%$ & $43 \mathrm{~W}$ & - & [85] \\
\hline \multirow{2}{*}{ Toluene } & \multirow{2}{*}{$\begin{array}{l}\text { Honeycomb } \\
\text { zeolite }\end{array}$} & \multirow{2}{*}{-} & \multirow{2}{*}{ - } & $\begin{array}{c}\text { DBD (IPC) } \\
\text { Continuous }\end{array}$ & - & & 30 & $79 \%$ & \multirow{2}{*}{$\begin{array}{c}89 \mathrm{~W} \\
(60 \mathrm{~Hz})\end{array}$} & \multirow{2}{*}{-} & \multirow{2}{*}{ [33] } \\
\hline & & & & $\begin{array}{c}\text { DBD (IPC) } \\
\text { APC-closed } \\
\text { discharge }\end{array}$ & - & 150 & 25 & $70 \%$ to $93 \%$ & & & \\
\hline \multirow{2}{*}{ p-xylene } & \multirow{2}{*}{$\begin{array}{l}\text { HiSiv3000 } \\
\quad(4.8 \mathrm{~g})\end{array}$} & \multirow[t]{2}{*}{-} & \multirow[t]{2}{*}{ - } & $\begin{array}{r}\text { DBD (IPC) } \\
\mathrm{t}_{1}=130 \mathrm{~min} \\
\end{array}$ & Dry air & 2 & 20 & $5.2 \mathrm{~mL}$ & - & - & \multirow{4}{*}{ [47] } \\
\hline & & & & $\begin{array}{c}\text { DBD (IPC) } \\
\text { Open discharge }\end{array}$ & $\begin{array}{c}\text { Gas } \\
\text { circulation }\end{array}$ & 0.5 & - & $43 \%$ & $\begin{array}{c}38 \mathrm{~W} \\
(60 \mathrm{~Hz})\end{array}$ & $\mathrm{O}_{3}$ & \\
\hline \multirow{2}{*}{$\begin{array}{l}\text { Xylene mixture (p-, } \\
\mathrm{o-} \text {, and } \mathrm{m} \text { - xylene) }\end{array}$} & \multirow{2}{*}{$\begin{array}{l}\text { HiSiv3000 } \\
(2.5 \mathrm{~g}) \text { and } \\
\text { HiSiv1000 } \\
\quad(5.5 \mathrm{~g})\end{array}$} & \multirow[t]{2}{*}{-} & \multirow[t]{2}{*}{-} & $\begin{array}{r}\text { DBD (IPC) } \\
t_{1}=130 \mathrm{~min}\end{array}$ & Dry air & 2 & 20 & $5.2 \mathrm{~mL}$ & - & - & \\
\hline & & & & $\begin{array}{c}\text { DBD (IPC) } \\
\text { Open discharge }\end{array}$ & $\begin{array}{c}\text { Gas } \\
\text { circulation }\end{array}$ & 0.5 & - & $69 \%$ & $\begin{array}{c}38 \mathrm{~W} \\
(60 \mathrm{~Hz})\end{array}$ & $\mathrm{O}_{3}$ & \\
\hline $\begin{array}{l}\text { VOC mixture } \\
\left(\mathrm{C}_{2} \mathrm{Cl}_{4}, \mathrm{C}_{7} \mathrm{H}_{8},\right. \\
\mathrm{C}_{2} \mathrm{HCl}_{3}, \mathrm{C}_{6} \mathrm{H}_{6}, \\
\left.\mathrm{C}_{4} \mathrm{H}_{8} \mathrm{O}_{2}, \mathrm{CS}_{2}\right)\end{array}$ & $\begin{array}{l}\text { HZSM-5 } \\
(2 \mathrm{~g})\end{array}$ & 202.82 & - & $\begin{array}{l}\text { DDBD (IPC) } \\
\text { Continuous }\end{array}$ & $\mathrm{N}_{2}$ & 4 & 100 & $100 \%$ & $\begin{array}{l}65.8 \mathrm{~W} \\
(900 \mathrm{~Hz})\end{array}$ & $\begin{array}{c}\mathrm{SO}_{2}, \mathrm{C}_{2} \mathrm{H}_{5} \mathrm{Cl}, \\
\mathrm{C}_{2} \mathrm{H}_{4} \mathrm{O}, \\
\mathrm{C}_{6} \mathrm{H}_{8} \mathrm{~N}_{2}, \mathrm{CH}_{4} \\
\mathrm{C}_{2} \mathrm{H}_{3} \mathrm{NO}\end{array}$ & {$[126]$} \\
\hline
\end{tabular}




\section{Conclusions}

The main purpose of this article is to provide the readers an insight about the use of non-thermal plasma assisted/driven gas cleaning technology in combination with zeolites for VOC removal. The main conclusions that were obtained from this review are summarized as follows: (i) the adsorbing property of the zeolites enables the use of cyclic-adsorption plasma catalysis for VOC abatement, which is suitable for removal of low concentration of VOCs from large volume of gas, (ii) the energy efficiency of cyclic adsorption-plasma catalysis is improved by maximizing the adsorption time that can be achieved by using zeolites with suitable surface properties ( $\mathrm{S}_{\mathrm{BET}}$ and pore diameter) and/or by metal loading on zeolites, (iii) a proper selection of the nature and amount of metal ions for loading on zeolites is important as it can influence the adsorption of VOCs, characteristics of the plasma discharge, oxidation of adsorbed VOCs, mineralization efficiency and regeneration of zeolites, (iv) the use of oxygen as discharge gas for the complete regeneration of zeolite is economically feasible when the adsorption time is maximized in cyclic-adsorption plasma catalysis, and (v) the shaped zeolites are interesting to treat flue gas with high flow rate due to a reduced pressure drop. From this review, an unambiguous observation can be made that very few works concentrate on the following aspects of this technology: (i) stability of zeolites in continuous usage for longer time, (ii) the lifetime of zeolites and (iii) treating a mixture of VOCs, and (iv) realistic flue gas parameters (presence of humidity, high flow rate and low initial concentration of VOCs). Even though the stability of zeolites in cyclic adsorption-plasma catalysis is studied by some researchers, the number of cycles for which it has been investigated is very low ( $\leq 5$ cycles), which is not enough to estimate the lifetime of a catalyst. Therefore, more work focusing on the abovementioned aspects must be carried out in order to scale-up and apply this promising technology for real world applications.

Author Contributions: S.K.P.V. wrote the first draft of the article which was then refined by the comments and suggestions from R.M., N.D.G., J.-M.G., and J.-F.L.

Funding: This research was funded by the European Program INTERREG V France-Wallonie-Flanders project "DepollutAir" (grant number 1.1.18).

Acknowledgments: The "DepollutAir" project of the European Program INTERREG V France-Wallonie-Flanders FEDER) is acknowledged for supporting and funding this work.

Conflicts of Interest: The authors declare no conflict of interest.

\section{References}

1. EUR-Lex-31999L0013-EN-EUR-Lex. Available online: https://eur-lex.europa.eu/legal-content/EN/ TXT/?uri=celex\%3A31999L0013 (accessed on 3 September 2018).

2. Liu, Y.; Shao, M.; Fu, L.; Lu, S.; Zeng, L.; Tang, D. Source profiles of volatile organic compounds (VOCs) measured in China: Part I. Atmos. Environ. 2008, 42, 6247-6260. [CrossRef]

3. Kim, Y.M.; Harrad, S.; Harrison, R.M. Concentrations and sources of VOCs in urban domestic and public microenvironments. Environ. Sci. Technol. 2001, 35, 997-1004. [CrossRef] [PubMed]

4. Atkinson, R. Atmospheric chemistry of VOCs and NOx. Atmos. Environ. 2000, 34, 2063-2101. [CrossRef]

5. Finlayson-Pitts, B.J.; Pitts, J.N., Jr. Tropospheric air pollution: Ozone, airborne toxics, polycyclic aromatic hydrocarbons, and particles. Science 1997, 276, 1045-1052. [CrossRef] [PubMed]

6. Guo, H.; Lee, S.C.; Chan, L.Y.; Li, W.M. Risk assessment of exposure to volatile organic compounds in different indoor environments. Environ. Res. 2004, 94, 57-66. [CrossRef]

7. Pitten, F.A.; Bremer, J.; Kramer, A. Air pollution by volatile organic compounds (VOC) and health complaints. Dtsch. Med. Wochenschr. 2000, 125, 545-550. [CrossRef] [PubMed]

8. Kim, H.H.; Ogata, A.; Futamura, S. Oxygen partial pressure-dependent behavior of various catalysts for the total oxidation of VOCs using cycled system of adsorption and oxygen plasma. Appl. Catal. B Environ. 2008, 79, 356-367. [CrossRef]

9. Jones, A.P. Indoor air quality and health. Atmos. Environ. 1999, 33, 4535-4564. [CrossRef]

10. Wolkoff, P.; Nielsen, G.D. Organic compounds in indoor air-their relevance for perceived indoor air quality? Atmos. Environ. 2001, 35, 4407-4417. [CrossRef] 
11. Luengas, A.; Barona, A.; Hort, C.; Gallastegui, G.; Platel, V.; Elias, A. A review of indoor air treatment technologies. Rev. Environ. Sci. Biotechnol. 2015, 14, 499-522. [CrossRef]

12. Katari, V.S.; Vatavuk, W.M.; Wehe, A.H. Incineration techniques for control of volatile organic compound emissions Part I. fundamentals and process design considerations. JAPCA 1987, 37, 91-99. [CrossRef]

13. Van der Vaart, D.R.; Vatvuk, W.M.; Wehe, A.H. Thermal and catalytic incinerators for the control of VOCs. J. Air Waste Manag. Assoc. 1991, 41, 92-98. [CrossRef]

14. Kamal, M.S.; Razzak, S.A.; Hossain, M.M. Catalytic oxidation of volatile organic compounds (VOCs)—A review. Atmos. Environ. 2016, 140, 117-134. [CrossRef]

15. Zhang, Z.; Jiang, Z.; Shangguan, W. Low-temperature catalysis for VOCs removal in technology and application: A state-of-the-art review. Catal. Today 2016, 264, 270-278. [CrossRef]

16. Iranpour, R.; Cox, H.H.J.; Deshusses, M.A.; Schroeder, E.D. Literature review of air pollution control biofilters and biotrickling filters for odor and volatile organic compound removal. Environ. Prog. 2005, 24, 254-267. [CrossRef]

17. Guieysse, B.; Hort, C.; Platel, V.; Munoz, R.; Ondarts, M.; Revah, S. Biological treatment of indoor air for VOC removal: Potential and challenges. Biotechnol. Adv. 2008, 26, 398-410. [CrossRef] [PubMed]

18. Yang, C.; Qian, H.; Li, X.; Cheng, Y.; He, H.; Zeng, G.; Xi, J. Simultaneous removal of multicomponent VOCs in biofilters. Trends Biotechnol. 2018, 36, 673-685. [CrossRef] [PubMed]

19. Zhang, X.; Gao, B.; Creamer, A.E.; Cao, C.; Li, Y. Adsorption of VOCs onto engineered carbon materials: A review. J. Hazard. Mater. 2017, 338, 102-123. [CrossRef]

20. Vandenbroucke, A.M.; Morent, R.; De Geyter, N.; Leys, C. Non-thermal plasmas for non-catalytic and catalytic VOC abatement. J. Hazard. Mater. 2011, 195, 30-54. [CrossRef]

21. Vandenbroucke, A.M.; Morent, R.; De Geyter, N.; Leys, C. Decomposition of toluene with plasma-catalysis: A review. J. Adv. Oxid. Technol. 2012, 15, 232-241. [CrossRef]

22. Schmid, S.; Jecklin, M.C.; Zenobi, R. Degradation of volatile organic compounds in a non-thermal plasma air purifier. Chemosphere 2010, 79, 124-130. [CrossRef] [PubMed]

23. Mo, J.; Zhang, Y.; Xu, Q.; Lamson, J.J.; Zhao, R. Photocatalytic purification of volatile organic compounds in indoor air: A literature review. Atmos. Environ. 2009, 43, 2229-2246. [CrossRef]

24. Huang, Y.; Ho, S.S.H.; Lu, Y.; Niu, R.; Xu, L.; Cao, J.; Lee, S. Removal of indoor volatile organic compounds via photocatalytic oxidation: A short review and prospect. Molecules 2016, 21, 56. [CrossRef] [PubMed]

25. Kaliya Perumal Veerapandian, S.; Leys, C.; De Geyter, N.; Morent, R. Abatement of VOCs using packed bed non-thermal plasma reactors: A review. Catalysts 2017, 7, 113. [CrossRef]

26. Thevenet, F.; Sivachandiran, L.; Guaitella, O.; Barakat, C.; Rousseau, A. Plasma-catalyst coupling for volatile organic compound removal and indoor air treatment: A review. J. Phys. D Appl. Phys. 2014, 47, 224011. [CrossRef]

27. Zhu, T.; Wan, Y.D.; Li, J.; He, X.W.; Xu, D.Y.; Shu, X.Q.; Liang, W.J.; Jin, Y.Q. Volatile organic compounds decomposition using nonthermal plasma coupled with a combination of catalysts. Int. J. Environ. Sci. Technol. 2011, 8, 621-630. [CrossRef]

28. Kuroki, T.; Fujioka, T.; Kawabata, R.; Okubo, M.; Yamamoto, T. Regeneration of honeycomb zeolite by nonthermal plasma desorption of toluene. IEEE Trans. Ind. Appl. 2009, 45, 10-15. [CrossRef]

29. Kuroki, T.; Fujioka, T.; Okubo, M.; Yamamoto, T. Toluene concentration using honeycomb nonthermal plasma desorption. Thin Solid Films 2007, 515, 4272-4277. [CrossRef]

30. Karuppiah, J.; Sivachandiran, L.; Karvembu, R.; Subrahmanyam, C. Catalytic nonthermal plasma reactor for the abatement of low concentrations of isopropanol. Chem. Eng. J. 2010, 165, 194-199. [CrossRef]

31. Tang, X.; Feng, F.; Ye, L.; Zhang, X.; Huang, Y.; Liu, Z.; Yan, K. Removal of dilute VOCs in air by post-plasma catalysis over Ag-based composite oxide catalysts. Catal. Today 2013, 211, 39-43. [CrossRef]

32. Kim, H.-H.; Ogata, A. Nonthermal plasma activates catalyst: From current understanding and future prospects. Eur. Phys. J. Appl. Phys. 2011, 55, 13806. [CrossRef]

33. Yamagata, Y.; Niho, K.; Inoue, K.; Okano, H.; Muraoka, K. Decomposition of volatile organic compounds at low concentrations using combination of densification by zeolite adsorption and dielectric barrier Discharge. Jpn. J. Appl. Phys. 2006, 45, 8251-8254. [CrossRef]

34. Mok, Y.S.; Kim, D.H. Treatment of toluene by using adsorption and nonthermal plasma oxidation process. Curr. Appl. Phys. 2011, 11, S58-S62. [CrossRef] 
35. Lin, B.Y.; Chang, M.B.; Chen, H.L.; Lee, H.M.; Yu, S.J.; Li, S.N. Removal of $\mathrm{C}_{3} \mathrm{~F}_{8}$ via the combination of non-thermal plasma, adsorption and catalysis. Plasma Chem. Plasma Process. 2011, 31, 585-594. [CrossRef]

36. Oh, S.M.; Kim, H.H.; Einaga, H.; Ogata, A.; Futamura, S.; Park, D.W. Zeolite-combined plasma reactor for decomposition of toluene. Thin Solid Films 2006, 506-507, 418-422. [CrossRef]

37. Inoue, K.; Okano, H.; Yamagata, Y.; Muraoka, K.; Teraoka, Y. Performance tests of newly developed adsorption/plasma combined system for decomposition of volatile organic compounds under continuous flow condition. J. Environ. Sci. 2011, 23, 139-144. [CrossRef]

38. Wang, W.; Wang, H.; Zhu, T.; Fan, X. Removal of gas phase low-concentration toluene over Mn, Ag and Ce modified HZSM- 5 catalysts by periodical operation of adsorption and non-thermal plasma regeneration. J. Hazard. Mater. 2015, 292, 70-78. [CrossRef]

39. Liu, Y.; Li, X.; Liu, J.; Wu, J.; Zhu, A. Cycled storage-discharge (CSD) plasma catalytic removal of benzene over AgMn/HZSM-5 using air as discharge gas. Catal. Sci. Technol. 2016, 6, 3788-3796. [CrossRef]

40. Pham Huu, T.; Gil, S.; Da Costa, P.; Giroir-Fendler, A.; Khacef, A. Plasma-catalytic hybrid reactor: Application to methane removal. Catal. Today 2015, 257, 86-92. [CrossRef]

41. Kim, H.H.; Kim, J.H.; Ogata, A. Adsorption and oxygen plasma-driven catalysis for total oxidation of VOCs. Int. J. Plasma Environ. Sci. Technol. 2008, 2, 106-112.

42. Ohshima, T.; Kondo, T.; Kitajima, N.; Sato, M. Adsorption and plasma decomposition of gaseous acetaldehyde on fibrous activated carbon. IEEE Trans. Ind. Appl. 2010, 46, 23-28. [CrossRef]

43. Sivachandiran, L.; Thevenet, F.; Rousseau, A. Non-thermal plasma assisted regeneration of acetone adsorbed $\mathrm{TiO}_{2}$ surface. Plasma Chem. Plasma Process. 2013, 33, 855-871. [CrossRef]

44. Zhao, D.-Z.; Li, X.-S.; Shi, C.; Fan, H.-Y.; Zhu, A.-M. Low-concentration formaldehyde removal from air using a cycled storage-discharge (CSD) plasma catalytic process. Chem. Eng. Sci. 2011, 66, 3922-3929. [CrossRef]

45. Rajanikanth, B.S.; Srinivasan, A.D.; Nandiny, B.A. A cascaded discharge plasma-adsorbent technique for engine exhaust treatment. Plasma Sci. Technol. 2003, 5, 1825-1833. [CrossRef]

46. Nishimura, J.; Kawamura, T.; Takahashi, K.; Teramoto, Y.; Takaki, K.; Koide, S.; Suga, M.; Orikasa, T.; Uchino, T. Removal of ethylene and by-products using packed bed dielectric barrier discharge with Ag nanoparticle-loaded zeolite. Electron. Commun. Jpn. 2017, 100, 320-327. [CrossRef]

47. Kuroki, T.; Hirai, K.; Kawabata, R.; Okubo, M.; Yamamoto, T. Decomposition of adsorbed xylene on adsorbents using nonthermal plasma with gas circulation. IEEE Trans. Ind. Appl. 2010, 46, 672-679. [CrossRef]

48. Bagreev, A.; Rahman, H.; Bandosz, T.J. Thermal regeneration of a spent activated carbon previously used as hydrogen sulfide adsorbent. Carbon 2001, 39, 1319-1326. [CrossRef]

49. Yun, J.-H.; Yun, J.-H.; Choi, D.-K.; Moon, H. Benzene adsorption and hot purge regeneration in activated carbon beds. Chem. Eng. J. 2000, 55, 5857-5872. [CrossRef]

50. Lee, D.-G.; Kim, J.-H.; Lee, C.-H. Adsorption and thermal regeneration of acetone and toluene vapors in dealuminated Y-zeolite bed. Sep. Purif. Technol. 2011, 77, 312-324. [CrossRef]

51. Kim, K.-J.; Ahn, H.-G. The effect of pore structure of zeolite on the adsorption of VOCs and their desorption properties by microwave heating. Microporous Mesoporous Mater. 2012, 152, 78-83. [CrossRef]

52. Ghoshal, A.K.; Manjare, S.D. Selection of appropriate adsorption technique for recovery of VOCs: An analysis. J. Loss Prev. Process Ind. 2002, 15, 413-421. [CrossRef]

53. Fan, Y.; Cai, Y.; Li, X.; Yin, H.; Chen, L.; Liu, S. Regeneration of the HZSM-5 zeolite deactivated in the upgrading of bio-oil via non-thermal plasma injection (NTPI) technology. J. Anal. Appl. Pyrolysis 2015, 111, 209-215. [CrossRef]

54. Shiau, C.H.; Pan, K.L.; Yu, S.J.; Yan, S.Y.; Chang, M.B. Desorption of isopropyl alcohol from adsorbent with non-thermal plasma. Environ. Technol. 2017, 38, 2314-2323. [CrossRef] [PubMed]

55. Ogata, A.; Einaga, H.; Kabashima, H.; Futamura, S.; Kushiyama, S.; Kim, H.-H. Effective combination of nonthermal plasma and catalysts for decomposition of benzene in air. Appl. Catal. B Environ. 2003, 46, 87-95. [CrossRef]

56. Bahri, M.; Haghighat, F.; Rohani, S.; Kazemian, H. Metal organic frameworks for gas-phase VOCs removal in a NTP-catalytic reactor. Chem. Eng. J. 2017, 320, 308-318. [CrossRef]

57. Delkash, M.; Bakhshayesh, B.E.; Kazemian, H. Using zeolitic adsorbents to cleanup special wastewater streams: A review. Microporous Mesoporous Mater. 2015, 214, 224-241. [CrossRef] 
58. Zaitan, H.; Manero, M.H.; Valdés, H. Application of high silica zeolite ZSM-5 in a hybrid treatment process based on sequential adsorption and ozonation for VOCs elimination. J. Environ. Sci. 2016, 41, 59-68. [CrossRef] [PubMed]

59. Liu, C.; Zou, J.; Yu, K.; Cheng, D.; Han, Y.; Zhan, J.; Ratanatawanate, C.; Jang, B.W.-L. Plasma application for more environmentally friendly catalyst preparation. Pure Appl. Chem. 2006, 78, 1227-1238. [CrossRef]

60. Rhodes, C.J. Electric fields in zeolites: Fundamental features and environmental implications. Chem. Pap. 2016, 70, 4-21. [CrossRef]

61. Yi, H.; Yang, X.; Tang, X.; Zhao, S.; Xie, X.; Feng, T.; Ma, Y.; Cui, X. Performance and pathways of toluene degradation over $\mathrm{Co} / 13 \mathrm{X}$ by different processes based on nonthermal plasma. Energy Fuels 2017, 31, 11217-11224. [CrossRef]

62. Weitkamp, J. Zeolites and Catalysis. Solid State Ion. 2000, 131, 175-188. [CrossRef]

63. Moshoeshoe, M.; Nadiye-tabbiruka, M.S.; Obuseng, V. A Review of the Chemistry, Structure, Properties and Applications of Zeolites. Am. J. Mater. Sci. 2017, 7, 196-221.

64. Zhang, L.; Peng, Y.; Zhang, J.; Chen, L.; Meng, X.; Xiao, F.-S. Adsorptive and catalytic properties in the removal of volatile organic compounds over zeolite-based materials. Chin. J. Catal. 2016, 37, 800-809. [CrossRef]

65. Khodayar, M.; Franzson, H. Fracture pattern of Thjórsárdalur central volcano with respect to rift-jump and a migrating transform zone in South Iceland. J. Struct. Geol. 2007, 29, 898-912. [CrossRef]

66. Wang, H.; Cao, Y.; Chen, Z.; Yu, Q.; Wu, S. High-efficiency removal of $\mathrm{NO}_{\mathrm{x}}$ over natural mordenite using an enhanced plasma-catalytic process at ambient temperature. Fuel 2018, 224, 323-330. [CrossRef]

67. Barrer, R.M. Zeolites and their synthesis. Zeolites 1981, 1, 130-140. [CrossRef]

68. Barrer, R.M. Synthesis of a zeolitic mineral with chabazite-like sorptive properties. J. Chem. Soc. 1948, 127-132. [CrossRef]

69. Breck, D.W.; Eversole, W.G.; Milton, R.M. New synthetic crystalline zeolites. J. Am. Chem. Soc. 1956, 78, 2338-2339. [CrossRef]

70. Jha, B.; Singh, D.N. A review on synthesis, characterization and industrial applications of flyash zeolites. J. Mater. Educ. 2011, 33, 65-132.

71. Valdés, M.G.; Pérez-Cordoves, A.I.; Díaz-García, M.E. Zeolites and zeolite-based materials in analytical chemistry. Trends Anal. Chem. 2006, 25, 24-30. [CrossRef]

72. Hashimoto, S. Zeolite photochemistry: Impact of zeolites on photochemistry and feedback from photochemistry to zeolite science. J. Photochem. Photobiol. C Photochem. Rev. 2003, 4, 19-49. [CrossRef]

73. Corma, A.; Rey, F.; Valencia, S.; Jordá, J.L.; Rius, J. A zeolite with interconnected 8-, 10- and 12-ring pores and its unique catalytic selectivity. Nat. Mater. 2003, 2, 493-497. [CrossRef] [PubMed]

74. Teramoto, Y.; Kim, H.-H.; Negishi, N.; Ogata, A. The role of ozone in the reaction mechanism of a bare zeolite-plasma hybrid system. Catalysts 2015, 5, 838-850. [CrossRef]

75. Xu, M.; Mukarakate, C.; Robichaud, D.J.; Nimlos, M.R.; Richards, R.M.; Trewyn, B.G. Elucidating zeolite deactivation mechanisms during biomass catalytic fast pyrolysis from model reactions and zeolite syntheses. Top. Catal. 2016, 59, 73-85. [CrossRef]

76. Lutz, W.; Zeolite, Y. Synthesis, modification, and properties-A case revisited. Adv. Mater. Sci. Eng. 2014, 36, 1389-1404.

77. Guo, Y.; Zhang, H.; Liu, Y. Desorption characteristics and kinetic parameters determination of molecular sieve by thermogravimetric analysis/differential thermogravimetric analysis technique. Adsorpt. Sci. Technol. 2018, 36, 1389-1404. [CrossRef]

78. Khan, N.A.; Yoo, D.K.; Bhadra, B.N.; Jun, J.W.; Kim, T.-W.; Kim, C.-U.; Jhung, S.H. Preparation of SSZ-13 zeolites from beta zeolite and their application in the conversion of ethylene to propylene. Chem. Eng. J. 2018. [CrossRef]

79. Al-Dughaither, A.S.; De Lasa, H. HZSM-5 zeolites with different $\mathrm{SiO}_{2} / \mathrm{Al}_{2} \mathrm{O}_{3}$ ratios. Characterization and $\mathrm{NH}_{3}$ desorption kinetics. Ind. Eng. Chem. Res. 2014, 53, 15303-15316. [CrossRef]

80. Datka, J.; Tuznik, E. Infrared Spectroscopic Studies of Acid Properties of NaHZSM-5 Zeolites. J. Catal. 1986, 102, 43-51. [CrossRef]

81. Reitmeier, S.J.; Gobin, O.C.; Jentys, A.; Lercher, J.A. Enhancement of sorption processes in the zeolite H-ZSM5 by postsynthetic surface modification. Angew. Chem. Int. Ed. 2009, 48, 533-538. [CrossRef] 
82. Weber, R.W.; Fletcher, J.C.Q.; Möller, K.P.; O'Connor, C.T. The characterization and elimination of the external acidity of ZSM-5. Microporous Mater. 1996, 7, 15-25. [CrossRef]

83. Armaroli, T.; Simon, L.J.; Digne, M.; Montanari, T.; Bevilacqua, M.; Valtchev, V.; Patarin, J.; Busca, G. Effects of crystal size and $\mathrm{Si} / \mathrm{Al}$ ratio on the surface properties of H-ZSM-5 zeolites. Appl. Catal. A Gen. 2006, 306, 78-84. [CrossRef]

84. GhavamiNejad, A.; Kalantarifard, A.; Yang, G.S.; Kim, C.S. In-situ immobilization of silver nanoparticles on ZSM-5 type zeolite by catechol redox chemistry, a green catalyst for $\mathrm{A}^{3}$-coupling reaction. Microporous Mesoporous Mater. 2016, 225, 296-302. [CrossRef]

85. Dou, B.; Liu, D.; Zhang, Q.; Zhao, R.; Hao, Q.; Bin, F.; Cao, J. Enhanced removal of toluene by dielectric barrier discharge coupling with $\mathrm{Cu}-\mathrm{Ce}-\mathrm{Zr}$ supported $\mathrm{ZSM}-5 / \mathrm{TiO}_{2} / \mathrm{Al}_{2} \mathrm{O}_{3}$. Catal. Commun. 2017, 92, 15-18. [CrossRef]

86. Ogata, A.; Ito, D.; Mizuno, K.; Kushiyama, S.; Yamamoto, T. Removal of dilute benzene using a zeolite-hybrid plasma reactor. IEEE Trans. Ind. Appl. 2001, 37, 959-964. [CrossRef]

87. Makowski, W.; Ogorzałek, $€$. Determination of the adsorption heat of $n$-hexane and $n$-heptane on zeolites beta, L, 5A, 13X, Y and ZSM-5 by means of quasi-equilibrated temperature-programmed desorption and adsorption (QE-TPDA). Thermochim. Acta 2007, 465, 30-39. [CrossRef]

88. Yi, H.; Yang, X.; Tang, X.; Zhao, S.; Wang, J.; Cui, X.; Feng, T.; Ma, Y. Removal of toluene from industrial gas over 13X zeolite supported catalysts by adsorption-plasma catalytic process. J. Chem. Technol. Biotechnol. 2017, 92, 2276-2286. [CrossRef]

89. Huang, R.; Lu, M.; Wang, P.; Chen, Y.; Wu, J.; Fu, M.; Chen, L.; Ye, D. Enhancement of the non-thermal plasma-catalytic system with different zeolites for toluene removal. RSC Adv. 2015, 5, 72113-72120. [CrossRef]

90. Díaz, E.; Ordóñez, S.; Vega, A.; Coca, J. Adsorption characterisation of different volatile organic compounds over alumina, zeolites and activated carbon using inverse gas chromatography. J. Chromatogr. A 2004, 1049, 139-146. [CrossRef]

91. Yu, Y.; Zheng, L.; Wang, J. Adsorption behavior of toluene on modified $1 \mathrm{X}$ molecular sieves. J. Air Waste Manag. Assoc. 2012, 62, 1227-1232. [CrossRef]

92. Triebe, R.W.; Tezel, F.H.; Khulbe, K.C. Adsorption of methane, ethane and ethylene on molecular sieve zeolites. Gas Sep. Purif. 1996, 10, 81-84. [CrossRef]

93. Trinh, Q.H.; Mok, Y.S. Effect of the adsorbent/catalyst preparation method and plasma reactor configuration on the removal of dilute ethylene from air stream. Catal. Today 2015, 256, 170-177. [CrossRef]

94. Van Mao, R.L.; Mclaughlin, G.P. Ethylene recovery from low grade gas stream by adsorption on zeolites and controlled desorption. Can. J. Chem. Eng. 1988, 66, 686-690.

95. Trinh, Q.H.; Lee, S.B.; Mok, Y.S. Removal of ethylene from air stream by adsorption and plasma-catalytic oxidation using silver-based bimetallic catalysts supported on zeolite. J. Hazard. Mater. 2015, 285, 525-534. [CrossRef]

96. Takahashi, A.; Yang, F.H.; Yang, R.T. Aromatics/aliphatics separation by adsorption: New sorbents for selective aromatics adsorption by $\pi$-complexation. Ind. Eng. Chem. Res. 2000, 39, 3856-3867. [CrossRef]

97. Zhu, R.; Mao, Y.; Jiang, L.; Chen, J. Performance of chlorobenzene removal in a nonthermal plasma catalysis reactor and evaluation of its byproducts. Chem. Eng. J. 2015, 279, 463-471. [CrossRef]

98. Kim, H.; Park, J.; Jung, Y. The binding nature of light hydrocarbons on Fe/MOF-74 for gas separation. Phys. Chem. Chem. Phys 2013, 15, 19644-19650. [CrossRef]

99. Shen, B.; Fan, K.; Wang, W.; Deng, J. Ab initio study on the adsorption and oxidation of $\mathrm{HCHO}$ with $\mathrm{Ag}_{2}$ cluster. J. Mol. Struct. 1999, 469, 157-161. [CrossRef]

100. Qin, C.; Huang, X.; Zhao, J.; Huang, J.; Kang, Z.; Dang, X. Removal of toluene by sequential adsorption-plasma oxidation: Mixed support and catalyst deactivation. J. Hazard. Mater. 2017, 334, $29-38$. [CrossRef]

101. Fan, H.-Y.; Shi, C.; Li, X.-S.; Zhao, D.-Z.; Xu, Y.; Zhu, A.-M. High-efficiency plasma catalytic removal of dilute benzene from air. J. Phys. D Appl. Phys. 2009, 42, 225105. [CrossRef]

102. Fan, H.-Y.; Li, X.-S.; Shi, C.; Zhao, D.-Z.; Liu, J.-L.; Liu, Y.-X.; Zhu, A.-M. Plasma catalytic oxidation of stored benzene in a cycled storage-discharge (CSD) process: Catalysts, reactors and operation conditions. Plasma Chem. Plasma Process. 2011, 31, 799-810. [CrossRef] 
103. Einaga, H.; Futamura, S. Catalytic oxidation of benzene with ozone over Mn ion-exchanged zeolites. Catal. Commun. 2007, 8, 557-560. [CrossRef]

104. Xia, J.F.; Gao, X.X.; Kong, J.Y.; Hui, H.X.; Cui, M.; Yan, K.P. By-products $\mathrm{NO}_{\mathrm{x}}$ control and performance improvement of a packed-bed nonthermal plasma reactor. Plasma Chem. Plasma Process. 2000, 20, 225-233. [CrossRef]

105. Xu, X.; Wang, P.; Xu, W.; Wu, J.; Chen, L.; Fu, M.; Ye, D. Plasma-catalysis of metal loaded SBA-15 for toluene removal: Comparison of continuously introduced and adsorption-discharge plasma system. Chem. Eng. J. 2016, 283, 276-284. [CrossRef]

106. Bahri, M.; Haghighat, F. Plasma-Based Indoor Air Cleaning Technologies: The State of the Art-Review. Clean-Soil Air Water 2014, 42, 1667-1680. [CrossRef]

107. Oda, T.; Takahashi, T.; Kohzuma, S. Decomposition of dilute trichloroethylene by using non-thermal plasma processing-Frequency and catalyst effect. In Proceedings of the Thirty-Third IAS Annual Meeting Conference Record of 1998 IEEE Industry Applications Conference, St. Louis, MO, USA, 12-15 October 1998; pp. 1871-1876.

108. Oda, T. Non-thermal plasma processing for environmental proection: Decomposition of dilute VOCs in air. J. Electrost. 2003, 57, 293-311. [CrossRef]

109. Trinh, Q.H.; Gandhi, M.S.; Mok, Y.S. Adsorption and plasma-catalytic oxidation of acetone over zeolite-supported silver catalyst. Jpn. J. Appl. Phys. 2015, 54, 01AG04. [CrossRef]

110. Kim, H.H.; Ogata, A.; Futamura, S. Effect of different catalysts on the decomposition of VOCs using flow-type plasma-driven catalysis. IEEE Trans. Plasma Sci. 2006, 34, 984-995. [CrossRef]

111. Hu, J.; Jiang, N.; Li, J.; Shang, K.; Lu, N.; Wu, Y. Degradation of benzene by bipolar pulsed series surface/packed-bed discharge reactor over $\mathrm{MnO}_{2}-\mathrm{TiO}_{2}$ / zeolite catalyst. Chem. Eng. J. 2016, 293, $216-224$. [CrossRef]

112. Li, W.; Gibbs, G.V.; Oyama, S.T. Mechanism of ozone decomposition on a manganese oxide catalyst. 1. In situ Raman spectroscopy and ab initio molecular orbital calculations. J. Am. Chem. Soc. 1998, 120, 9041-9046. [CrossRef]

113. Li, W.; Oyama, S.T. Mechanism of ozone decomposition on a manganese oxide catalyst. 2. Steady-state and transient kinetic studies. J. Am. Chem. Soc. 1998, 120, 9047-9052. [CrossRef]

114. Reed, C.; Xi, Y.; Oyama, S.T. Distinguishing between reaction intermediates and spectators: A kinetic study of acetone oxidation using ozone on a silica-supported manganese oxide catalyst. J. Catal. 2005, 235, 378-392. [CrossRef]

115. Reed, C.; Lee, Y.-K.; Oyama, S.T. Structure and oxidation state of silica-supported manganese oxide catalysts and reactivity for acetone oxidation with ozone. J. Phys. Chem. B 2006, 110, 4207-4216. [CrossRef] [PubMed]

116. Garcia, T.; Agouram, S.; Sánchez-Royo, J.F.; Murillo, R.; Mastral, A.M.; Aranda, A.; Vázquez, I.; Dejoz, A.; Solsona, B. Deep oxidation of volatile organic compounds using ordered cobalt oxides prepared by a nanocasting route. Appl. Catal. A Gen. 2010, 386, 16-27. [CrossRef]

117. Youn, J.S.; Bae, J.; Park, S.; Park, Y.K. Plasma-assisted oxidation of toluene over Fe/zeolite catalyst in DBD reactor using adsorption/desorption system. Catal. Commun. 2018, 113, 36-40. [CrossRef]

118. Qin, C.; Guo, H.; Liu, P.; Bai, W.; Huang, J.; Huang, X.; Dang, X.; Yan, D. Toluene abatement through adsorption and plasma oxidation using ZSM-5 mixed with $\gamma-\mathrm{Al}_{2} \mathrm{O}_{3}, \mathrm{TiO}_{2}$ or $\mathrm{BaTiO}_{3}$. J. Ind. Eng. Chem. 2018, 63, 449-455. [CrossRef]

119. Kim, H.-H.; Teramoto, Y.; Negishi, N.; Ogata, A. A multidisciplinary approach to understand the interactions of nonthermal plasma and catalyst: A review. Catal. Today 2015, 256, 13-22. [CrossRef]

120. Patil, B.S.; Cherkasov, N.; Lang, J.; Ibhadon, A.O.; Hessel, V.; Wang, Q. Low temperature plasma-catalytic $\mathrm{NO}_{\mathrm{x}}$ synthesis in a packed DBD reactor: Effect of support materials and supported active metal oxides. Appl. Catal. B Environ. 2016, 194, 123-133. [CrossRef]

121. Kim, H.-H.; Teramoto, Y.; Sano, T.; Negishi, N.; Ogata, A. Effects of Si/Al ratio on the interaction of nonthermal plasma and Ag/HY catalysts. Appl. Catal. B Environ. 2015, 166-167, 9-17. [CrossRef]

122. Hamada, S.; Hojo, H.; Einaga, H. Effect of catalyst composition and reactor configuration on benzene oxidation with a nonthermal plasma-catalyst combined reactor. Catal. Today 2018. [CrossRef]

123. Wallis, A.E.; Whitehead, J.C.; Zhang, K. The removal of dichloromethane from atmospheric pressure nitrogen gas streams using plasma-assisted catalysis. Appl. Catal. B Environ. 2007, 72, 282-288. [CrossRef] 
124. Fitzsimmons, C.; Ismail, F.; Whitehead, J.C.; Wilman, J.J. The chemistry of dichloromethane destruction in atmospheric-pressure gas streams by a dielectric packed-bed plasma reactor. J. Phys. Chem. A 2000, 104, 6032-6038. [CrossRef]

125. Jiang, L.; Nie, G.; Zhu, R.; Wang, J.; Chen, J.; Mao, Y.; Cheng, Z.; Anderson, W.A. Efficient degradation of chlorobenzene in a non-thermal plasma catalytic reactor supported on $\mathrm{CeO}_{2} / \mathrm{HZSM}-5$ catalysts. J. Environ. Sci. 2017, 55, 266-273. [CrossRef] [PubMed]

126. Mustafa, M.F.; Fu, X.; Liu, Y.; Abbas, Y.; Wang, H.; Lu, W. Volatile organic compounds (VOCs) removal in non-thermal plasma double dielectric barrier discharge reactor. J. Hazard. Mater. 2018, 347, 317-324. [CrossRef] [PubMed]

127. Formisano, B.; Bonten, C. Extruded zeolitic honeycombs for sorptive heat storage. AIP Conf. Proc. 2016, 1779, 030003.

128. Chang, F.-T.; Lin, Y.-C.; Bai, H.; Pei, B.-S. Adsorption and desorption characteristics of semiconductor volatile organic compounds on the thermal swing honeycomb zeolite concentrator. J. Air Waste Manag. Assoc. 2003, 53, 1384-1390. [CrossRef] [PubMed]

129. Kim, H.-H.; Oh, S.-M.; Ogata, A.; Futamura, S. Decomposition of gas-phase benzene using plasma-Driven catalyst reactor: Complete oxidation of adsorbed benzene using oxygen plasma. J. Adv. Oxid. Technol. 2005, 8, 226-233. [CrossRef]

130. Dang, X.; Huang, J.; Cao, L.; Zhou, Y. Plasma-catalytic oxidation of adsorbed toluene with gas circulation. Catal. Commun. 2013, 40, 116-119. [CrossRef]

131. Yi, H.; Yang, X.; Tang, X.; Zhao, S. Removal of toluene from industrial gas by adsorption-plasma catalytic process: Comparison of closed discharge and ventilated discharge. Plasma Chem. Plasma Process. 2018, 38, 331-345. [CrossRef]

132. Oh, S.M.; Kim, H.H.; Ogata, A.; Einaga, H.; Futamura, S.; Park, D.W. Effect of zeolite in surface discharge plasma on the decomposition of toluene. Catal. Lett. 2005, 99, 101-104. [CrossRef]

133. Urashima, K.; Kostov, K.G.; Chang, J.S.; Okayasu, Y.; Iwaizumi, T.; Yoshimura, K.; Kato, T. Removal of $\mathrm{C} 2 \mathrm{~F} 6$ from a semiconductor process flue gas by a ferroelectric packed-bed barrier discharge reactor with an adsorber. IEEE Trans. Ind. Appl. 2001, 37, 1456-1463. [CrossRef]

(C) 2019 by the authors. Licensee MDPI, Basel, Switzerland. This article is an open access article distributed under the terms and conditions of the Creative Commons Attribution (CC BY) license (http:/ / creativecommons.org/licenses/by/4.0/). 